\title{
Circulation and convection in the Irminger Sea
}

\author{
by \\ Kjetil Våge
}

B.S. Physics, University of New Brunswick, Canada, 2003

M.S. Physical Oceanography, MIT/WHOI Joint Program, 2006

Submitted in partial fulfillment of the requirements for the degree of

Doctor of Philosophy

at the

MASSACHUSETTS INSTITUTE OF TECHNOLOGY

and the

\section{WOODS HOLE OCEANOGRAPHIC INSTITUTION}

February 2010

(c) Kjetil Våge, 2010. All rights reserved.

The author hereby grants to MIT and WHOI permission to reproduce and distribute publicly paper and electronic copies of this thesis document in whole or in part.

Author

MIT/WHOI Joint Program in Physical Oceanography

December 18, 2009

Certified by

Robert S. Pickart

Senior Scientist, Woods Hole Oceanographic Institution

Thesis Supervisor

Accepted by

Karl R. Helfrich

Chairman, Joint Committee for Physical Oceanography 


\title{
Circulation and convection in the Irminger Sea
}

by

\author{
Kjetil Våge \\ Submitted to the Massachusetts Institute of Technology \\ and the Woods Hole Oceanographic Institution \\ in partial fulfillment of the requirements for the degree of \\ Doctor of Philosophy
}

\begin{abstract}
Aspects of the circulation and convection in the Irminger Sea are investigated using a variety of in-situ, satellite, and atmospheric reanalysis products.

Westerly Greenland tip jet events are intense, small-scale wind phenomena located east of Cape Farewell, and are important to circulation and convection in the Irminger Sea. A climatology of such events was used to investigate their evolution and mechanism of generation. The air parcels constituting the tip jet are shown to have a continental origin, and to exhibit a characteristic deflection and acceleration around southern Greenland. The events are almost invariably accompanied both by a notable coherence of the lower-level tip jet with an overlying upper-level jet stream, and by a surface cyclone located in the lee (east) of Greenland. It is argued that the tip jet arises from the interplay of the synopticscale flow evolution and the perturbing effects of Greenland's topography upon the flow.

The Irminger Gyre is a narrow, cyclonic recirculation confined to the southwest Irminger Sea. While the gyre's existence has been previously documented, relatively little is known about its specific features or variability. The mean strength of the gyre's circulation between 1991 and 2007 was $6.8 \pm 1.8 S v$. It intensified at a rate of $4.3 S v$ per decade over the observed period despite declining atmospheric forcing. Examination of the temporal evolution of the LSW layer thickness across the Irminger Basin suggests that local convection formed LSW during the early 1990s within the Irminger Gyre. In contrast, LSW appeared outside of the gyre in the eastern part of the Irminger Sea with a time lag of 2-3 years, consistent with transit from a remote source in the Labrador Sea.

In the winter of 2007-08 deep convection returned to both the Labrador and Irminger seas following years of shallow overturning. The transition to a convective state took place abruptly, without going through a preconditioning phase, which is contrary to general expectations. Changes in the hemispheric air temperature, tracks of storms, flux of freshwater to the Labrador Sea, and distribution of pack ice all conspired to enhance the air-sea heat flux, resulting in the deep overturning.
\end{abstract}

Thesis Supervisor: Robert S. Pickart

Title: Senior Scientist, Woods Hole Oceanographic Institution 


\section{Acknowledgments}

First and foremost I would like to thank my advisor, Bob. I have thoroughly enjoyed working with him, and the things I have learned from him go far beyond what is required to be an oceanographer. I am very thankful for the many opportunities he's given me, including participation in numerous research cruises and a year-long stay in Fairbanks. I am very grateful to have worked with such a fine scientist and person.

My thesis committee, Fiamma Straneo, Mike Spall, and Carl Wunsch, have given me many valuable comments and suggestions that improved, in particular, the last chapter of the thesis.

I have also received much help and advice from the group more or less closely working with Bob: Terry McKee, Paula Fratantoni, Dan Torres, Dave Sutherland, and Wilken-Jon von Appen. It has been a pleasure to be part of this group, both at sea and in the office.

I have not done all of this work on my own. In addition to Bob, I would like to thank all of the collaborators that contributed both to the analysis and with data: Thomas Spengler, Huw Davies, Virginie Thierry, Gilles Reverdin, Craig Lee, Brian Petrie, Tom Agnew, Amy Wong, Mads Ribergaard, Øyvind Knutsen, Artem Sarafanov, Herlé Mercier, Pascale Lherminier, Manfred Bersch, Hendrik van Aken, Jens Meincke, and Detlef Quadfasel. It is much appreciated.

The Academic Programs Office, and in particular Marsha Gomes and Julia Westwater, have always been very helpful, especially when I requested a leave of absence from the program. In the PO department Annie Doucette and Hazel Salazar have been particularly helpful on a number of occasions.

I have been lucky to make many great friends through the Joint Program, and in particular my classmates, officemates, and roommates deserve special recognition: Anne, Ari, Beatriz, Carlos, Dan, Daniel, Dave, Dave, Evgeny, Greg, Holly, Hristina, Ian, Jake, Jessica, Jim, Jinbo, Matt, Max, Melanie, Nick, Paul, Rachel, Rebecca, Shaoyu, Sophie, Stephanie, Stephanie, Tatiana, Tom, and Wilken. I would also like to acknowledge the lunch-time soccer crowd that has provided an important and much appreciated outlet during all seasons. It would have been very difficult, if at all possible, to go through the program without this 
community.

Last, but not least, I would like to thank my parents, Kari and Sigbjørn, and my brothers, Stian and Vidar, for their continuous support and encouragement through all of these years. I am exceedingly grateful to my wife, Selina, for her invaluable and unbounded love, care and understanding.

Financial support for this work was provided by National Science Foundation grant OCE-0450658. 


\section{Contents}

1 Introduction $\quad 8$

1.1 Circulation and ventilation of the subpolar gyre $\ldots \ldots \ldots \ldots$

1.2 Convection in the Irminger Sea . . . . . . . . . . . . . . 10

1.3 Effect of atmospheric variability on the circulation . . . . . . . . 12

1.4 Convective activity and the MOC . . . . . . . . . . . . . . . . 14

1.5 Climatic impacts of LSW formation . . . . . . . . . . . . . . 16

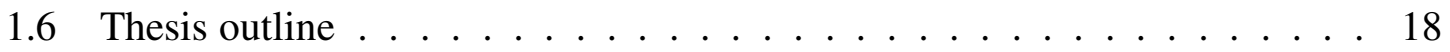

2 Multi-event analysis of the westerly Greenland tip jet based upon 45 winters in ERA-40 20

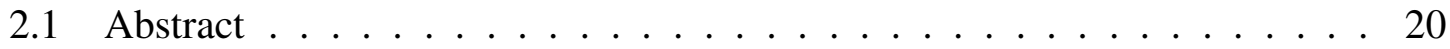

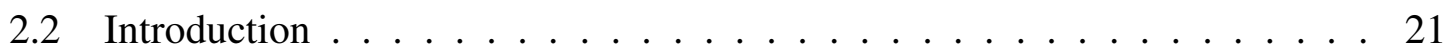

2.3 Data and methods . . . . . . . . . . . . . . . . . . . 24

2.3.1 ERA-40 reanalysis product . . . . . . . . . . . . . . 24

2.3.2 Tip jet detection $\ldots \ldots \ldots \ldots \ldots \ldots$

2.4 ERA-40 versus QuikSCAT winds $\ldots \ldots \ldots \ldots \ldots \ldots$

2.4 .1 Winter conditions . . . . . . . . . . . . . . . . 27

2.4 .2 Tip jet conditions . . . . . . . . . . . . . . . . . . . . . . . 29

2.5 Tip jets and the NAO $\ldots \ldots \ldots \ldots$

2.6 Tip jet composites . . . . . . . . . . . . . . . . . . . . . . . 31

2.7 Air parcel trajectories . . . . . . . . . . . . . . . . . . . . . 34

2.8 Flow features accompanying the tip jet . . . . . . . . . . . . . 37

2.8 .1 Low-level cyclone . . . . . . . . . . . . . . . . . . . 37 
2.8.2 Vertical structure of the tip jet and relationship to the jet stream . . 39

2.9 Summary and discussion . . . . . . . . . . . . . . 45

2.10 Acknowledgments . . . . . . . . . . . . . . 46

3 Surprising return of deep convection to the subpolar North Atlantic in winter 2007-08 48

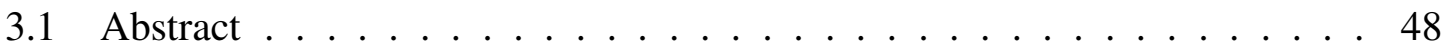

3.2 Introduction . . . . . . . . . . . . . . . . . . 49

3.3 Mixed layers in the subpolar North Atlantic . . . . . . . . . . . . . . . 50

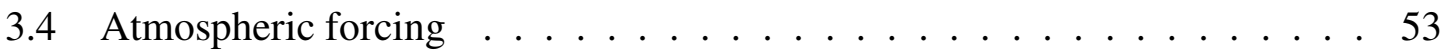

3.5 Storm patterns . . . . . . . . . . . . . . . . . 57

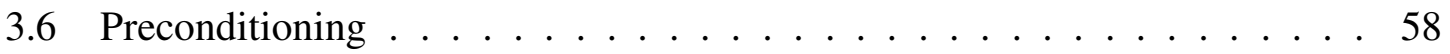

3.7 Methods . . . . . . . . . . . . . . . . . . 60

3.8 Acknowledgments ..................... 61

4 The Irminger Gyre: Circulation, convection, and interannual variability 63

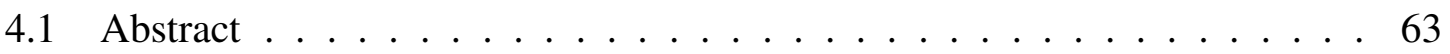

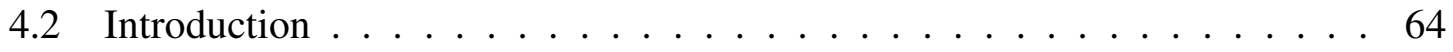

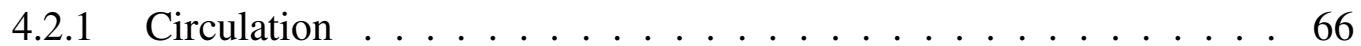

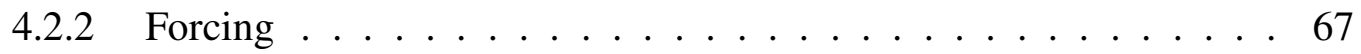

4.2 .3 Convection ....................... 69

4.3 Data and methods . . . . . . . . . . . . . . 72

4.3.1 Hydrography ..................... 72

4.3.2 Shipboard velocities ................... 74

4.3 .3 Satellite altimetry . . . . . . . . . . . . . . . . 74

4.3.4 Atmospheric reanalysis . . . . . . . . . . . . 75

4.3.5 Projection and gridding . . . . . . . . . . . . . 76

4.3.6 ADCP-referenced geostrophic velocities . . . . . . . . . . 78

4.3.7 AVISO-referenced geostrophic velocities . . . . . . . . . 79

4.3.8 Absolute geostrophic velocity errors . . . . . . . . . . . 83

4.4 Mean structure . . . . . . . . . . . . . . . . . . . 86 
4.5 Temporal variability . . . . . . . . . . . . . . . . . . . . . . 89

4.5.1 Contrasting the early 1990 s to the early $2000 \mathrm{~s} \ldots \ldots \ldots$. . . . 89

4.5.2 Decadal variability . . . . . . . . . . . . . . . . 95

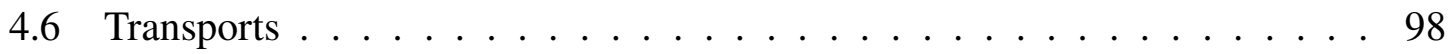

4.6.1 The Irminger Gyre . . . . . . . . . . . . . . . 100

4.6.2 The Irminger Current . . . . . . . . . . . . . . . . . . 101

4.6.3 The Western Boundary Current system . . . . . . . . . . . 103

4.6.4 The Deep Western Boundary Current … . . . . . . . . . 105

4.7 Convection . . . . . . . . . . . . . . . . . . . 107

4.7.1 Intermediate salinity maximum layer _ . . . . . . . . 107

4.7.2 Labrador Sea Water layer thickness . . . . . . . . . . . . 109

4.8 Discussion . . . . . . . . . . . . . . . . . . . . . . 113

4.9 Summary and conclusions $\ldots \ldots \ldots \ldots \ldots \ldots$

4.10 Acknowledgments . . . . . . . . . . . . . . . . . . . . . 119

5 Conclusions and Discussion $\quad 121$

5.1 Ramifications of LSW formation in the Irminger Sea . . . . . . . . . 121

5.2 Comparison with hindcast simulations . . . . . . . . . . . 122

5.3 Effects of an intensifying Irminger Gyre circulation . . . . . . . . . 124

5.4 Meridional heat transport and a changing climate $\ldots \ldots \ldots \ldots$ 


\section{Chapter 1}

\section{Introduction}

The Irminger and Labrador seas form the two deep basins in the western subpolar North Atlantic (Fig. 1-1). Wintertime convection in this region leads to the formation of an intermediate water mass called Labrador Sea Water (LSW), which ventilates a vast area of the North Atlantic and impacts the stratification of the water column. The process of convection has important climatic impacts: Heat is released from the ocean to the atmosphere, which energizes the North Atlantic storm track and contributes to the net poleward heat transport by the ocean-atmosphere system. $\mathrm{CO}_{2}$ dissolved near the surface is also sequestered at depth by this process.

\subsection{Circulation and ventilation of the subpolar gyre}

From its formation region in the northwestern subpolar gyre, LSW spreads out and influences a large area of the North Atlantic and beyond (e.g. Talley and McCartney, 1982; Straneo et al., 2003; Yashayaev et al., 2007a). Internal cyclonic recirculations in the Labrador and Irminger seas maintain an exchange of LSW between these two basins. Along interior pathways LSW spreads to the eastern North Atlantic, and LSW is also a direct component of the Deep Western Boundary Current (DWBC), by which it is exported equatorward and out of the subpolar North Atlantic. ${ }^{1}$ The DWBC is the deep limb of the Atlantic Merid-

\footnotetext{
${ }^{1}$ The recent study of Bower et al. (2009) suggests that pathways in the interior basin may be as important as the DWBC for the equatorward export of LSW south of the Grand Banks.
} 


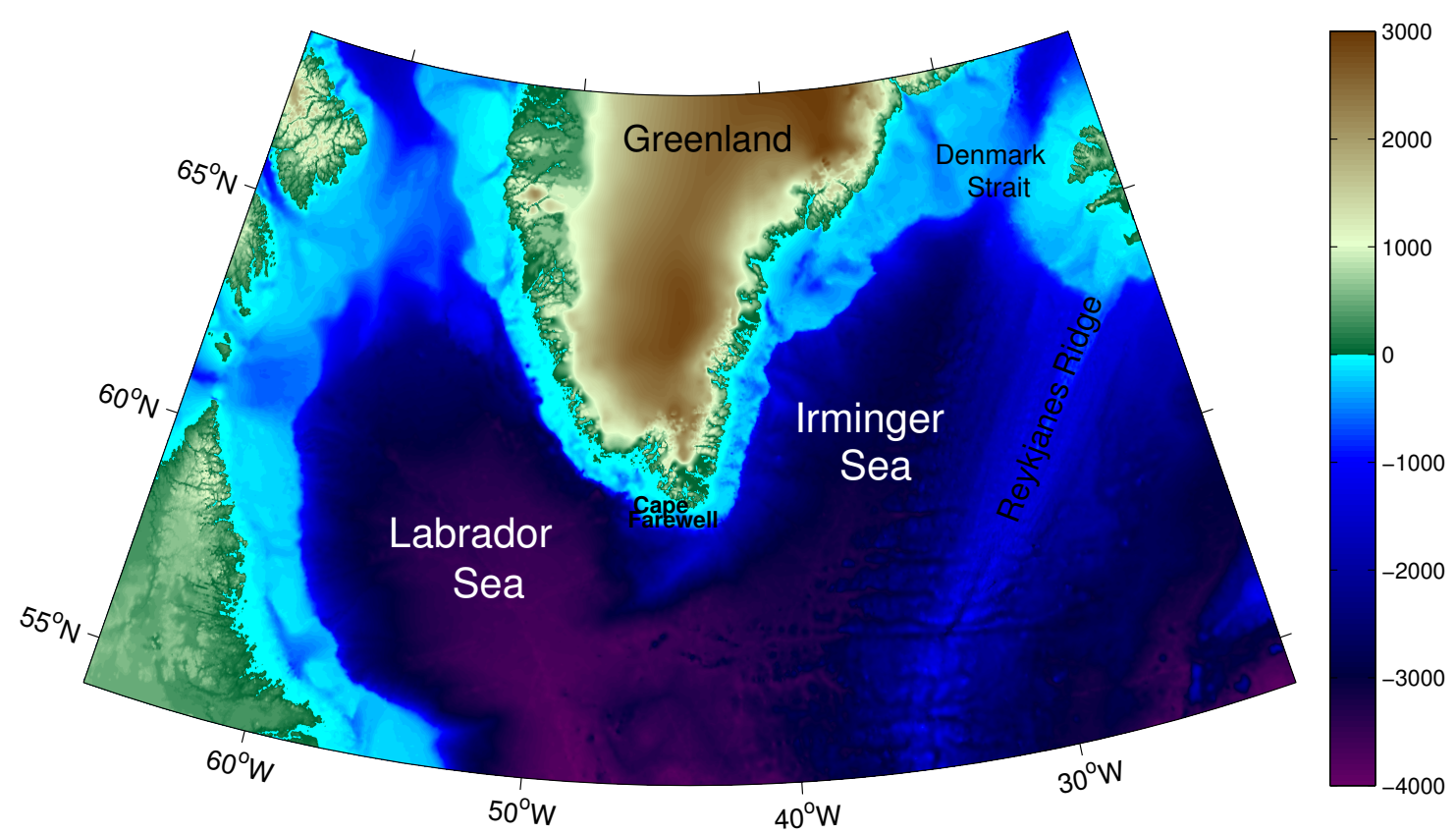

Figure 1-1: Topography of the subpolar North Atlantic from the Etopo2 2-minute elevation data base.

ional Overturning Circulation (MOC), which is of critical importance to the climate of northwestern Europe (e.g. Vellinga and Wood, 2002). The other components of the DWBC besides LSW are the overflow waters from the Nordic seas: Denmark Strait Overflow Water (DSOW) and Iceland-Scotland Overflow Water (ISOW). As the overflow waters descend from the sills of the Greenland-Iceland-Scotland Ridge, ambient water is entrained. Primary among the entrained waters is LSW (Fogelqvist et al., 2003), and in this capacity LSW participates also in the deepest part of the DWBC. The three water masses that constitute the DWBC (LSW, ISOW, and DSOW) are collectively referred to as North Atlantic Deep Water (NADW). The properties of this composite water mass are set in the subpolar North Atlantic, and it is found throughout the World Ocean (Johnson, 2008).

The North Atlantic subpolar gyre circulates cyclonically between about $50^{\circ}$ and $65^{\circ} \mathrm{N}$. According to Sverdrup theory, the gyre consists of a mass-balanced slow, northward interior flow and a swift, southward western boundary current driven by positive wind stress curl. In practice, the subpolar gyre circulation appears to be more complicated, and does not obey simple Sverdrup dynamics (Bryan et al., 1995; Treguier et al., 2005). A schematic of the boundary currents in the Irminger Sea (Fig. 1-2) shows warm, salty Atlantic-origin 
water flowing northward along the Reykjanes Ridge in the Irminger Current (IC). After a bifurcation south of the Denmark Strait, where a smaller branch continues northward through the strait to form the Icelandic Irminger Current, the bulk of the current recirculates to the south to flow alongside the East Greenland Current (EGC), which carries cold, fresh Arctic-origin water equatorward near the shelfbreak. On the inner shelf the East Greenland Coastal Current (EGCC), predominantly a bifurcated branch of the EGC, advects a combination of Arctic-origin water and coastal runoff to the south (Sutherland and Pickart, 2008). Seaward of the shelfbreak, on the mid to deep continental slope, resides the DWBC.

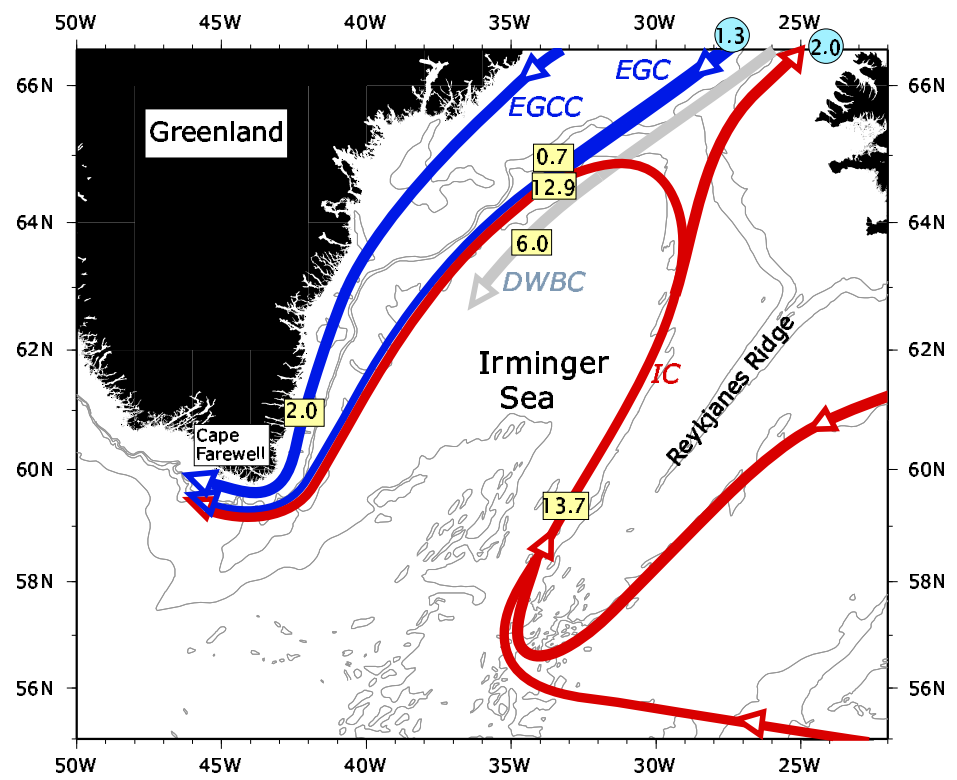

Figure 1-2: The boundary currents of the Irminger Sea, from Pickart et al. (2005). The acronyms are: $\mathrm{IC}=$ Irminger Current; EGC $=$ East Greenland Current EGCC $=$ East Greenland Coastal Current; DWBC $=$ Deep Western Boundary Current. Red (blue) arrows indicate upper-layer transport of warm (cold) water, and the numbers are transport estimates in Sverdrups $\left(1 \mathrm{~Sv}=10^{6} \mathrm{~m}^{3} / \mathrm{s}\right)$. The 500, 1000, 2000 and $3000 m$ isobaths are plotted.

\subsection{Convection in the Irminger Sea}

Contrary to the implications of its name, a growing body of evidence suggests that LSW can be formed in the Irminger Sea as well as in the Labrador Sea (e.g. Pickart et al., 2003a,b; Bacon et al., 2003; Falina et al., 2007; Våge et al., 2008). This idea is not new. The no- 
tion of deep convection in the Irminger Sea was proposed almost 100 years ago by Nansen (1912), who presented a limited number of hydrographic stations with matching surface and deep properties. Despite further evidence of deep convection in the Irminger Sea (e.g. Wattenberg, 1938), this idea was largely forgotten once deep convection was directly observed in the Labrador Sea. ${ }^{2}$ The idea was recently revisited by Pickart et al. (2003b), who showed that the observed lateral distribution of LSW in the western subpolar North Atlantic was inconsistent with a single source in the Labrador Sea. Pickart et al. (2003b) pointed out that conditions favorable for open ocean convection existed in the southwestern Irminger Sea as well. In particular, during a string of severe winters in the early 1990s the atmospheric forcing, together with the oceanic preconditioning and cyclonic circulation, satisfied the criteria for deep convection as outlined by Marshall and Schott (1999).

In contrast to the Labrador Sea, the conditions leading to deep convection in the Irminger Sea are to a greater extent governed by small-scale atmospheric and oceanic phenomena. Consider first the atmospheric conditions. Due to the impact of the high Greenland topography on low pressure systems that pass nearby, causing a variety of intense, small-scale wind phenomena, the region near Cape Farewell (the southern tip of Greenland) is the windiest location of the World Ocean (Sampe and Xie, 2007). Of particular importance to wintertime convection in the southwestern Irminger Sea is the westerly Greenland tip jet (see Figure 1-3, Pickart et al., 2003a; Våge et al., 2008). Tip jets are narrow, intermittent wind patterns east of Cape Farewell, whereby strong winds help elevate wintertime air-sea heat fluxes to levels comparable to those in the Labrador Sea. Although tip jet events are short-lived (up to 3 days, Pickart et al., 2003a), they occur repeatedly throughout the winter months. For example, during the winter of 1993-94 Pickart et al. (2003a) documented 10 westerly tip jet events.

The small-scale oceanic feature that is important to deep convection in the Irminger Sea is a closed, cyclonic recirculation gyre in the western part of the basin called the Irminger Gyre (Lavender et al., 2000). Water parcels inside the gyre are trapped and isolated, thereby subject to the strong atmospheric forcing for a longer period of time. The gyre circulation

\footnotetext{
${ }^{2}$ The historical perspective of the oceanographic community's evolving view on convection in the subpolar North Atlantic is detailed in Pickart et al. (2008)
} 


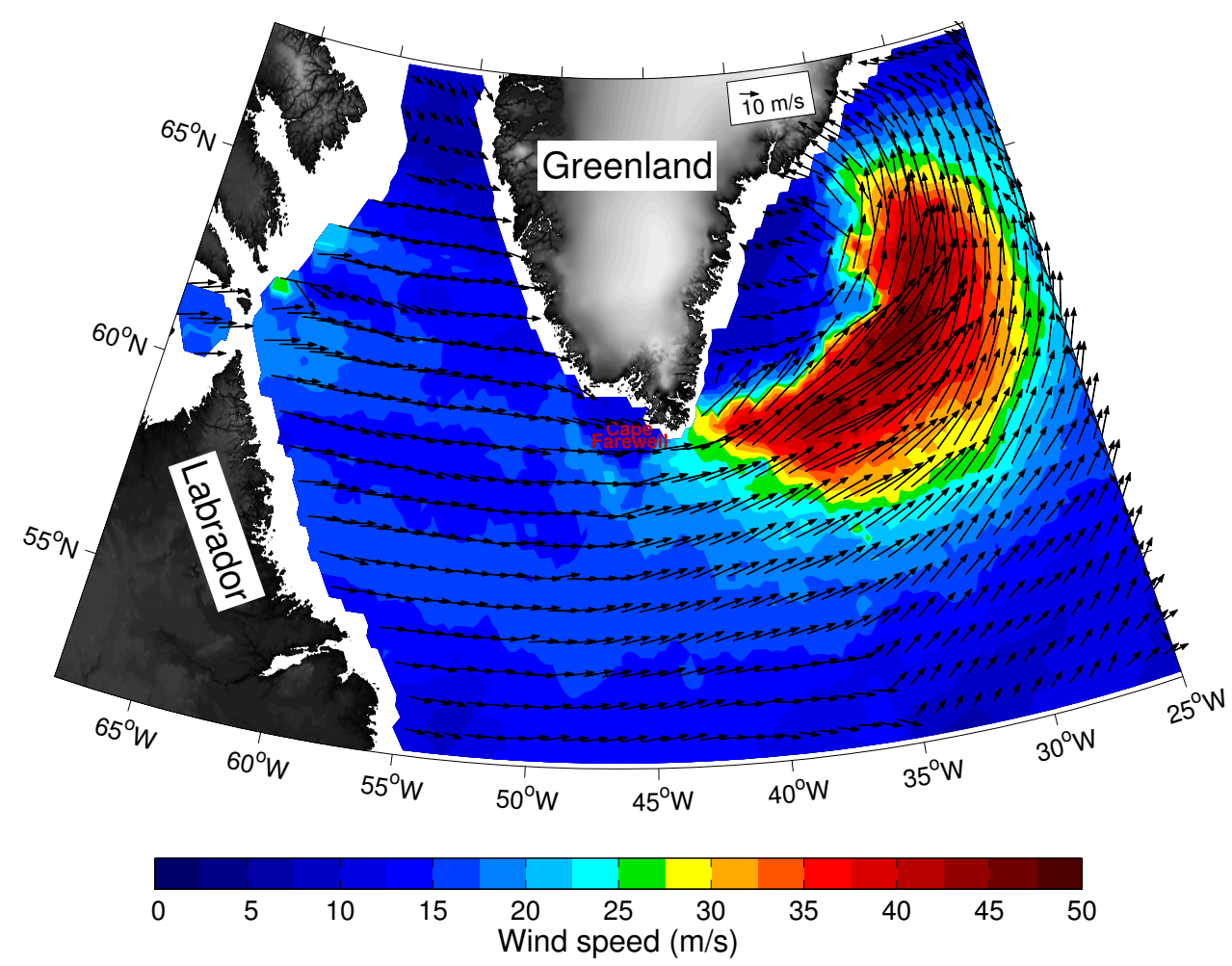

Figure 1-3: Satellite scatterometer (QuikSCAT) wind speed (m/s, color) and vectors showing a tip jet on 5 December, 2002.

also promotes retention of previous winters' convected products, which acts to reduce the stratification of the water column. Finally, isopycnal doming inside the gyre brings the weakly stratified water closer to the surface. In an integrated sense a series of westerly tip jet events over the course of a winter have a strong effect on the evolution of the mixed layer of the isolated water column near the center of the gyre (Våge et al., 2008).

\subsection{Effect of atmospheric variability on the circulation}

The subpolar gyre is strongly affected by interannual atmospheric variability. The dominant mode of variability in this region is the North Atlantic Oscillation (NAO, e.g. Hurrell, 1995). The NAO is described by an index computed from the normalized sea level pressure difference between the regions of the Icelandic Low and the Azores High. Winters of a high NAO index are typically characterized by stronger westerly winds, enhanced air-sea buoyancy fluxes, and deeper convection. Modulated by significant year to year variability, 


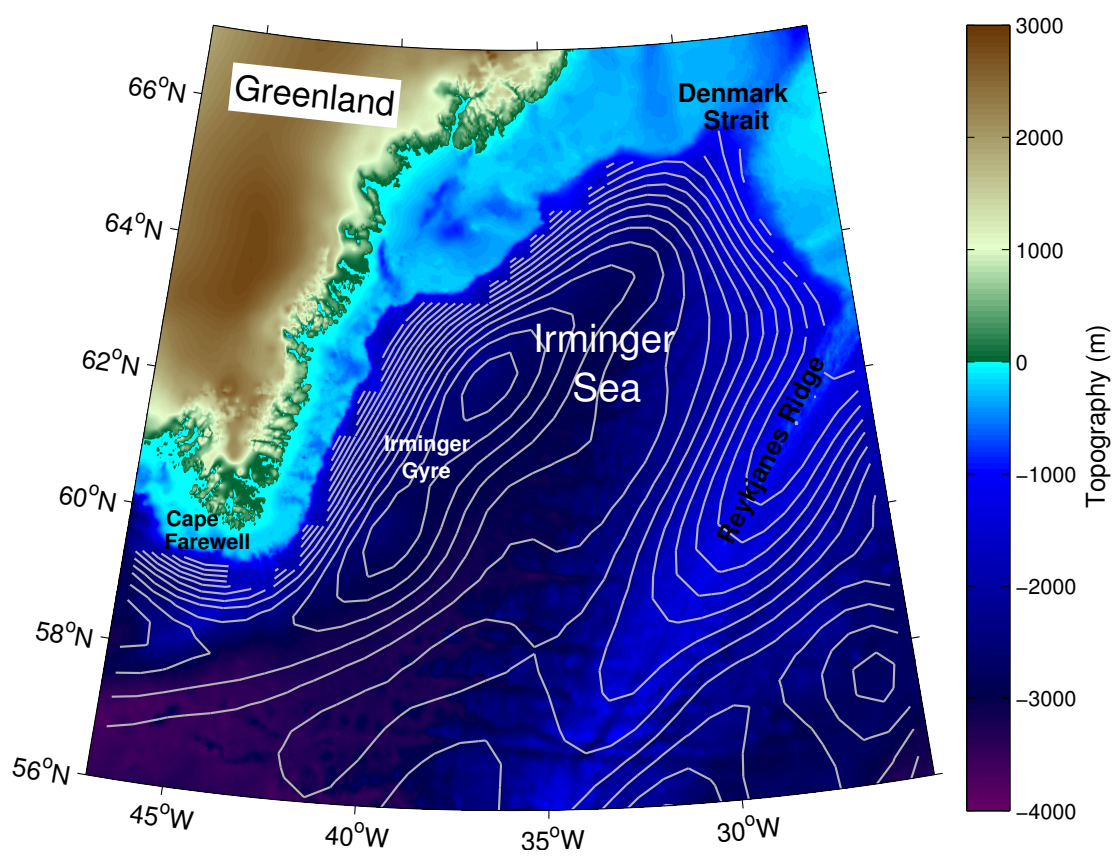

Figure 1-4: Topography of southeast Greenland and the Irminger Sea from the Etopo2 2-minute elevation data base. The gray lines are contours of objectively mapped geostrophic pressure at 700 $d b$, from Lavender et al. (2000). The closed contours in the western Irminger Sea reveal the location of the Irminger Gyre.

the NAO index evolved from strongly negative values in the mid-1960s to strongly positive values in the mid-1990s. Towards the end of this period the coldest and densest LSW on record was formed in large amounts (Yashayaev, 2007). This trend abruptly halted in the winter of 1995-96, and the decreased levels of wind and air-sea buoyancy forcing during the majority of the subsequent winters have led to a significant reduction of LSW formation (e.g. Lazier et al., 2002; Yashayaev, 2007).

The effect of the varying NAO and LSW formation rates on the subpolar gyre was nicely illustrated by Häkkinen and Rhines (2004). Their analysis of sea surface height anomalies in the North Atlantic revealed a spin-down of the subpolar gyre in concert with the persistent decline of the NAO index following the extreme positive state in the mid1990s. Considering hydrographic data and the declining buoyancy forcing, they linked the weakening gyre circulation to reduced levels of convective activity. During this period the gyre also contracted laterally (Hátún et al., 2005; Bersch et al., 2007). Similarly, Curry and McCartney (2003) found that the gyre circulation reflected a time integral of the NAO index, to a large extent governed by dense water formation in the subpolar North Atlantic. 


\subsection{Convective activity and the MOC}

Coupled ocean-atmosphere models integrated over long periods of time often display a coherence between LSW formation and MOC intensity ${ }^{3}$, with a reduced convective activity in the subpolar North Atlantic linked to a decline in the MOC (e.g. Jungclaus et al., 2005; Stouffer et al., 2006). The performance of such coupled climate models used in the Intergovernmental Panel on Climate Change (IPCC) Fourth Assessment Report (AR4) was evaluated in the Labrador and Irminger seas by de Jong et al. (2009). They found that in general the simulations were less than satisfactory, with model biases exceeding the observed range of variability by orders of magnitude. The overall tendencies of the coupled models were to have a low surface salinity and high intermediate and deep salinities, which led to increased stratification in the upper $1000 \mathrm{db}$ of the models. Cold surface water above warm intermediate and deep layers in most models had a negative influence on the stability, but far from sufficient to compensate for the stabilizing effect of the salinity. As a result the convective activity was confined to a thin upper layer. Another group of models had high salinity and potential density biases over the entire water column, which led to excessively deep convection. Several of the models exhibited stronger convection in the Irminger Sea than in the Labrador Sea, and formation of LSW was in general poorly represented in the coupled models. Model drift often became a considerable problem, in particular for models that required a long spin-up time. Since the MOC and other aspects of climate variability are highly sensitive to the hydrographic conditions and circulation of the western subpolar North Atlantic, these low-resolution simulations must be interpreted with caution. While high resolution is required for a realistic simulation of the circulation field, a redeeming feature of the coupled models is that variability consistent with observed conditions can be simulated with lower resolution (Böning et al., 2006).

A number of high-resolution hindcast simulations of the subpolar North Atlantic have been performed over the last few years. While more realistic than the low-resolution simulations, such regional studies of the subpolar gyre circulation using general circulation

\footnotetext{
${ }^{3}$ The overturning circulation may be considered in both depth space and density space, involving sinking and water mass transformation, respectively (e.g. Pickart and Spall, 2007). Unless otherwise noted, results are discussed in depth space.
} 
models (GCMs) are also challenging for a number of reasons, including the importance of buoyancy forcing on the dynamics of the system, the low stratification, and the difficulty of maintaining the small temperature and salinity contrasts between the water masses (e.g. Treguier et al., 2005; Haine et al., 2008). It was recently suggested that with a current state-of-the-art global GCM it is not possible to achieve both dynamic and thermodynamic fidelity, in other words realistically simulating both the intensity of the circulation and the water mass characteristics at the same time is very difficult (Yaeger and Jochum, 2009). Though directly applicable only to their model, it may have a bearing also on other simulations.

A shared feature also among many of these high-resolution GCMs is a link between convective activity in the subpolar gyre and the Atlantic MOC (e.g. Eden and Willebrand, 2001; Böning et al., 2006; Deshayes and Frankignoul, 2008). Closer inspection of some of these models reveal that even though they tend to simulate the gross features of the subpolar gyre circulation reasonably realistically, important features of the observed conditions such as the magnitude of the overflows and the location and intensity of convection are problematic. For example, in the $20 \mathrm{~km}$ resolution model of Deshayes and Frankignoul (2008) convection in the Irminger Sea was too intense and occurred in the northeastern part of the basin (Deshayes et al., 2007), while it is well established that the deepest convection occurs in the southwestern part of the basin (Pickart et al., 2003b; Centurioni and Gould, 2004). The location matters. The close proximity of the model's Irminger Sea convective region to the boundary current led to rapid export of newly convected water out of the basin via the DWBC, which resulted in an excessive influence on the circulation. Despite these shortcomings, Deshayes and Frankignoul (2008) argue that the Atlantic MOC can to first order be considered an integrator of NAO-modulated atmospheric forcing, with a particularly strong link to convection in the Irminger Sea.

Data assimilation, the combination of observations and model output, is a common practice in the atmospheric sciences. This approach has recently been applied also in physical oceanography (an example of which is the consortium Estimating the Circulation and Climate of the Ocean (ECCO), Wunsch and Heimbach, 2007), where it is referred to as "state estimation". Essentially the state estimate is computed from a GCM whose initial 
and boundary conditions are subject to a least squares adjustment in order to bring the result into agreement with observations within estimated errors. State estimation provides a promising avenue to synthesize diverse ocean observations and estimate quantities that are difficult to infer from observations alone, such as the MOC.

The evaluation of state estimates' realism and usefulness compared to GCMs is only beginning (Schott and Brandt, 2007). Presently available computational resources dictate that the resolution remains relatively low (currently 1 degree for the ECCO project), and this is likely to be a problem for the foreseeable future (Wunsch and Heimbach, 2007). Comparison between assimilated and directly observed hydrographic properties in the Irminger Sea is not very convincing (de Jong et al., 2009). Relative to observations, the mean ECCO vertical profile was significantly offset in terms of both temperature and salinity, and identification of distinct water masses was not possible. Excessive convection was a contributing factor; the water column was regularly mixed all the way to the bottom in both the Labrador and the Irminger seas (Schott and Brandt, 2007; de Jong et al., 2009).

\subsection{Climatic impacts of LSW formation}

The importance of dense water formation in the northern North Atlantic is well illustrated by the meridional heat transport in the Atlantic, which is northward at all latitudes, including south of the equator. The magnitude of the heat transport has been estimated from a number of hydrographic transects and inverse calculations in the vicinity of $25^{\circ} \mathrm{N}$ to be about 1.3 PW (1 PW = 10 ${ }^{15}$ W, e.g. Hall and Bryden, 1982; Ganachaud and Wunsch, 2000; Talley, 2003). At this latitude the oceanic heat transport is comparable in magnitude to the atmospheric heat transport, while outside of the tropics the atmosphere dominates the meridional heat transport (Trenberth and Caron, 2001). The Atlantic heat transport may be divided into three separate components; shallow, intermediate, and deep overturning, where the latter two are associated with LSW and NADW formation, respectively. From such an analysis in density space Talley (2003) determined that the three components were of similar magnitude. On the other hand, a repeat hydrographic data-based estimate of Labrador Sea heat loss by Pickart and Spall (2007) resulted in values an order of magnitude smaller, 
with the heat loss predominantly resulting from the horizontal rather than the overturning circulation both in depth and density space. They concluded that the Atlantic MOC is not largely impacted locally by deep convection in the Labrador Sea. The discrepancy between these results partly stems from different locations and NAO periods from which the hydrographic data were obtained, as well as the low horizontal resolution of the data used by Talley (2003). The estimate of Pickart and Spall (2007) includes only a limited part of the convective area in the subpolar gyre (although this does contain the area where convective activity is expected to be most intense). In particular, convection in the Irminger Sea was not accounted for, which may be a considerable source of heat loss to the atmosphere. The disparity between different observational estimates regarding the importance of LSW formation to meridional heat transport, not to mention the disparity between observations and GCMs, illustrates how much remains to be learned about the subpolar North Atlantic.

To summarize: The subpolar North Atlantic is a critical component of the global climate system. Deep convection in the subpolar gyre releases heat from the ocean to the atmosphere, and is crucial to the climate of northwestern Europe (e.g. Vellinga and Wood, 2002). A resulting effect is that more anthropogenic carbon is stored in the subpolar North Atlantic per unit area than in any other ocean (Sabine et al., 2004). Atmospheric variability, primarily NAO-related, strongly impacts convective activity as well as the circulation and extent of the subpolar gyre. Consequent changes in hydrographic properties have direct economic repercussions on commercial fisheries, even to the extent that timeseries of registered catches of various species may be used as proxies for the state of the subpolar gyre (Hátún et al., 2009). Numerical models struggle to realistically simulate the subpolar North Atlantic in various ways, but most agree that LSW formation impacts the MOC. The Irminger Sea is of particular interest given its potential to form LSW.

Despite the evidence to date, there is not an overall consensus in the oceanographic community that formation of LSW can occur in the Irminger Sea. A second location of LSW formation outside the Labrador Sea would have important consequences for our understanding of the North Atlantic MOC, the modification of the dense overflow waters from the Nordic seas, and the stratification and ventilation of the interior North Atlantic. LSW 
formation rates and ventilation times would have to be reconsidered, and both observations and model results from this area must be interpreted in a new perspective. Because of close contact and mixing between the NADW constituent water masses, local deep convection, and recipience of export from the Arctic, there is, to quote Yashayaev and Dickson (2008), a unique global importance of regional processes in the Irminger Sea for the transfer of ocean climate signals between water masses and to great ocean depths.

\subsection{Thesis outline}

The focus of this thesis is on deep convection and LSW formation in the subpolar North Atlantic, with a special emphasis on the Irminger Sea and the small-scale atmospheric and oceanic processes that are important to local overturning. The thesis is structured as three self-contained articles, two of which are published; the third will be submitted for publication shortly.

In Chapter 2 the impact of Greenland on the atmospheric circulation in its vicinity is investigated, with a particular emphasis on the westerly Greenland tip jet. An objective and sensitive method is used to explore the ERA-40 meteorological reanalysis product for the signatures of tip jets, with the goal of forming a comprehensive and consistent climatology of such events. This is then used to investigate the evolution of the tip jet and to gain further dynamical insight regarding its mechanism of generation. The main caveat of using a the ERA-40 product is its coarse resolution, but comparison with satellite wind measurements for the period where both products were available shows that while the tip jet magnitudes were underestimated, the vast majority of the tip jets were detected. This chapter was published in the Quarterly Journal of the Royal Meteorological Society as part of the Greenland Flow Dynamics Experiment special issue. The co-authors, Thomas Spengler, Huw Davies, and Bob Pickart, contributed to the study with comments and insights.

In Chapter 3 the return of deep convection to the subpolar North Atlantic in winter 2007-08 following years of shallow overturning is documented. Various data sets are analyzed with the objective to elucidate the reasons why it happened, and the study illuminates the complexity of the North Atlantic convective system. This chapter was published in Na- 
ture Geoscience. Specific contributions of the co-authors are as follows: Virginie Thierry and Gilles Reverdin first noticed the return of deep convection from real-time ARGO data which helped motivate the study. Craig Lee and Brian Petrie did the freshwater flux calculation for Davis Strait, which was discussed in Section 3.6. Tom Agnew and Amy Wong supplied movies of ice concentration and motion in the Arctic/North Atlantic that motivated a part of the discussion section. Mads Ribergaard provided meteorological data from Greenland. All of the co-authors contributed to the study with comments and insights.

The main objectives of Chapter 4 are to quantify the structure, transport and interannual variability of the Irminger Gyre and to investigate the importance of the Irminger Sea as a source region for LSW. In situ data were generously provided by Øyvind Knutsen, Artem Sarafanov, Herlé Mercier, Pascale Lherminier, Manfred Bersch, Hendrik van Aken, Jens Meincke, and Detlef Quadfasel.

Collectively the thesis chapters are intended to add to our body of knowledge regarding the atmospheric forcing, the nature and interplay of the atmosphere-ice-ocean system, and the structure and variability of the circulation in the subpolar North Atlantic, and how these phenomena impact upon convection in this region. The purpose is to contribute to a basis from which we can better interpret existing observations and improve models, so that we can ultimately understand more thoroughly how Earth's climate system works. 


\section{Chapter 2}

\section{Multi-event analysis of the westerly Greenland tip jet based upon 45 winters in ERA-40}

This chapter has been published online as an article in the Quarterly Journal of the Royal Meteorological Society as part of the Greenland Flow Dynamics Experiment special issue, and is reprinted with their permission. The authors are Kjetil Våge, Thomas Spengler, Huw C. Davies, and Robert S. Pickart.

\subsection{Abstract}

The westerly Greenland tip jet is an intense, narrow and intermittent wind phenomenon located southeast of Cape Farewell that occurs frequently during the winter season. Using the ERA-40 reanalysis data set, a catalogue of 586 objectively detected westerly tip jet events is compiled for the winters 1957-2002, and an analysis is undertaken of the character of the jet and its accompanying atmospheric features. It is shown that the tip jet frequency exhibits a significant positive correlation with both the NAO index and the latitude of the Icelandic Low. The peak wind speed and accompanying heat fluxes of the jet have values up to $30 \mathrm{~m} \mathrm{~s}^{-1}$ and $600 \mathrm{~W} \mathrm{~m}^{-2}$, respectively, and are sustained for less than one day. The air parcels constituting the tip jet are shown, based upon a trajectory model and the 
ERA-40 data set, to have a continental origin, and to exhibit a characteristic deflection and acceleration around southern Greenland. The events are almost invariably accompanied both by a notable coherence of the lower-level tip jet with an overlying upper-level jet stream, and by a surface cyclone located to the lee of Greenland. It is also shown that the cyclone originates upstream of and is advected to the lee of Greenland, and thereby it both precedes in time and contributes dynamically to the formation of the tip jet. On this basis it is suggested that the tip jet arises from the interplay of the synoptic-scale flow evolution and the perturbing effects of Greenland's topography upon the flow.

\subsection{Introduction}

Greenland exerts a significant impact on the atmospheric circulation of the Northern Hemisphere. Among other things, it is known to cause a southward shift of the North Atlantic storm track (Petersen et al., 2004). Both the orography and sharp low-level temperature gradients arising from the warm interior ocean adjacent to the cold water and ice on the east Greenland shelf partially account for the presence of the Icelandic Low (Tsukernik et al., 2007). On shorter time scales, numerical simulations have shown that the high topography of Greenland affects synoptic storm systems in its vicinity (e.g. Kristjánsson and McInnes, 1999; Petersen et al., 2003).

The region near Cape Farewell (the southern tip of Greenland) is the windiest area of the World Ocean (Sampe and Xie, 2007). This is to a large extent due to a variety of intense, small-scale wind phenomena that arise from the impact of the Greenland topography on low pressure systems that pass nearby. (Such orographically induced winds are not unique to Greenland, see for example Schwerdtfeger, 1975; Parish, 1982; McCauley and Sturman, 1999; Seefeldt and Cassano, 2008). Near Greenland these phenomena predominantly occur in winter. Most notable are westerly (forward) and easterly (reverse) tip jets and barrier winds. Tip jets are narrow, intermittent wind patterns near the southern tip of Greenland, while barrier winds are a geostrophic response to stable air being forced towards the high eastern coast of Greenland (Moore, 2003; Moore and Renfrew, 2005; Petersen et al., 2009). The focus of this study is on the westerly tip jet (see Figure 2-1, hereafter referred to simply 
as a "tip jet").

Tip jets often develop when a low pressure system moves into the region east of southern Greenland (Pickart et al., 2003a; Moore, 2003). Two mechanisms generating the tip jet have been proposed: The first involves orographic descent. Doyle and Shapiro (1999) argued that the tip jets are governed by conservation of the Bernoulli function when air parcels descend sharply down the lee slope of Greenland (the Bernoulli function is the sum of enthalpy, kinetic energy, and potential energy per unit mass; Schär, 1993). The second mechanism, also noted by Doyle and Shapiro (1999) and later expanded upon by Moore and Renfrew (2005), involves blocking due to the high topography of Greenland. The dynamical parameter space governing the occurrence of blocking in the case when stratified flow encounters a topographic barrier has been investigated both in the absence (Smith, 1989; Ólafsson and Bougeault, 1996) and presence (Pierrehumbert and Wyman, 1985; Petersen et al., 2003) of rotation (see Doyle and Shapiro, 1999, for a theoretical overview). Moore and Renfrew (2005) found that acceleration through deflection of surface winds around the southern tip of Greenland during periods of blocking was a consistent feature of tip jets in their climatological study of high wind speed events in the vicinity of Greenland.

The small meridional scale of the tip jet results in a region of localized high cyclonic wind-stress curl east of Cape Farewell (Pickart et al., 2003a). Using an idealized ocean model, Spall and Pickart (2003) showed that this patch of enhanced wind-stress curl is sufficient to drive the recirculation gyre observed in the Irminger Sea east of Greenland (Lavender et al., 2000). The cyclonic wind-stress curl leads to upwelling and isopycnal doming in the water column below, which, together with the large heat fluxes caused by the strong winds, are conducive for driving deep oceanic convection in winter (Pickart et al., 2003a; Våge et al., 2008). It has been hypothesized that the southwestern Irminger Sea, within the Irminger Gyre and under the direct influence of the tip jet, may be another region where the densest type of subpolar mode water, Labrador Sea Water (LSW), is formed during sufficiently severe winters (Pickart et al., 2003b). (LSW was previously thought to originate solely from the Labrador Sea). The strong tip jet winds also present a significant marine hazard (e.g. Moore, 2003).

In this work we use an objective and sensitive method to explore the ERA-40 meteoro- 


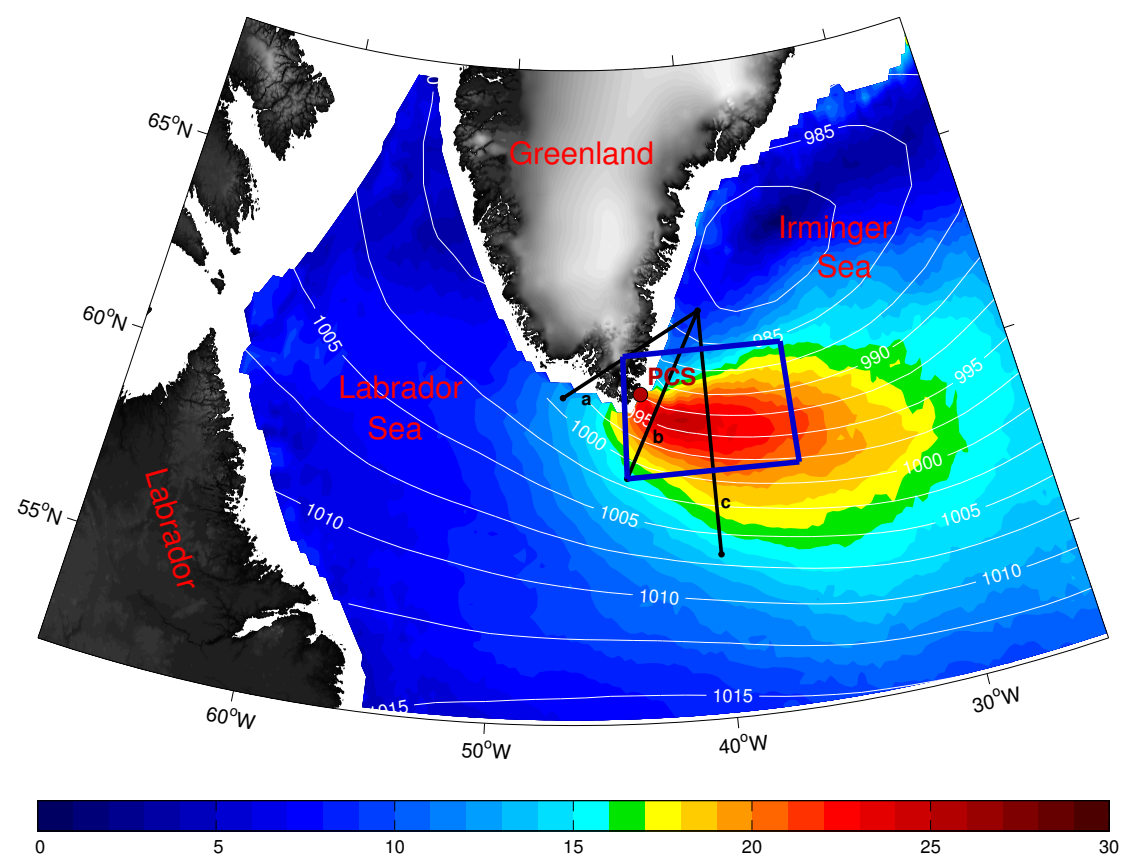

Figure 2-1: Mean tip jet QuikSCAT winds (colour, $m s^{-1}$ ) and ERA-40 sea level pressure (contours, $h \mathrm{~Pa}$ ) over the period 1999-2002. See text for explanation of rectangle and lines. The red dot marks the location of the Prins Christian Sund (PCS) meteorological station near Cape Farewell. The Labrador Sea to the southwest and the Irminger Sea to the southeast of Greenland are regions of dense water formation.

logical reanalysis product for the signatures of tip jets. The goal is to form a comprehensive and consistent climatology of such events, which is then used to investigate the evolution of the tip jet and to gain further dynamical insight regarding its mechanism of generation. The main advantages of using a meteorological reanalysis for climatological studies are the long time periods covered and the availability of all relevant meteorological fields on a 3dimensional grid, while the main disadvantage is a relatively coarse horizontal and vertical resolution. The advent of satellite scatterometers (in particular the QuikSCAT satellite in 1999), which measure the surface wind field over the ocean at high resolution, provides an opportunity to check the consistency of the lower-resolution reanalysis surface winds in the vicinity of Cape Farewell.

The paper is outlined as follows. The ERA-40 reanalysis product and the tip jet detection routine are described in Section 2.3. A comparison with the QuikSCAT satellite scatterometer winds follows in Section 2.4. In Section 2.5 the relationship between tip jet frequency and large-scale North Atlantic atmospheric patterns are examined. Composite 
averages provide a robust description of the evolution of the tip jet and are described in Section 2.6. A Lagrangian trajectory analysis, presented in Section 2.7, complements the description of the tip jet by identifying the paths and origin of the air parcels contained within the jet. The atmospheric conditions during tip jet events are investigated in Section 2.8. In Section 2.9 we discuss the dependency of the tip jet on the low-level flow interaction with the topography of Greenland as well as on the large-scale atmospheric conditions.

\subsection{Data and methods}

\subsubsection{ERA-40 reanalysis product}

The European Centre for Medium-Range Weather Forecasts (ECMWF) 45-year reanalysis product (ERA-40, Uppala et al., 2005) covering the period 1957 to 2002 was analyzed in this study. The horizontal and temporal resolutions at the surface and at 23 pressure levels are one degree and six hours, respectively. Produced with a fixed numerical weather prediction data assimilation system, ERA-40 (and other reanalysis products) provides a physically consistent interpolation of historical observational data through space and time. However, the observing system did not remain constant during this period. The growing importance of satellite instruments after 1979 had a particularly large impact on the meteorological analyses, mainly in regions where ground-based observations were sparse and in the upper troposphere and stratosphere (Bengtsson et al., 2004). Thus the ERA-40 fields may not be regarded as fully consistent throughout the entire period. For our tip jet climatology this issue is not addressed, but it is less of a concern in the northern hemisphere. Furthermore upper-level atmospheric data are only considered for the most recent period.

As a check on the accuracy of the ECMWF model in a subpolar region of sparse data, Renfrew et al. (2002) compared the surface fields from the National Centers for Environmental Prediction (NCEP, Kalnay et al., 1996) and the ECMWF operational analysis with data recorded by the research vessel Knorr during a 1997 winter cruise in the Labrador Sea. They found that the ECMWF model fields represented the observed data reasonably 
well, but contained a cold bias for sea surface temperature and $2 \mathrm{~m}$ air temperature near the ice edge, and a tendency to overestimate the latent and sensible heat fluxes. In the present study the latter issue is circumvented to some extent by application of a bulk formula (Fairall et al., 2003) to compute the heat fluxes in Section 2.6.

Concerns regarding the ability of a global product of relatively coarse resolution like ERA-40 to accurately capture small-scale atmospheric phenomena such as the Greenland tip jet (illustrated in Figure 2-2) have been raised previously (Pickart et al., 2003a; Moore, 2003). This is examined further in Section 2.4.

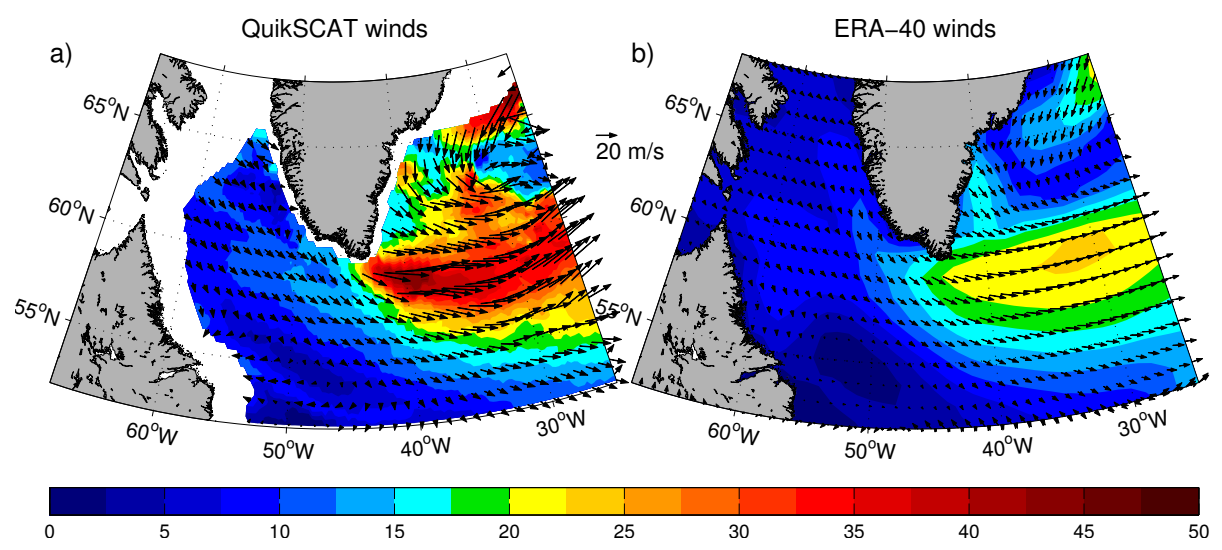

Figure 2-2: Surface wind field $\left(m s^{-1}\right)$ during the February 21, 2002, tip jet event illustrating the difference between (a) QuikSCAT and (b) ERA-40.

\subsubsection{Tip jet detection}

Two empirical orthogonal function (EOF) approaches have been used in previous studies to objectively detect tip jet events. Pickart et al. (2003a) found that tip jets were characterized by strong westerly winds, anomalously low air temperatures, and low sea level pressure. They constructed an EOF based on these three variables using nearly 30 years of meteorological data from the Prins Christian Sund weather station near Cape Farewell (labeled PCS in Fig. 2-1) to identify the events. Våge et al. (2008) noted that tip jet events were relatively insensitive to the location and central pressure of their parent low pressure systems, and showed that the gradient of sea level pressure was a better metric than sea level pressure alone. Some tip jets were also observed to completely evade the meteorological station. Correspondingly, Våge et al. (2008) devised an EOF routine that employed time- 
series of (i) the maximum $10 \mathrm{~m}$ zonal wind speed within the blue rectangle of Figure 2-1 recorded by the QuikSCAT satellite scatterometer (retrieved using the "Ku-2001" model, Wentz et al., 2001); (ii) the mean NCEP sea level pressure gradient along the lines a, b, and $\mathrm{c}$ in Figure 2-1; and (iii) the PCS air temperature. This method proved to be more sensitive to tip jet detection, and had the advantage of utilizing accurate, high-resolution satellite wind speed data covering a larger geographical area. Våge et al. (2008) used a threshold zonal wind speed of $25 \mathrm{~m} \mathrm{~s}^{-1}$ to define a robust tip jet. Manual inspection of the scatterometer winds confirmed that all of the robust tip jets that took place during the two winters that they considered were detected.

In this work we primarily use the EOF routine developed by Våge et al. (2008). We note that satellite scatterometers were not available prior to 1987, and that there are temporal gaps in the PCS air temperature record. Hence we use only timeseries extracted from ERA-40 as input for the EOF routine. ERA-40 was used alone in order to have a consistent detection algorithm covering the entire period. Furthermore it is desirable to avoid data from the location of the PCS weather station due to suspected influence of the high local topography. Instead of temperatures from the PCS location, we used a roving temperature timeseries. At each time step, the temperature at the location of the maximum zonal wind speed within the blue rectangle of Figure 2-1 was tabulated. In this way the temperature at the core of the tip jet was always considered. For completeness we also applied the same EOF method implemented by Pickart et al. (2003a) using the PCS data only. For the majority of cases the two EOF routines identified the same events.

While we use the same routine as Våge et al. (2008), our reconstructed tip jet winds are weaker than theirs largely because of the coarser resolution of the ERA-40 winds. As such, the threshold reconstructed zonal wind speed for defining an event as robust was lowered from 25 to $18 \mathrm{~m} \mathrm{~s}^{-1}$. This limit was chosen to achieve a balance between avoiding false positive identifications, and at the same time not missing robust tip jets. The threshold value was determined by carefully comparing the ERA- 40 and QuikSCAT winds for the period of overlap (1999-2002). In reality there exists a continuum of tip jet magnitudes, and the label "robust" is somewhat arbitrary. All tip jets discussed from this point onwards are robust according to the above definition, hence the label will be dropped. 
All of the events that satisfied the criteria from either of the two EOF routines above were examined manually to ensure that each tip jet was recorded once, at its peak intensity, and to locate the centres of their parent low pressure systems. In addition to the two EOFs, a

final procedure was applied to detect wind speed events exceeding $20 \mathrm{~m} \mathrm{~s}^{-1}$ with a direction deviating at most $30^{\circ}$ from west within the blue rectangle of Figure 2-1. This was done to identify any events that might have been missed by the EOFs. Only a few such cases were identified. In total, 586 tip jet events were detected in the ERA-40 reanalysis for the winters (Nov-Apr) of 1957 to 2002. This is on average 13 per winter. Validation of our climatology through comparison with QuikSCAT for the period of overlap indicates that $88 \%$ of all of the tip jets that had mean QuikSCAT wind speeds within the blue rectangle in Figure 2-1 exceeding $25 \mathrm{~m} \mathrm{~s}^{-1}$ were detected in ERA-40 without reporting false positives. The tip jets found only in the QuikSCAT data set were in general weaker and/or of shorter duration than the tip jets identified in ERA-40.

\subsection{ERA-40 versus QuikSCAT winds}

\subsubsection{Winter conditions}

To examine the correspondence between ERA-40 and QuikSCAT winds, the mean $10 \mathrm{~m}$ wind speed within the blue rectangle of Figure 2-1 was determined for every realization of each data set during the winters of overlap (1999-2002). The ERA-40 timeseries was then temporally interpolated onto the same twice daily time base as the QuikSCAT data (Fig. 2-3a). The correlation between the wind speeds from the two products in this region is 0.89 . All correlations reported are significant at the $99 \%$ confidence level. (Confidence intervals were determined using a bootstrap algorithm, a procedure that involves random sampling with replacement from the data set and does not require any assumptions about the underlying probability distribution.) The linear least squares best fit resulted in the following relation between the two wind speed products:

$$
|\overrightarrow{\mathbf{v}}|_{\text {QuikSCAT }}=1.4|\overrightarrow{\mathbf{v}}|_{E R A-40}-0.9
$$



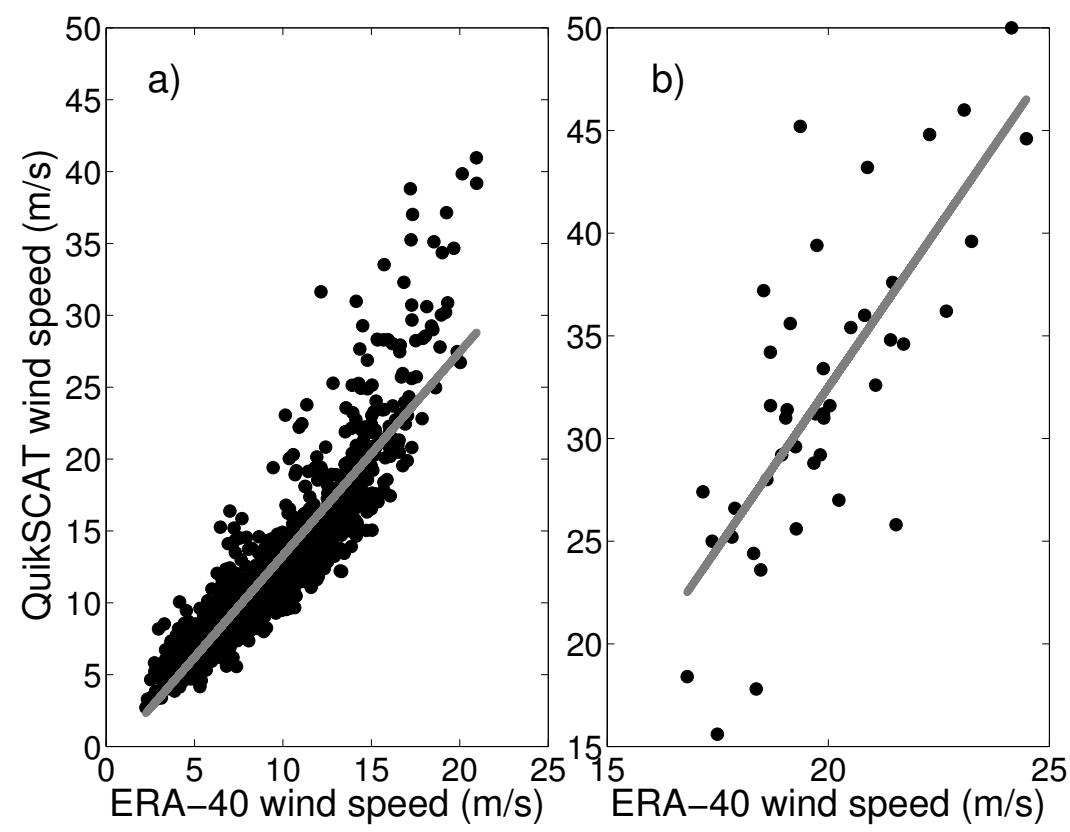

Figure 2-3: Relationships between (a) mean ERA-40 and QuikSCAT $10 \mathrm{~m}$ wind speeds within the blue rectangle of Figure 2-1 twice daily during all of the winters of overlap and (b) maximum ERA-40 and QuikSCAT $10 \mathrm{~m}$ wind speeds found within the same box during tip jet events (43 events in total).

In the region near Cape Farewell the ERA-40 and QuikSCAT winds are generally well correlated, but the good correlation tends to break down for the highest wind speeds. In particular, all of the QuikSCAT wind speeds exceeding $30 \mathrm{~m} \mathrm{~s}^{-1}$ were associated with small-scale wind events: Westerly and easterly tip jets and barrier winds. As mentioned in the introduction, these wind phenomena result from the impact of the high topography of Greenland on a nearby low pressure system, and it is clear that they are not as well represented in the lower resolution ERA-40 fields. However, Moore et al. (2008) found that, relative to a meteorological buoy in the Irminger Sea, QuikSCAT showed evidence of a high wind speed bias. Renfrew et al. (2009) reached a similar conclusion using aircraftbased observations east of southern Greenland. This bias may be a contributing factor to the reduced correlation at extreme wind speeds, though the underestimation of high winds in ERA-40 due to low resolution and orographic effects is likely the dominant reason. 


\subsubsection{Tip jet conditions}

Considering only the wind speeds during tip jet events, the correlation between ERA-40 and QuikSCAT maximum wind speeds dropped to 0.75 (Fig. 2-3b), and the least squares relation changed to

$$
|\overrightarrow{\mathbf{v}}|_{\text {QuikSCAT }}=3.1|\overrightarrow{\mathbf{v}}|_{\text {ERA-40 }}-30
$$

We chose to consider the maximum wind speed instead of the mean because the scale of the tip jet is much smaller than the rectangle. (When considering the mean wind speed during tip jet events, the correlation was 0.78.) We will also use (2.2) to estimate the "true" wind speed at the core of the composite average tip jet in Section 2.6.

It is clear that ERA-40 significantly underestimates the wind speeds during tip jet events relative to the scatterometer. Using the global ECMWF forecast model, Jung and Rhines (2007) found that increasing the model resolution beyond that of ERA-40 continuously improved the representation of the tip jet as judged by high-resolution scatterometer studies of the tip jet (Moore and Renfrew, 2005). In particular, both the heat flux and surface wind stress curl were increased. In any case, the significant positive correlation between ERA-40 and QuikSCAT winds during tip jet events indicates that our tip jet climatology effectively captures the most intense tip jet events.

\subsection{Tip jets and the NAO}

The North Atlantic Oscillation (NAO) is the dominant pattern of climate variability in the North Atlantic (Hurrell, 1995). Winters that are characterized by a positive NAO index are associated with stronger westerly winds, enhanced air-sea buoyancy fluxes, and are often linked with deep convection in the subpolar North Atlantic Ocean (Dickson et al., 1996; Våge et al., 2009a). Pickart et al. (2003a) also found that a greater number of tip jet events took place during high NAO index winters. Figure 2-4 shows the timeseries of winter (Nov-Apr) tip jet frequency over the 45 year period of ERA-40. Significant interannual variability is evident; some winters have as few as 3-5 tip jets, while others have as many 
as 20-25. On average, there are 13 tip jet events per winter, with a standard deviation of 5. Figure 2-4 also illustrates the temporal relation between tip jet frequency and the monthly NAO index of Hurrell (1995) averaged over the winter months (Nov-Apr). Using the tip jet climatology of Pickart et al. (2003a) and the atmospheric NAO pattern decomposed into indices of Icelandic Low (IL) and Azores High (AH) centres of actions (COA, Hameed et al., 1995), Bakalian et al. (2007) found that the number of tip jet events per winter was more sensitive to the latitude of the IL than to the NAO index.

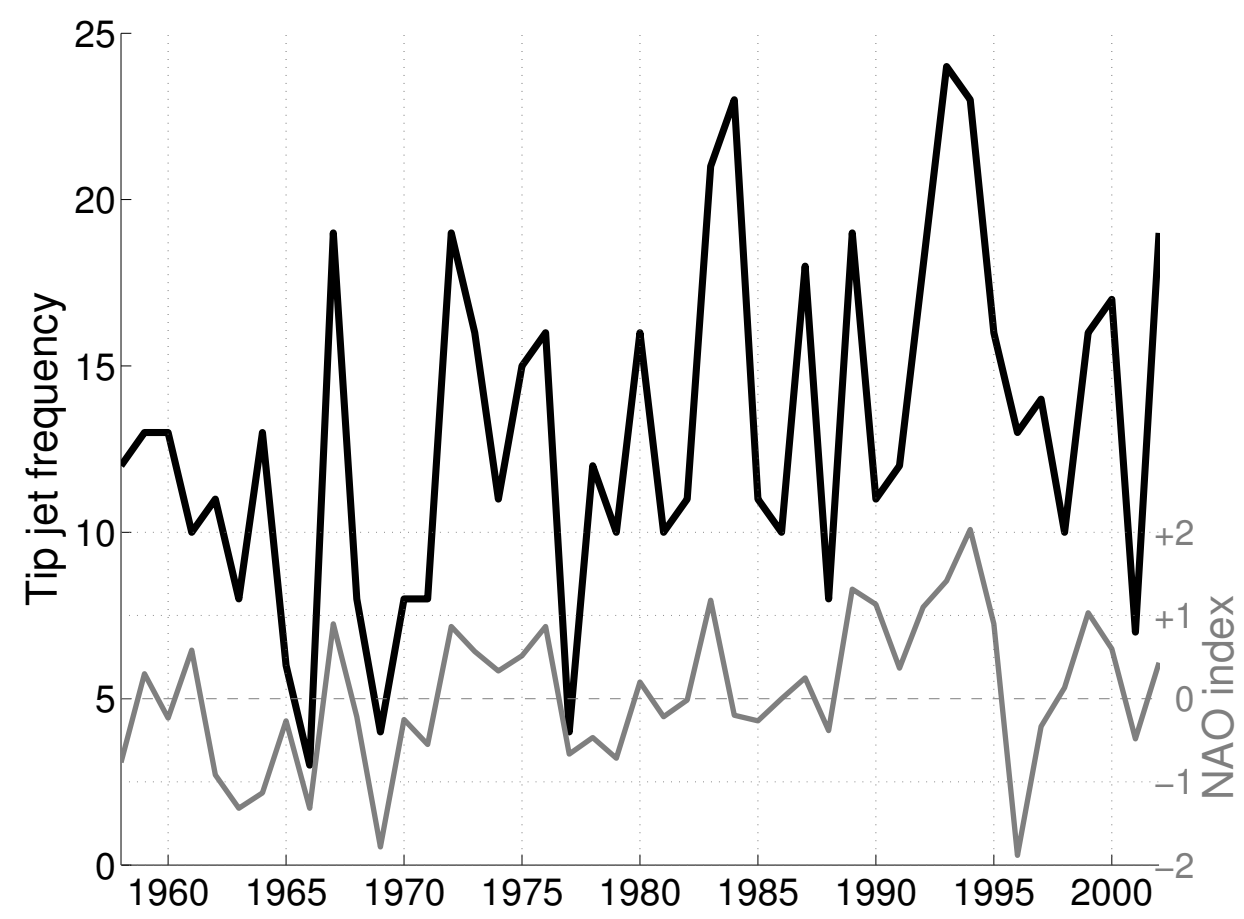

Figure 2-4: Timeseries of winter tip jet frequency (black) and NAO index (grey).

Using the present climatology, with the monthly NAO index of Hurrell (1995) and the COA indices of Hameed et al. (1995) averaged over the winter months (Nov-Apr), we find similar correlations. This is true despite the underrepresented tip jet frequency in Pickart et al. (2003a)'s climatology (see Våge et al., 2008). In particular, we find correlations of 0.71 and 0.69 between the number of tip jet events per winter and the NAO index and latitude of the IL, respectively. This suggests that the NAO state and the meridional location of the IL are of comparable importance for the frequency of tip jet events (Fig. 2-5). As the location of the IL may influence the value of the station-based NAO index, these variables are not expected to be completely independent. Indeed, a correlation of 0.86 was found be- 
tween the NAO index and the latitude of the IL. Using the wintertime NAO index (Hurrell, 1995) based upon the months December through March, the correlation decreased to 0.64 (a similarly low correlation of 0.65 was obtained when averaging the monthly NAO index over the same months). This shows that the shoulder months, November and April, which are important from an oceanic convection perspective, also contribute a sizeable number of tip jet events (16 and 8 percent, respectively).
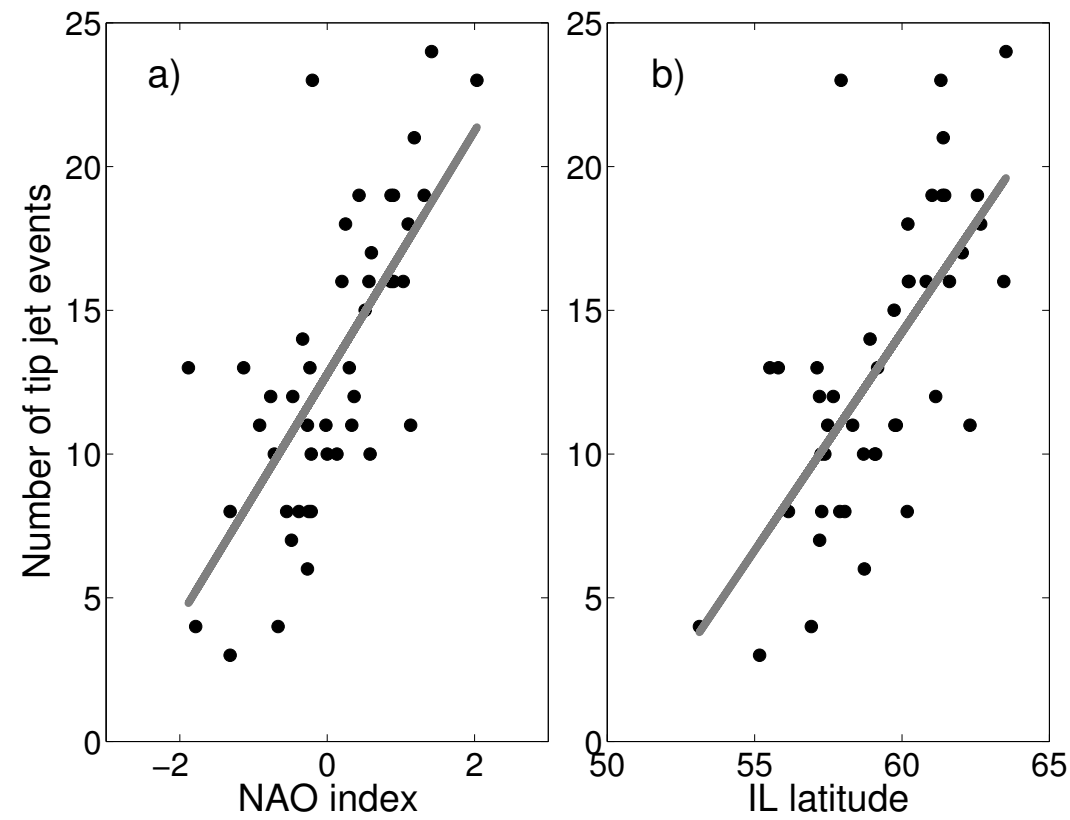

Figure 2-5: Relationships between winter tip jet frequency and (a) the NAO index and (b) the latitude of the Icelandic Low.

\subsection{Tip jet composites}

Composite averages of all 586 tip jets from the ERA-40 data set during the 24 hour period surrounding an event portray the tip jet as an intense, short-lived phenomenon (Fig. 26). Peak wind speeds approaching $20 \mathrm{~m} \mathrm{~s}^{-1}$ were sustained for less than a day (Fig. 26a). Pickart et al. (2003a) found that tip jets at the Prins Christian Sund meteorological station on average lasted approximately 3 days. The discrepancy between these estimates of tip jet duration is mainly due to our focus on peak tip jet wind speeds, while they also considered the shoulders of the tip jet events. Using Equation 2.2 the "true" wind speed 
at the core of the composite average tip jet was estimated to exceed $30 \mathrm{~m} \mathrm{~s}^{-1}$. The region of low sea level pressure localized northeast of Cape Farewell was at its deepest and most compact at the peak of the tip jets (Fig. 2-6b), and at a lag of +12 hours had moved in the downstream direction towards Iceland. This is reflected in the gradient of sea level pressure. The strong pressure gradient extending eastward from Cape Farewell, which in agreement with Våge et al. (2008) was found to be a feature common to every tip jet event, was most intense at the peak of the composite event compared to lags plus and minus 12 hours. This is consistent with the composite velocities (Fig. 2-6a). In agreement with previous studies (e.g. Pickart et al., 2003a), every tip jet event was associated with a parent low pressure system (marked with an L in Figure 2-6b). Although most of the parent cyclones were located close to the east coast of Greenland, there was a significant scatter in their positions, but never to the extent that the strong pressure gradients east of Cape Farewell were compromised.

Turbulent heat fluxes were computed using a bulk formula (COARE 3.0, Fairall et al., 2003) with the inputs of wind speed, humidity, air temperature, and sea surface temperature, and were on average more than 3 times greater during tip jet events compared to background levels (Fig. 2-6c). Replacing the ERA-40 wind speed with our estimate of the true wind speed in the bulk formula raised the heat fluxes in the centre of the composite tip jet from $400 \mathrm{~W} \mathrm{~m}^{-2}$ to almost $600 \mathrm{~W} \mathrm{~m}^{-2}$. Even though the QuikSCAT-based true wind speed estimate may have a positive bias (Moore et al., 2008; Renfrew et al., 2009), the magnitude of the heat flux at the core of the tip jet is still likely to be underestimated. Tip jets are associated with a drop in air temperature (Pickart et al., 2003a), and it will be shown in Section 2.7 that cold, low-humidity air of continental origin tends to comprise the tip jets. Neither of these features are well captured by the ERA-40 data set, and both would tend to further increase the tip jet heat fluxes. This suspected heat flux underestimate is also consistent with the case studies of Jung and Rhines (2007).

As seen in Figure 2-6c, large heat fluxes are also present over the Labrador Sea 12 hours prior to the peak of the tip jet events. These are most likely associated with cold air outbreaks, during which low pressure systems following the North Atlantic storm track draw cold and dry continental air from Labrador over the relatively warm ocean, thereby 


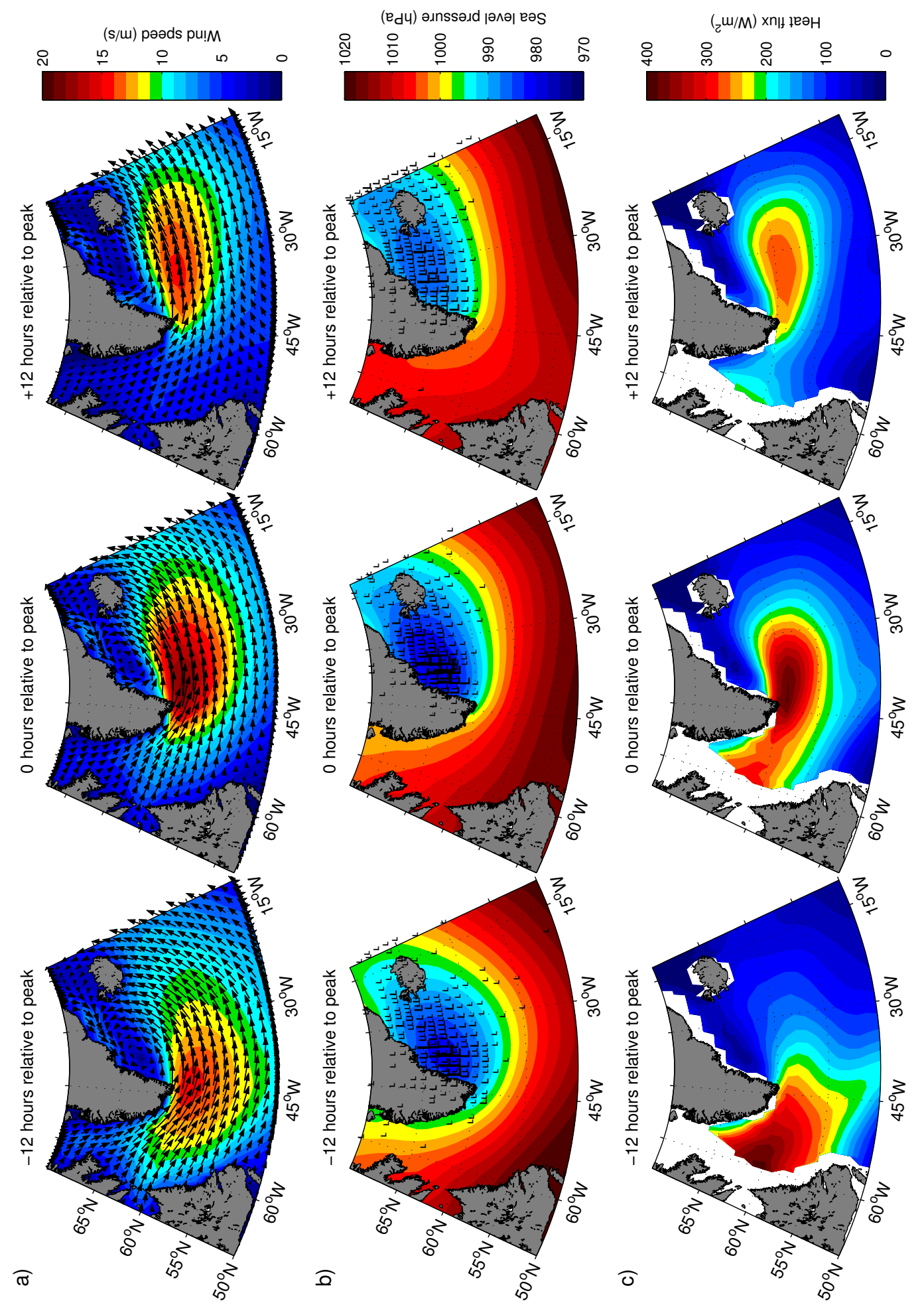

Figure 2-6: Composite averages of (a) wind speed $\left(\mathrm{m} \mathrm{s}^{-1}\right)$, (b) sea level pressure $(\mathrm{hPa})$, and (c) turbulent heat fluxes $\left(W \mathrm{~m}^{-2}\right.$ ) illustrating the temporal evolution of the Greenland tip jet. The title of each panel refers to the time lag relative to the peak of the composite tip jet. The L's in (b) indicate the locations of the centres of the parent cyclones, the sizes of the L's are proportional to the number of cyclones that they represent. 
enhancing the air-sea heat fluxes (e.g. Pickart et al., 2008). The analysis of Våge et al. (2009a) shows that the very same storms that cause cold air outbreaks in the Labrador Sea tend to trigger tip jet events a few hours later as they progress northeastward along the storm track. Both of these locations of high heat fluxes, the western Labrador Sea and the southwestern Irminger Sea, are regions where deep convection is known to take place during severe winters. For the evolution of the oceanic mixed layer in the Irminger Sea, the integrated effect of many tip jets during the course of a winter is of great importance (Våge et al., 2008).

\subsection{Air parcel trajectories}

To better understand the potential impact of tip jets on oceanic convection, it is necessary to know the origin of the air that they transport. Cold and dry continental air will extract more heat from the ocean than relatively warm and moist maritime air. The upstream path of air parcels comprising the tip jets might also provide evidence supporting one of the proposed mechanisms of formation; i.e. either the orographic descent hypothesis of Doyle and Shapiro (1999) or the acceleration through deflection hypothesis advocated by Moore and Renfrew (2005).

A 3-dimensional Lagrangian trajectory model (Wernli and Davies, 1997) was applied to compute 2-day backwards air parcel trajectories terminating above the southwestern Irminger Sea (900 to $950 \mathrm{hPa}$ ) using ERA-40 winds as input. Only trajectories from the core of each tip jet were included, selected objectively by requiring the wind speed to exceed $20 \mathrm{~m} \mathrm{~s}^{-1}$ and the direction to deviate no more than $30^{\circ}$ from west at the point of termination. Given the evolving observing system (Bengtsson et al., 2004) and computation constraints, only the most recent winters (1994 to 2002) were considered for this analysis, resulting in nearly 3000 trajectories from 101 tip jet events (Fig. 2-7).

The trajectories so computed clearly illustrate the continental origin of the air parcels constituting the tip jet. This has important implications for the air-sea heat exchange in the Irminger Sea, as the air originating from northern Canada in winter is usually very cold and dry. Before reaching the Irminger Sea, the air must cross the Labrador Sea, whose 


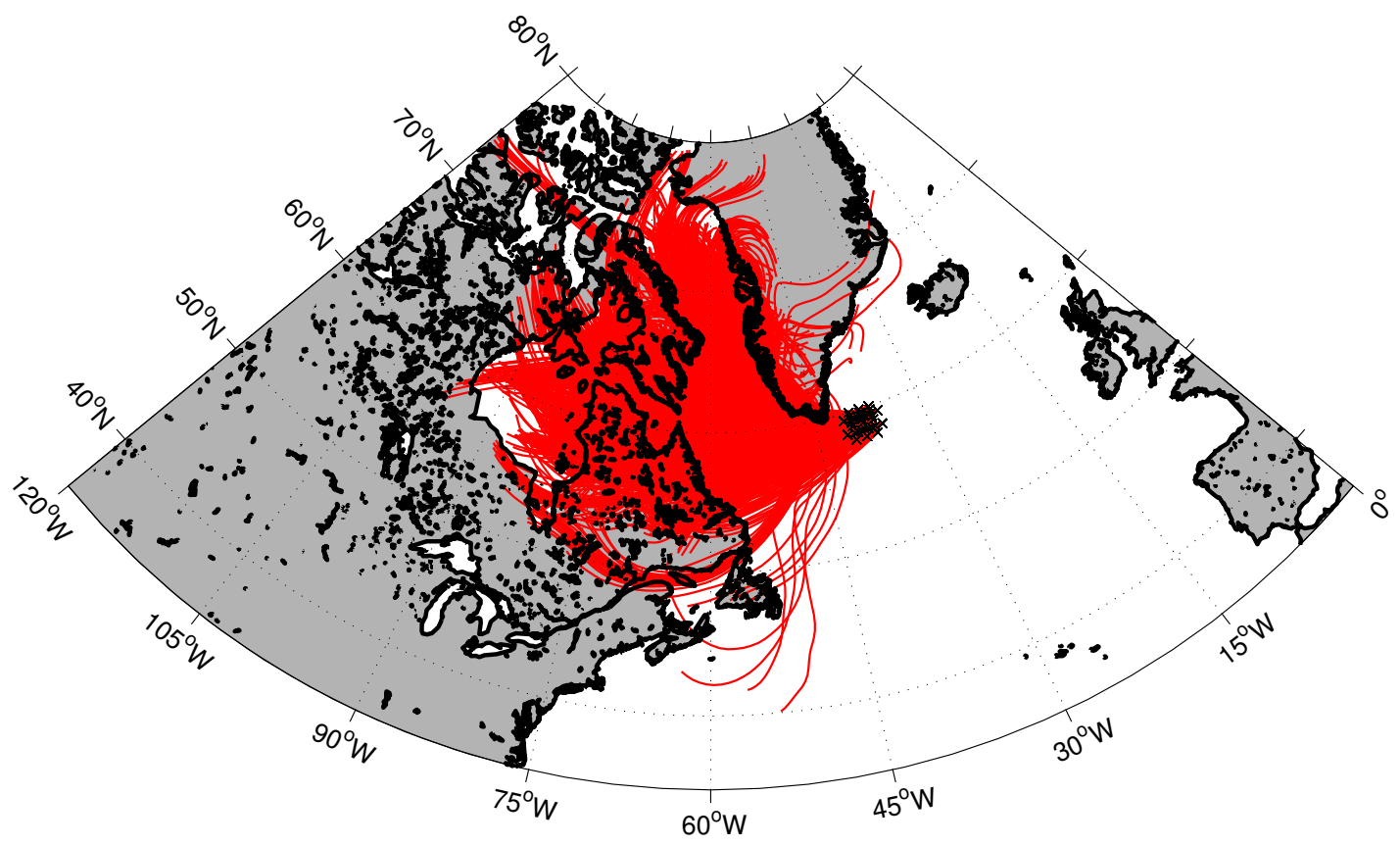

Figure 2-7: Backward 2-day trajectories of air parcels within tip jets (see text for selection parameters). Note the continental origin of the air composing the tip jet and how the trajectories curve around southern Greenland.

western margin and northern end are covered with ice in winter. Hence modification by air-sea interaction in the Labrador Sea is somewhat reduced, and, as shown in Section 2.6, tip jets are very effective at extracting heat from the southwestern part of the Irminger Sea. A marked difference in origin of the air comprising the westerly and easterly tip jets is likely a major reason why the latter is not believed to cause deep oceanic convection in the southeastern Labrador Sea (Sproson et al., 2008).

Figure 2-7 also demonstrates that most of the trajectories curve around Greenland, suggesting that acceleration by deflection is a key mechanism of tip jet generation (e.g. Moore and Renfrew, 2005). In order to shed more light on this, the pressure change and velocity along each trajectory were computed and interpolated onto a $0.5^{\circ} \times 0.5^{\circ}$ grid using a Laplacian-spline interpolator. The resulting along-trajectory pressure change (Fig. 2-8a, colour) indicates that some sinking takes place over southern Greenland, which would support the orographic descent under Bernoulli conservation hypothesis of Doyle and Shapiro (1999). However, this involves only a small number of trajectories (less than $18 \%$ of the trajectories experienced a temporal pressure change greater than $25 \mathrm{hPa} \mathrm{hr} r^{-1}$, Fig. 2-8, 
contours). The vast majority of the trajectories pass to the south of Cape Farewell, and the acceleration associated with deflection around Greenland is evident (Fig. 2-8b, colour).

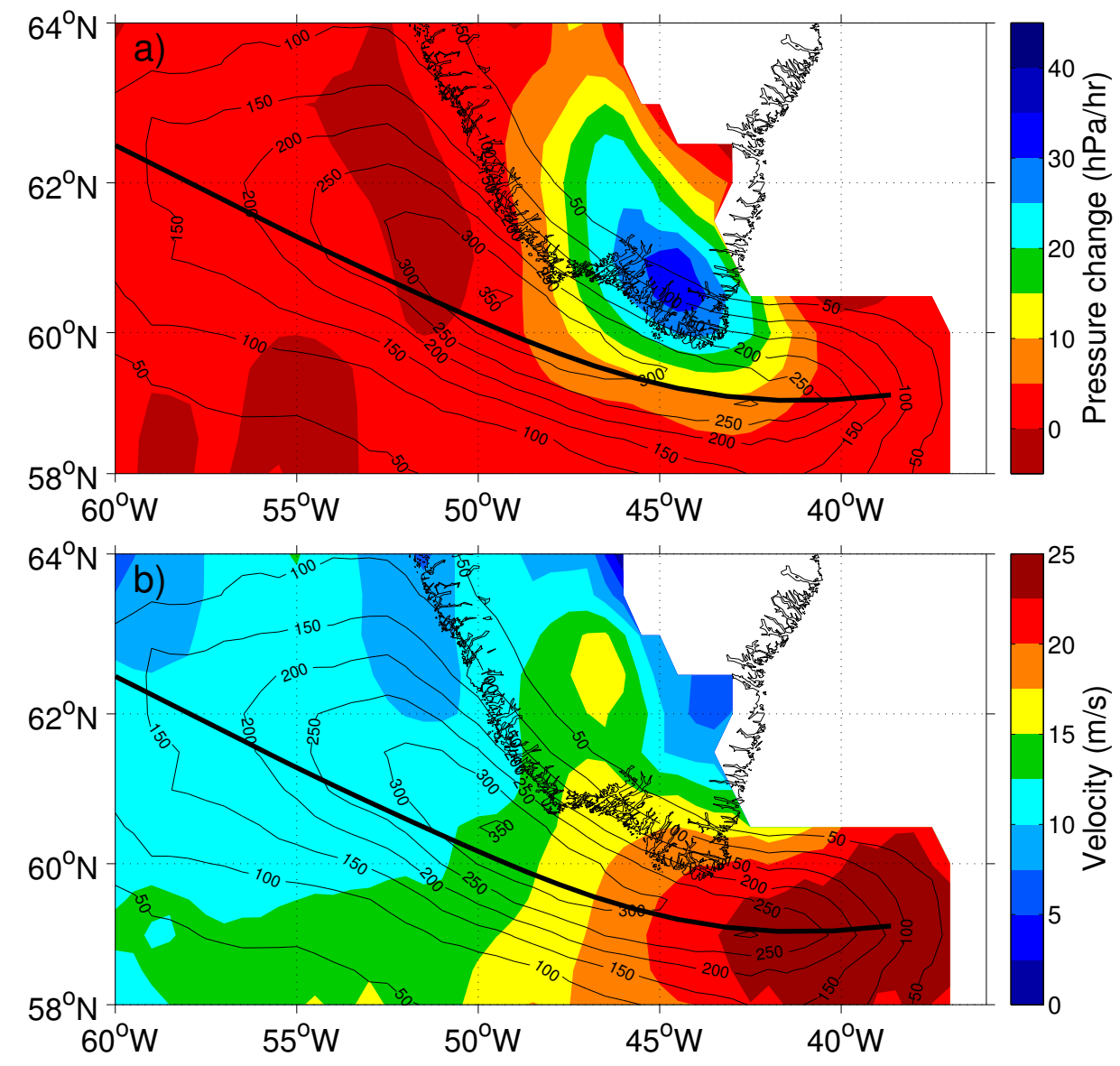

Figure 2-8: Pressure change (a, $h P a h r^{-1}$ ) and velocity (b, $m s^{-1}$ ) computed along the trajectories from Figure 2-7. The contours denote the number of realizations, and the black line marks the mean tip jet trajectory.

The mean Froude number estimated west of Greenland during tip jet events is much less than 1. (The Froude number is computed as $F r=\frac{U}{N H}$, where $\mathrm{U}$ is wind speed, $\mathrm{N}$ is buoyancy frequency, a measure of static stability, and $\mathrm{H}$ is the obstacle height. $\mathrm{U}$ and $\mathrm{N}$ were computed from the ERA-40 climatology upstream and below the height of the obstacle, which was taken to be $2500 \mathrm{~m}$.) This indicates that stratification dominates the inertia of the air parcels, and hence the air is more likely to flow around than over Greenland (Skeie et al., 2006). This corroborates the evidence from the trajectory model. 


\subsection{Flow features accompanying the tip jet}

To improve our understanding of the processes leading to the formation of tip jets, we examine the major atmospheric flow features that accompany these events and how they relate to the results from the air parcel trajectory model. In particular we focus on the low-level cyclones and the tropopause-level jet stream.

\subsubsection{Low-level cyclone}

It was noted earlier that the synoptic-scale flow incident upon Greenland can generate numerous small-scale weather phenomena (see Renfrew et al., 2008, for an overview). Here we examine the occurrence and nature of the low-level cyclonic systems that appear to be a ubiquitous accompanying feature of tip jets. The aim is to shed light upon the relationship between the cyclone and the tip jet. To this end we use a data base (Wernli and Schwierz, 2006) that identifies the storm tracks and cyclone field (defined as the area within the outermost closed $2 \mathrm{hPa}$ pressure contour of a low pressure system) based upon the ERA-40 reanalysis sea level pressure data. To select the cyclones that were associated with tip jet events from the data base, we matched their spatio-temporal locations with the manually determined positions of the tip jets' parent low pressure systems. A success rate of $98 \%$ testifies to the robustness of the data base.

Consider in turn the storm track and the along-track pressure change and speed of translation of the subset of ERA-40 cyclones that were associated with tip jet events. For the tracks (Fig. 2-9) it is evident that most of the cyclones linked to the occurrence of tip jets followed a well-defined path from the eastern seaboard of North America into the Irminger Sea. A similar picture emerged from the manually tracked parent low pressure systems for the two individual winters of 2002-03 and 2003-04 analyzed by Vage et al. (2008), and is also consistent with the results of Hoskins and Hodges (2002).

The pre-existence of the cyclonic systems prior to their arrival over the Irminger Sea has important ramifications. It demonstrates that the cyclogenesis that spawns these systems tends to occur upstream of Greenland rather than being an example of in-situ lee cyclogenesis off southern Greenland (e.g. Jung and Rhines, 2007; Kristjánsson and Thorsteinsson, 


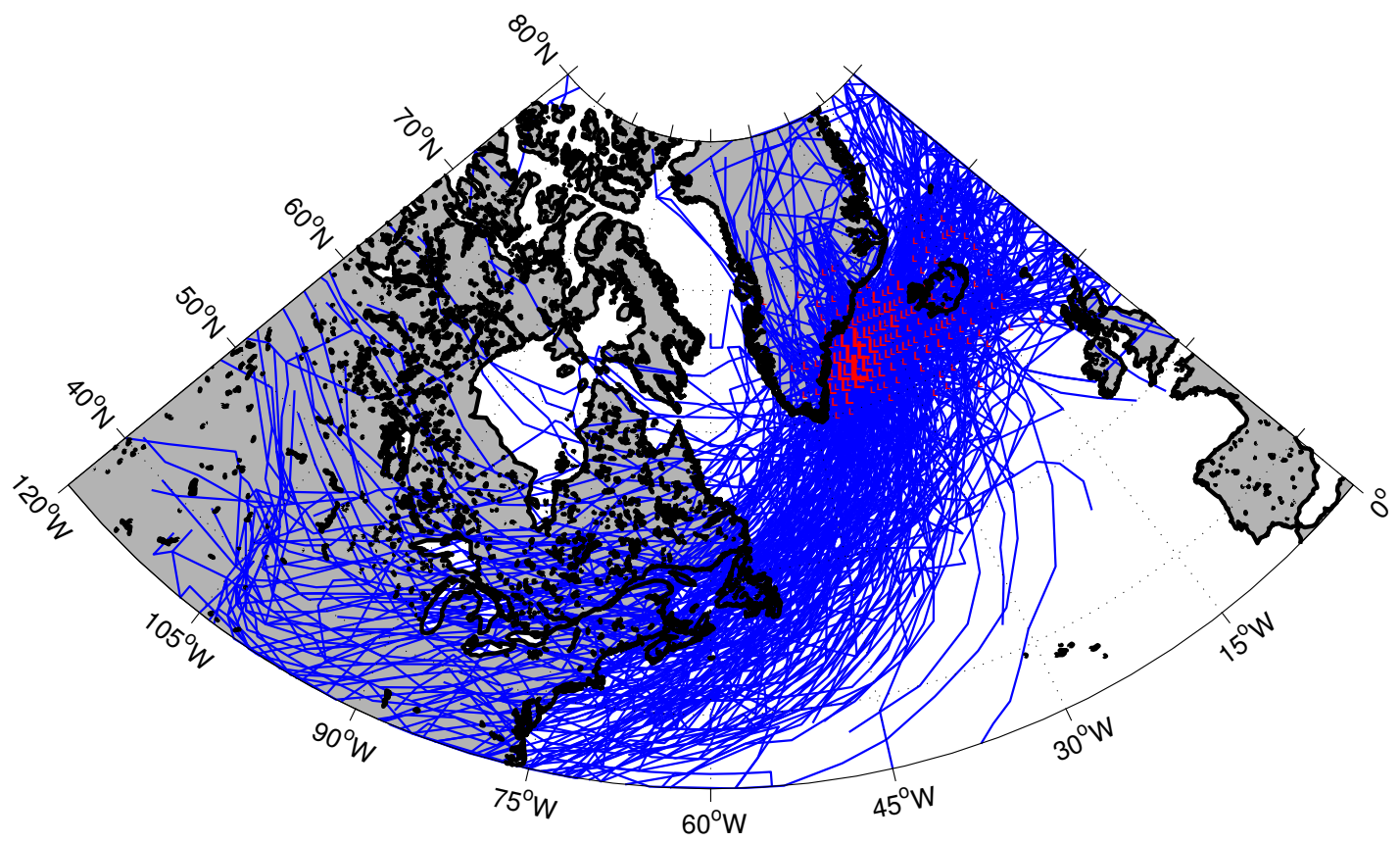

Figure 2-9: Tracks of tip jet-generating cyclones for the duration of their existence. The L's mark the locations of the centres of the parent cyclones at the peak of each event, with the size proportional to the number of cyclones represented.

2009; McInnes et al., 2009). Consequently it suggests that orography alone does not produce the conditions necessary for tip jet formation, and that the upstream synoptic-scale flow evolution plays an important role as well.

To examine these issues further, consider the pressure change and translation speed of these systems (Fig. 2-10) computed along each cyclone's track in the same manner as the along-trajectory evolution in Section 2.7. These patterns show that the mean behaviour of the cyclones was to deepen while rapidly approaching Greenland from the southwest, and thereafter decelerate and start to fill as they traverse the Irminger Sea and migrate toward Iceland. The large translation speeds northwest of Iceland in Figure 2-10b reflects a tendency of a substantial subset of cyclones to rapidly transit through the Denmark Strait separating Greenland and Iceland. These features both indicate that the storms were spawned upstream and de-emphasize the role of lee-cyclogenesis, either acting in isolation or in tandem with the synoptic development, on the subset of low pressure systems associated with tip jet events. Also, the decrease in translation speed of the systems between Greenland and Iceland (Fig. 2-10b and Hoskins and Hodges, 2002) is consistent with this, suggest- 
ing that many of the cyclones are "captured" in the lee of Greenland (Jung and Rhines, 2007) and that their slow translation may be a contributing factor to the formation of the semi-permanent Icelandic Low.

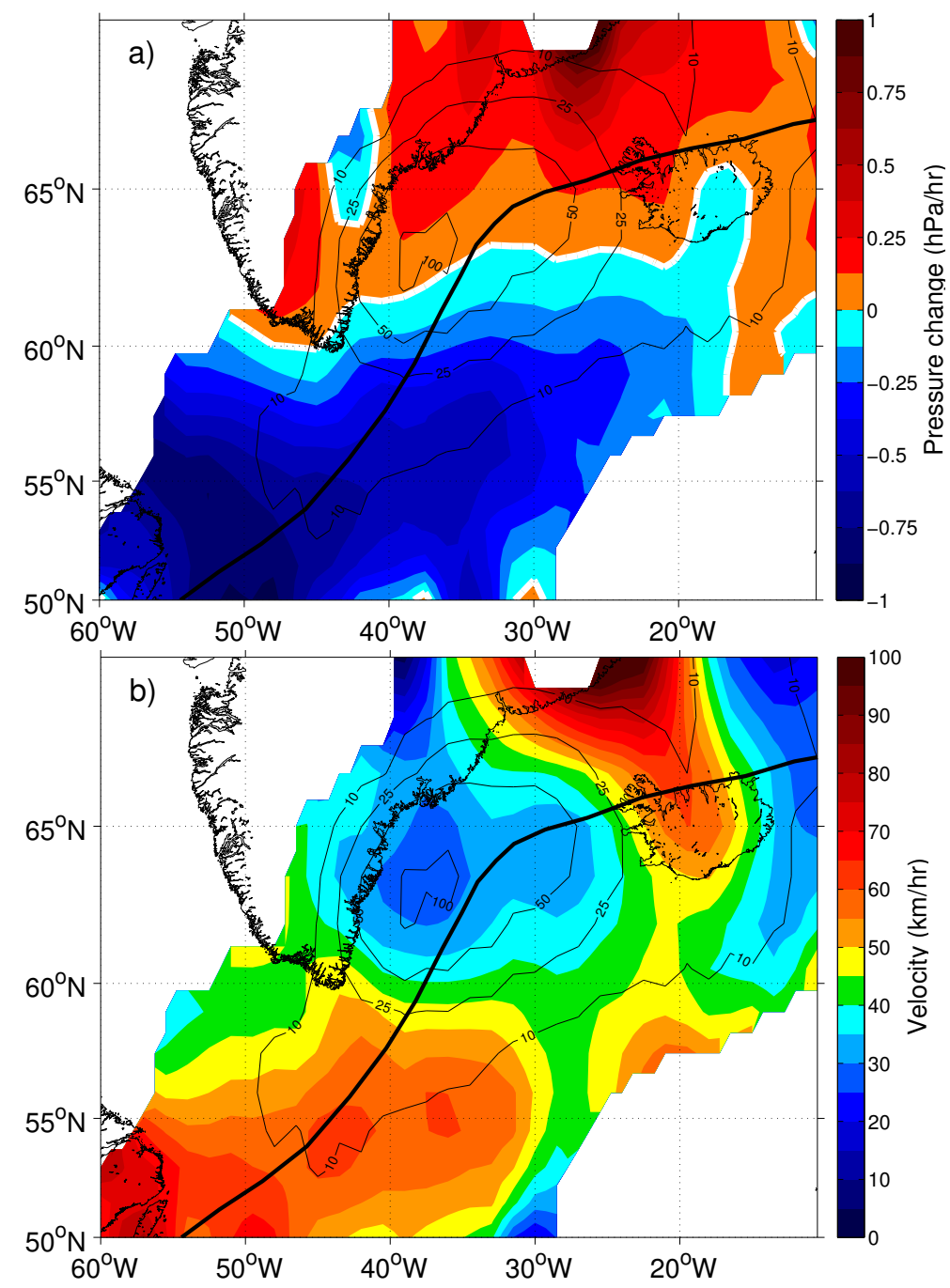

Figure 2-10: Pressure change (a, $\left.h P a h r^{-1}\right)$ and translation speed (b, $\left.k m h r^{-1}\right)$ computed along the storm tracks from Figure 2-9. The contours indicate the number of realizations, the black line denotes the mean path of the cyclones, and the white line is the zero contour.

\subsubsection{Vertical structure of the tip jet and relationship to the jet stream}

Further consideration of the ambient synoptic-scale flow is prompted by the finding that its evolution plays a significant role in the development of the tip jet. A key component of that ambient flow is the tropopause-level jet stream, and to depict its character Figure 2-11 
shows the composite average wind speed for the recent subset (1994-2002) of tip jet events. In these depictions the tip jet itself is evident as the laterally-confined, low-level band of strong wind speed south and east of Cape Farewell, and is associated with comparatively small case-to-case variability. The jet stream corresponds to the broader and more elongated band of strong winds at upper-levels located slightly more equatorward. A similar structure to this composite was observed for a single tip jet event during a November 2003 aircraft flight equipped with dropsondes and an airborne Doppler wind light detection and ranging (LIDAR) instrument (A. Dörnbrack, personal communication, 2007).

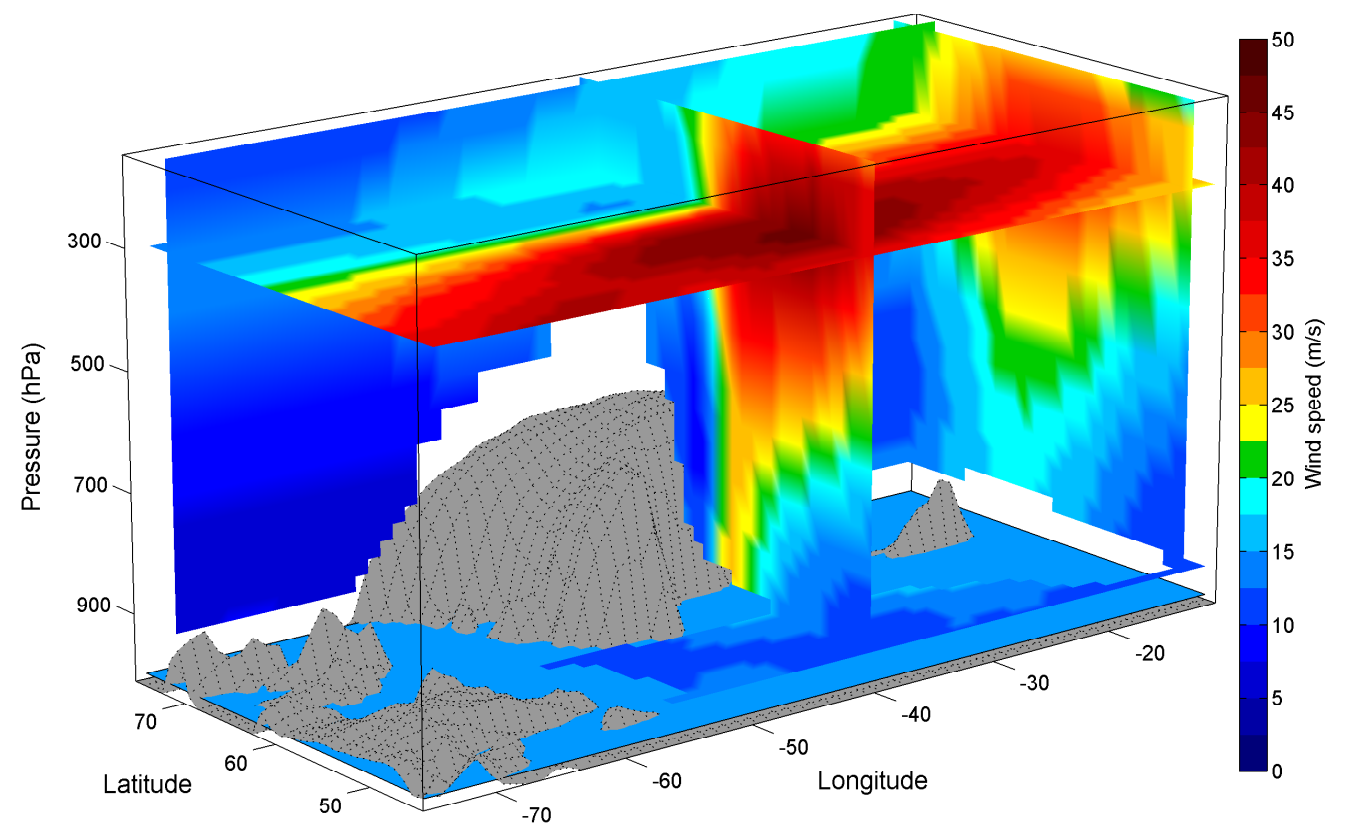

Figure 2-11: The frame contains a 3-dimensional image of the composite ERA-40 wind speed during the most recent (1994-2002) tip jet events. The dominant land mass in the north is Greenland, flanked by Iceland in the east and Baffin Island and Labrador in the west. The tip jet is the tongue of high velocity winds extending down from the maximum aloft near Cape Farewell at the southern tip of Greenland.

A significant feature of the composite shown in Figure 2-11 is the spatial coherence between the lower-level tip jet and the upper-level jet stream. This coherence might be indicative of either (a) a direct dynamical connection in which the tip jet is merely the low-level component of the incident ambient upper-level jet stream supplemented by a contribution due to the flow diversion around the topography, or (b) an indirect relationship whereby the overall synoptic evolution results in both the development and propagation of 
the low-level cyclone to the lee of Greenland and the alignment of the jet stream overhead of the tip jet. The evolution of the synoptic-scale flow is illustrated by composite vertical cross sections during the 24 hour period surrounding a tip jet event. Figures 2-12a and 2$12 \mathrm{c}$ show that the jet stream both precedes the tip jet and remains after the peak tip jet winds have waned, indicating that the tip jet is not merely a low-level signature of the jet stream.

To consider this aspect further, an examination was undertaken of the contemporaneous occurrence of jet stream and tip jet events. A climatology of jet stream events in the vicinity of southern Greenland was compiled using the approach of Koch et al. (2006). This entails identifying when and where the mean wind speed in the range between 100 and $400 \mathrm{hPa}$ exceeds $30 \mathrm{~m} \mathrm{~s}^{-1}$ using the global ERA-40 wind field for the period after the advent of satellite instruments in 1979 (H.Wernli, personal communication, 2007). The associated jet stream frequency field signifies how often a jet stream is present at a grid point. Consideration of this jet stream climatology during tip jet conditions (Fig. 2-13a) indicates that tip jet events are almost invariably accompanied by the presence of a jet stream directly south of Greenland. Indeed only two tip jet events (out of 341) were not accompanied by a jet stream being resident within the domain enclosed by the $75 \%$ frequency field contour in Figure 2-13a. Thus virtually all tip jet events are associated both with a low pressure system generally located east of southern Greenland and a jet stream located directly south of Greenland.

Further insight on this can be gleaned from examining the difference between average winter conditions and those that prevail during tip jet events. Figure 2-13b shows that in general, during winter, the jet stream is present most frequently far to the southwest of Greenland and south of $50^{\circ} \mathrm{N}$. However, the anomaly field (Fig. 2-13c) clearly shows that during tip jet events the jet stream is present more frequently farther northeastward in the immediate vicinity of southern Greenland. In effect the upper-level jet stream and the lower-level tip jet exist in concert during tip jet events. (Note that the jet stream frequency field anomaly was computed by subtracting the mean winter conditions from the tip jet conditions and then dividing by the standard deviation at each grid point.)

Likewise examination of the difference in the cyclone frequency field between normal 

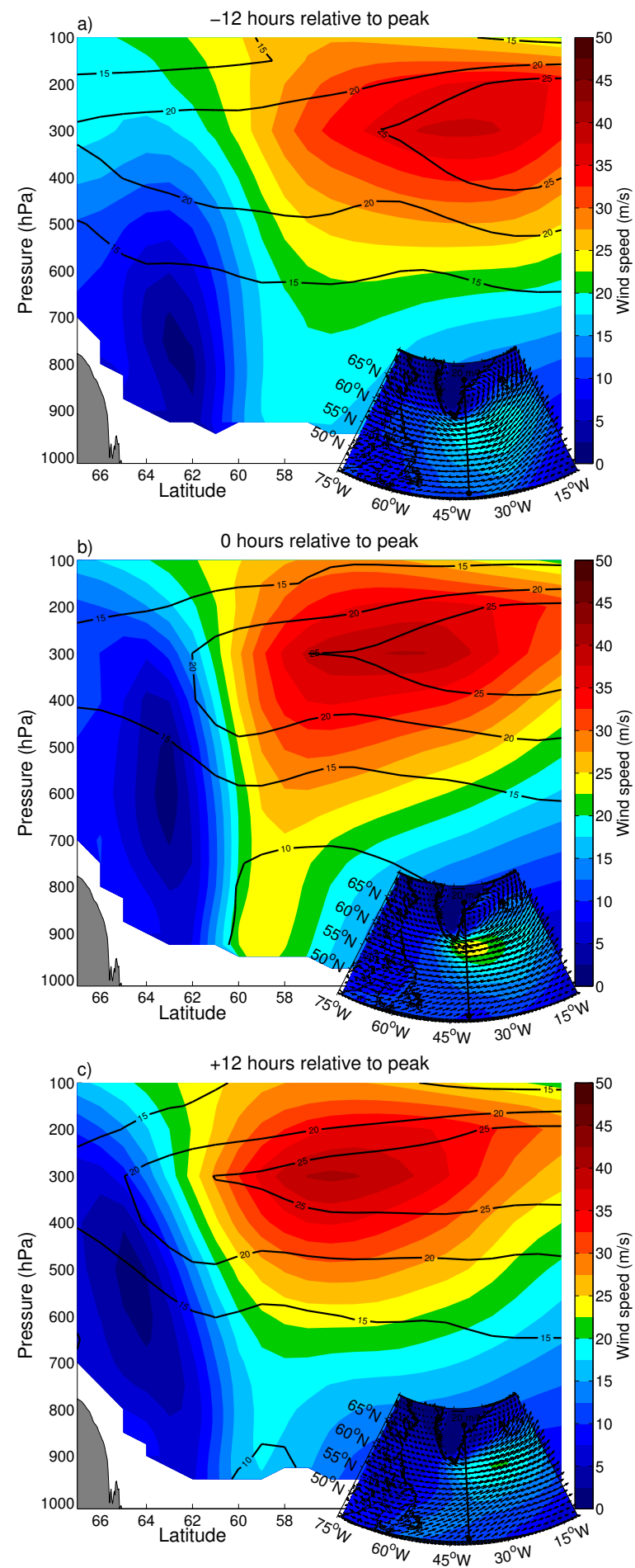

Figure 2-12: Vertical slices through the composite ERA-40 wind speed during the most recent (1994 to 2002) tip jet events at a longitude of $40^{\circ}$. The title of each figure refers to the time lag relative to the peak of the composite tip jet. Colours represent the mean wind speed $\left(\mathrm{m} \mathrm{s}^{-1}\right)$ and contours the standard deviation $\left(\mathrm{m} \mathrm{s}^{-1}\right)$. Greenland is visible in the northern end of the section, and the insets show the mean wind speed and vectors at $800 \mathrm{hPa}$ and the line along which the slice was taken. 

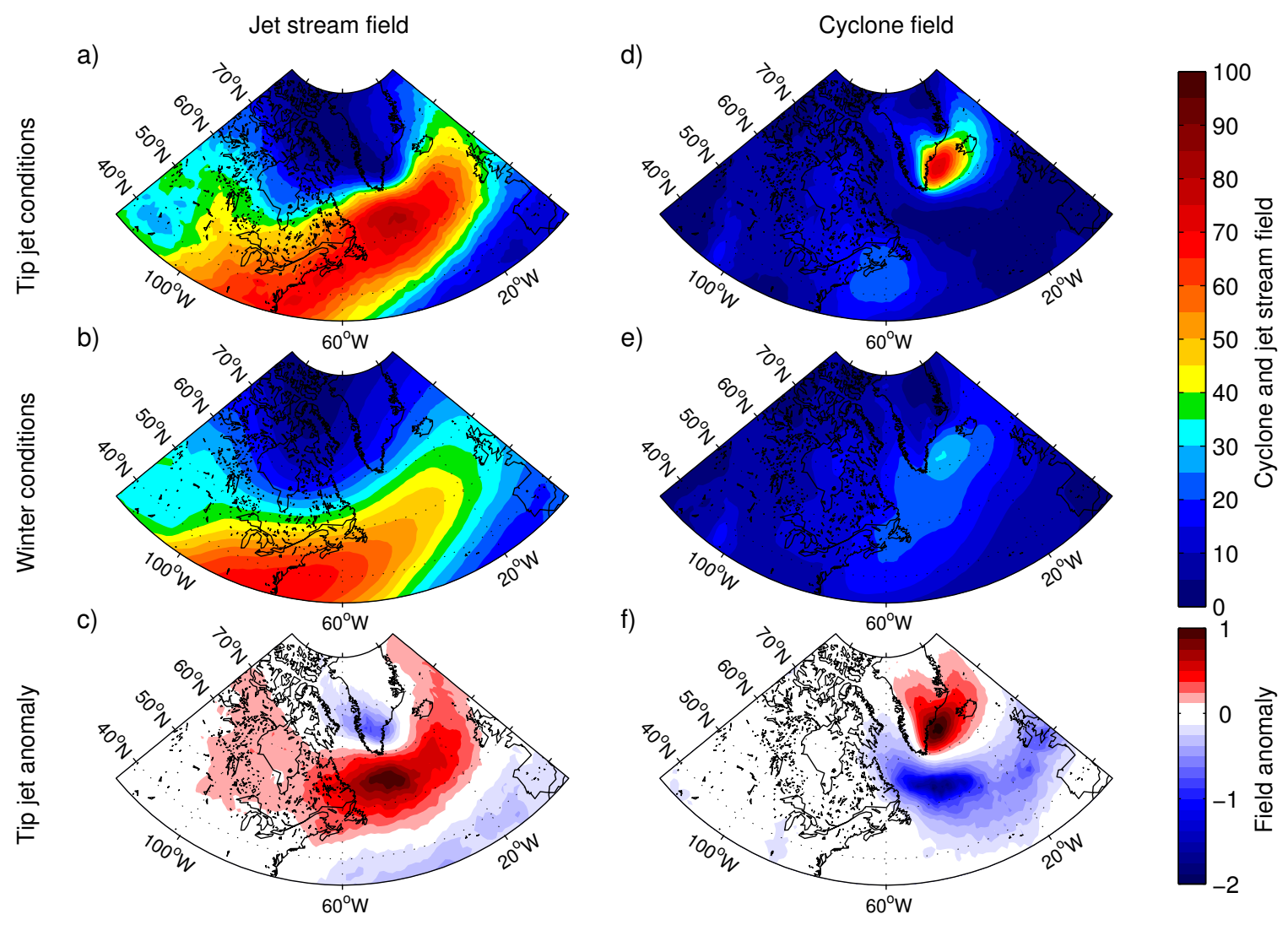

Figure 2-13: Jet stream (first column) and cyclone (second column) frequency fields. Top row shows tip jet conditions, middle row shows average winter conditions, and bottom row shows tip jet anomaly conditions. 
winter conditions and those that prevail during tip jet events (Fig. 2-13d-f) confirm that cyclones are far more often located in the lee of southern Greenland during tip jet events. While all tip jets were associated with a low pressure system in the general vicinity, the significant scatter in positions of the parent lows (Figs. 2-6b and 2-9) reduces the frequency field to below 100\%. Also discernible in Figure 2-13e is the signature of the North Atlantic storm track (Hoskins and Hodges, 2002). Moreover, during the winter season, low pressure systems often reside in the neighbourhood of the Irminger Sea (Fig. 2-13e) and this reflects in part the climatological signal of the Icelandic Low. Despite the presence of the Icelandic Low, cyclones are so much more prevalent east of southern Greenland during tip jet events that a strong positive frequency field anomaly is evident (Fig. 2-13f). Note also the strong negative anomaly south of Greenland that intersects the storm track, also evident in Figure $2-13 \mathrm{~d}$ as a band of near zero frequency field south of Greenland. As noted by Våge et al. (2008), cyclones in this region do not support the sea level pressure gradient field characteristic of tip jets (note the close spacing of the isobars near Cape Farewell in Figures 2-1 and 2-6b.), and correspondingly this region was devoid of cyclones during those events. The presence of a cyclone south of Greenland is typically associated with easterly tip jet events (Moore, 2003).

In light of the above results we can now elaborate on the link between the jet stream and the tip jet. Our results indicate that: (i) the air parcel trajectories entering the tip jet undergo a low-level deflection of flow around Cape Farewell, (ii) the tip jet evolves subsequent to the passage of a low-level synoptic cyclonic system toward Greenland and its arrival over the Irminger Sea, and (iii) the position and evolution of the cyclone is closely related to and influenced by the tropopause-level jet stream. This triple relationship is consistent with the tip jet's occurrence being determined by the combination of the ambient synoptic-scale flow spawning the parent cyclone and steering it to the lee of Greenland, and the subsequent evolution of the low-level jet via orographic effects. 


\subsection{Summary and discussion}

Westerly tip jets are intense, small-scale wind events that occur frequently east of Cape Farewell, Greenland, during the winter season. A multi-event climatology of tip jets based upon the ERA-40 reanalysis data set was compiled using an objective and sensitive detection method. For the winters investigated, 1957 to 2002, a total of 586 tip jets were identified, yielding an average of 13 per winter. The diagnostic analysis indicates that (i) the frequency of tip jet occurrence is sensitive both to the NAO index and to the latitude of the Icelandic Low, (ii) the events are short-lived phenomena with mean winds up to $30 \mathrm{~m} \mathrm{~s}^{-1}$ in the core typically lasting about a day, and (iii) during the event cold and dry continental air is advected from the north American continent to the Irminger Sea so that despite their episodic nature, both the high wind speeds and the strong heat fluxes significantly impact the ocean below (e.g. Pickart et al., 2008).

The present study sheds light on the relative role of two previously described, nonmutually exclusive, mechanisms for the generation of tip jets: (I) blocking of the lowlevel air upstream of Greenland along with the presence of a low pressure system east of southern Greenland resulting in deflection and acceleration of that blocked air around and downstream of the southern tip of Greenland (Moore and Renfrew, 2005); and (II) orographic descent down the lee slope of Greenland under conservation of the Bernoulli function resulting in an acceleration of the flow (Doyle and Shapiro, 1999). Our diagnostic analysis indicates in line with Mechanism (I) that the tip jet air approaches Greenland from the west, is deflected and accelerates around Cape Farewell, and results in a downstream tip jet. Likewise, in line with Mechanism (II), there is some indication of descending air over southern Greenland, but this pertains to only a small number of the calculated trajectories.

Our analysis has also revealed an apparently ubiquitous sequence of events that prevails in the run-up to and during a tip jet event. This involves the far-upstream genesis of a synoptic-scale cyclonic system that subsequently tracks to the lee of Greenland, coupled to the contemporaneous arrival of a tropopause-level jet stream immediately to the south of Greenland. The topography of Greenland impacts both the location of the lee-side cyclone and, primarily via Mechanism (I), the subsequent evolution of the strong westerly low-level 
tip jet flow. This sequence of events points to the precedence, if not the primacy, of the role and contribution of the lee-side cyclone and the jet stream to the establishment of the tip jet.

A caveat of the ERA-40 reanalysis is its coarse resolution, and it has been shown that an increase in resolution and better representation of the Greenland topography improves the rendition of the tip jet (Jung and Rhines, 2007). Comparison with the QuikSCAT scatterometer winds for the winters of overlap (1999-2002) show that although their magnitudes were underrepresented, most of the tip jets were detected $(88 \%)$. We also note that the back-trajectories calculated in this study are only as good as the ERA-40 data set from which they were computed. Present and future reanalyses of higher resolution (such as the North American Regional Reanalysis project, Mesinger et al., 2006) may provide a higher degree of realism. This should improve our understanding of the impact on weather systems by the topography of Greenland, and the myriad of small-scale phenomena that result (e.g. Renfrew et al., 2008).

Finally we note that if a changing climate is accompanied by a poleward shift of the extra-tropical jet stream, then one might also anticipate an increased frequency in the occurrence of tip jets. This in turn would impact the surface fluxes and air-sea interactions in an already highly sensitive area.

\subsection{Acknowledgments}

The authors wish to thank Harald Sodemann, Heini Wernli, Cornelia Schwierz, Andreas Dörnbrack, Christoph Schär, Jón Egill Kristjánsson, Haraldur Ólafsson, and Nicolas Gruber for stimulating discussions. Comments from Ian Renfrew and three anonymous reviewers greatly improved the manuscript. We thank Heini Wernli for assistance with the trajectory model and providing the jet stream data base, Cornelia Schwierz for access to the cyclone data base, and Sultan Hameed for sharing the COA indices. Access to ECMWF ERA-40 data was provided by MeteoSwiss with help from Dani Lüthi. QuikSCAT data are produced by Remote Sensing Systems and sponsored by the NASA Ocean Vector Winds Science Team. KV was funded in part by the NCCR Climate Programme of the Swiss Na- 
tional Foundation and by grant OCE-0450658 of the National Science Foundation (NSF). RP was supported by NSF grant OCE-0726640. 


\section{Chapter 3}

\section{Surprising return of deep convection to the subpolar North Atlantic in winter 2007-08}

This chapter has been published as an article in Nature Geoscience and is reprinted with their permission. The authors are Kjetil Våge, Robert S. Pickart, Virginie Thierry, Gilles Reverdin, Craig M. Lee, Brian Petrie, Tom A. Agnew, Amy Wong, and Mads H. Ribergaard.

\subsection{Abstract}

The process of open-ocean convection in the subpolar North Atlantic Ocean forms a dense water mass that impacts the meridional overturning circulation and heat flux, and sequesters atmospheric carbon. In recent years the convection has been shallow or non-existent, which could be construed as a consequence of a warmer climate. However, in the winter of 200708 deep convection returned to the subpolar gyre in both the Labrador and Irminger Seas. Here we document this return and elucidate the reasons why it happened. Profiling float data from the Argo programme are used to document the deep mixing, and a variety of in-situ, satellite, and reanalysis products are analyzed to describe the conditions leading to the overturning. The transition to a convective state took place abruptly, without going 
through a preconditioning phase, which is contrary to general expectations. Changes in the hemispheric air temperature, tracks of storms, flux of freshwater to the Labrador Sea, and distribution of pack ice all conspired to enhance the air-sea heat flux, resulting in the deep overturning. This study illuminates the complexity of the North Atlantic convective system.

\subsection{Introduction}

The subpolar North Atlantic Ocean is a critical component of the global climate system. Deep convection in the Labrador and Irminger Seas produces the water mass known as Labrador Sea Water (LSW, Clarke and Gascard, 1983). This results in a net transfer of heat from the ocean to the atmosphere, which is balanced by northward advection of heat via the surface limb of the meridional overturning circulation (MOC). In response to global warming, most climate models predict a decline of the MOC, often due to a reduction of LSW formation (e.g. Stouffer et al., 2006). The ocean is also an important sink of atmospheric $\mathrm{CO}_{2}$, and, as a result of dense water formation and transformation, more anthropogenic carbon per unit area is stored in the subpolar North Atlantic than in any other ocean (Sabine et al., 2004). Furthermore, LSW is entrained by the dense waters overflowing the Greenland-Scotland Ridge (Dickson and Brown, 1994). The composite water mass product, known as North Atlantic Deep Water, is found throughout the World Ocean (Johnson, 2008) and forms the deep limb of the MOC. Through this pathway $\mathrm{CO}_{2}$ can be sequestered in the abyssal ocean for centuries, but the pathway is only active as long as the depth of winter convection exceeds $1000 \mathrm{~m}$ (Yashayaev, 2007).

Since the mid-1990s, convection in the Labrador Sea has been shallow - and at times nearly absent (Lazier et al., 2002; Avsic et al., 2006; Yashayaev, 2007). The only major exception was the winter of 1999-00 (forming a water mass known as the "LSW 2000" class; Yashayaev, 2007; Yashayaev et al., 2007b). The last time convection occurred to depths of $2 \mathrm{~km}$ or more was during the late 1980s to early 1990s. This period was characterized by an extreme positive state of the North Atlantic Oscillation (NAO), which is the dominant pattern of climate variability in the North Atlantic (Hurrell, 1995). A positive NAO 
index is associated with strong westerly winds, enhanced air-sea buoyancy fluxes, and is often linked to the onset of deep convection in the Labrador Sea (Dickson et al., 1996) and Irminger Sea (Pickart et al., 2003b). However, there is not a one-to-one correspondence between convection and the NAO, since preconditioning plays an important role regulating the depth of convection (Yashayaev, 2007) and the NAO explains only some fraction of the atmospheric circulation variability (Hurrell et al., 2006). A recent study (Cassou et al., 2004) has revealed a zonal shift of the Atlantic centers of action associated with changes in the NAO, making it more difficult to interpret the significance of the traditionally defined NAO index for oceanic convection. Here we show that convection returned unexpectedly to the subpolar gyre during the winter of 2007-08, with little evidence of preconditioning and in spite of the fact that the NAO index was lower than the previous winter.

\subsection{Mixed layers in the subpolar North Atlantic}

Deep convection the North Atlantic subpolar gyre is commonly thought to occur principally in the Labrador Sea (e.g. Yashayaev, 2007). This view is based primarily on shipboard hydrographic surveys, which are typically carried out in late spring and summer after the convection has ceased. Float data from the Argo programme provide a means to sample throughout the convective season, though at more limited spatial resolution. During winter 2007-08, most of the Argo floats drifting in the northwestern part of the subpolar gyre measured deep mixed layers. This provides further direct evidence that deep convection occurs outside the Labrador Sea (Falina et al., 2007, see also figure 13 of Centurioni and Gould, 2004).

Three floats, documented for several years, are highlighted in Figure 3-1. These floats sampled the Labrador Sea, Irminger Sea, and the region south of Greenland. The deepest mixed layers in the records, measured in winter 2007-08, were approximately $1800 \mathrm{~m}$ in the Labrador Sea, $1000 \mathrm{~m}$ in the Irminger Sea, and $1600 \mathrm{~m}$ south of Greenland (see the Methods section below for details on the determination of the mixed layer depth). All of these were isolated mixed layers, where the float encountered a patch of convected water that had begun to re-stratify in the upper-layer since its last contact with the atmosphere. 
We examined the stratification in the central Labrador and Irminger Seas using the Argo data to verify that the very low values of buoyancy frequency $(N)$ within the isolated mixed layers in Figure 3-1a could not have survived the previous summer. With the exception of a weakly stratified eddy encountered by float 4900500 in November 2006, the lowest values of $N$ were observed in the winter mixed layers. Hence, in light of the weak advective speeds in these regions (Lavender et al., 2000), the overturning that caused the mixed layers in Figure 3-1a occurred close to the point of observation. This is corroborated by recent shipboard observations in the Labrador Sea (showing convection to $1600 \mathrm{~m}$, Yashayaev and Loder, 2009) and moored time series in the Irminger Sea (revealing mixed layers to nearly $1000 \mathrm{~m}$, Femke de Jong, personal communication). The deepest mixed layers reaching the surface that were observed by the profiling floats in winter 2007-08 were approximately $1600 \mathrm{~m}$ in the Labrador Sea (floats 4900494 and 4900677), $700 \mathrm{~m}$ in the Irminger Sea (float 6900240), and $1300 \mathrm{~m}$ south of Greenland (float 4900537). The properties of the LSW formed last winter are similar to the LSW 2000 class (Yashayaev, 2007). Interestingly, an $800 \mathrm{~m}$ deep mixed layer was measured by float 6900240 during winter 2006-07 in the northeastern Irminger Sea (Fig. 3-1c), in a region where deep mixed layers have previously been reported (Reverdin et al., 1999; Ólafsson, 2003).

To put the winter of 2007-08 into perspective, a climatology of mixed layer depths was created for the period 2000-07, hereafter referred to as the base period (the Labrador and Irminger Seas were not well sampled before winter 2003). In particular, for each winter (Feb-Apr), and for each given float, only mixed layers deeper than $80 \%$ of the maximum recorded mixed layer depth were included. This was done to isolate the mixed layers recorded near the time and location of the peak convective activity, thereby avoiding a shallow bias associated with the non-uniform temporal and spatial character of convection. All of the profiles satisfying this criterion ( $28 \%$ of the total winter profiles) were combined into a single data set and interpolated onto a $1^{\circ} \times 1^{\circ}$ grid using a Laplacian-spline interpolator (Fig. 3-2, filled contours). The resulting spatial distribution of mixed layer depths for the base period indicates that the deepest mixing occurred in the western Labrador Sea, consistent with previous wintertime hydrographic surveys (Clarke and Gascard, 1983; Pickart et al., 2002) and PALACE and SOLO float observations (Lavender et al., 2002). A 

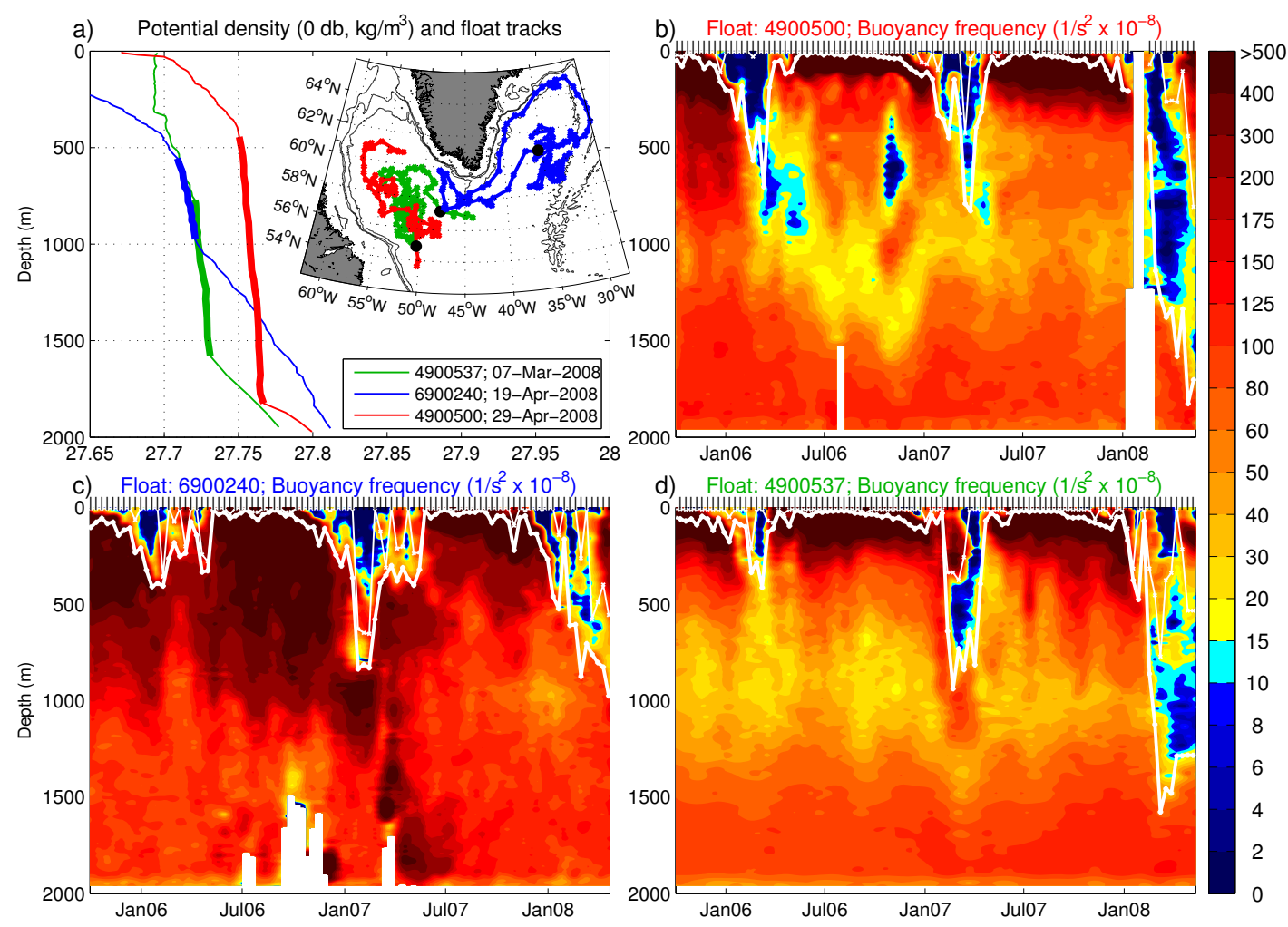

Figure 3-1: Potential density and buoyancy frequency squared for three selected Argo floats drifting in the Labrador and Irminger Seas from 2006-08. (a) Profiles showing the deepest recorded mixed layer in the Labrador Sea (red), in the Irminger Sea (blue), and south of Greenland (green). The inset shows the trajectories of each float and the locations of the highlighted profiles (black dots). (b-d) Temporal evolution of buoyancy frequency along the trajectories of floats 4900500 (b), 6900240 (c), and 4900537 (d). The white lines indicate the extent of the deepest mixed layer, and the vertical bars along the top denote the time of each profile along the trajectory. 
second region of enhanced convection is found south of Greenland. In general, the overturning throughout the 8-year base period was shallow (less than $1000 \mathrm{~m}$ ). By contrast, the mixed layers observed during winter 2007-08 (Fig. 3-2, triangles) were significantly deeper (by more than $1000 \mathrm{~m}$ in some instances). One sees enhanced mixing in the western Labrador Sea, in the region south of Greenland, and in the southern Irminger Sea east of Cape Farewell. It is clear that deep convection returned to a broad area of the western North Atlantic subpolar gyre in 2007-08; the obvious question is, why.

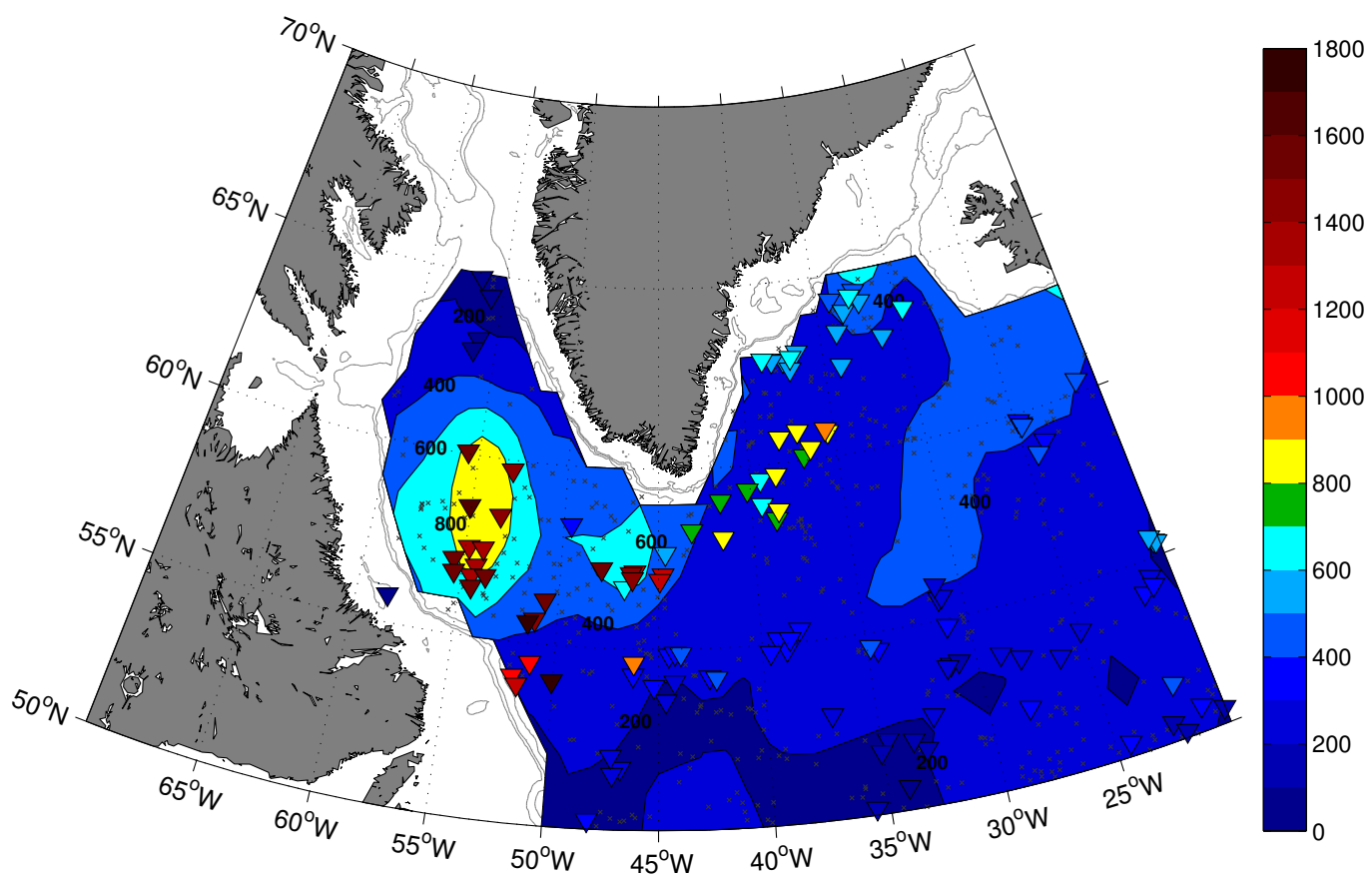

Figure 3-2: Changes in wintertime mixed layer depth distribution. The February - April mixed layer depths from winter 2007-08 (triangles) are contrasted to the average mixed layer depths for the period 2000-07 (filled contours). Only mixed layers deeper than 80\% of the maximum mixed layer depth recorded by each float were included. The black crosses indicate the locations of the data points. The depth contours are 500, 1000, and $2000 \mathrm{~m}$.

\subsection{Atmospheric forcing}

Applying a bulk formula, as described in the Methods section, we computed winter-averaged (Dec-Feb) heat flux anomalies for each of the winters of this decade, relative to the base period (Fig. 3-3). It is immediately obvious that the winter of 2007-08 was much more 
severe than the previous winters in terms of heat removal from the ocean. In particular, a band of strong heat flux anomalies exceeding $100 \mathrm{~W} / \mathrm{m}^{2}$ extends from the ice edge in the Labrador Sea, around southern Greenland into the Irminger Sea. Diagnosis of the heat flux components reveals that the main cause of the enhanced heat flux was unusually cold air temperatures (and associated low humidities) during this past winter. Figure 3-4 shows the 2 m North American Regional Reanalysis (NARR) air temperature anomalies for the individual months of December 2007 through February 2008, relative to monthly climatologies of the base period. The temperature over the northwestern part of the subpolar gyre was several degrees colder than the corresponding temperature of the base period for each of the months. Consistent with this, the air temperature recorded at the Prins Christian Sund meteorological station near Cape Farewell was $2.8^{\circ} \mathrm{C}$ colder in winter $2007-08$ than the corresponding mean of the base period.

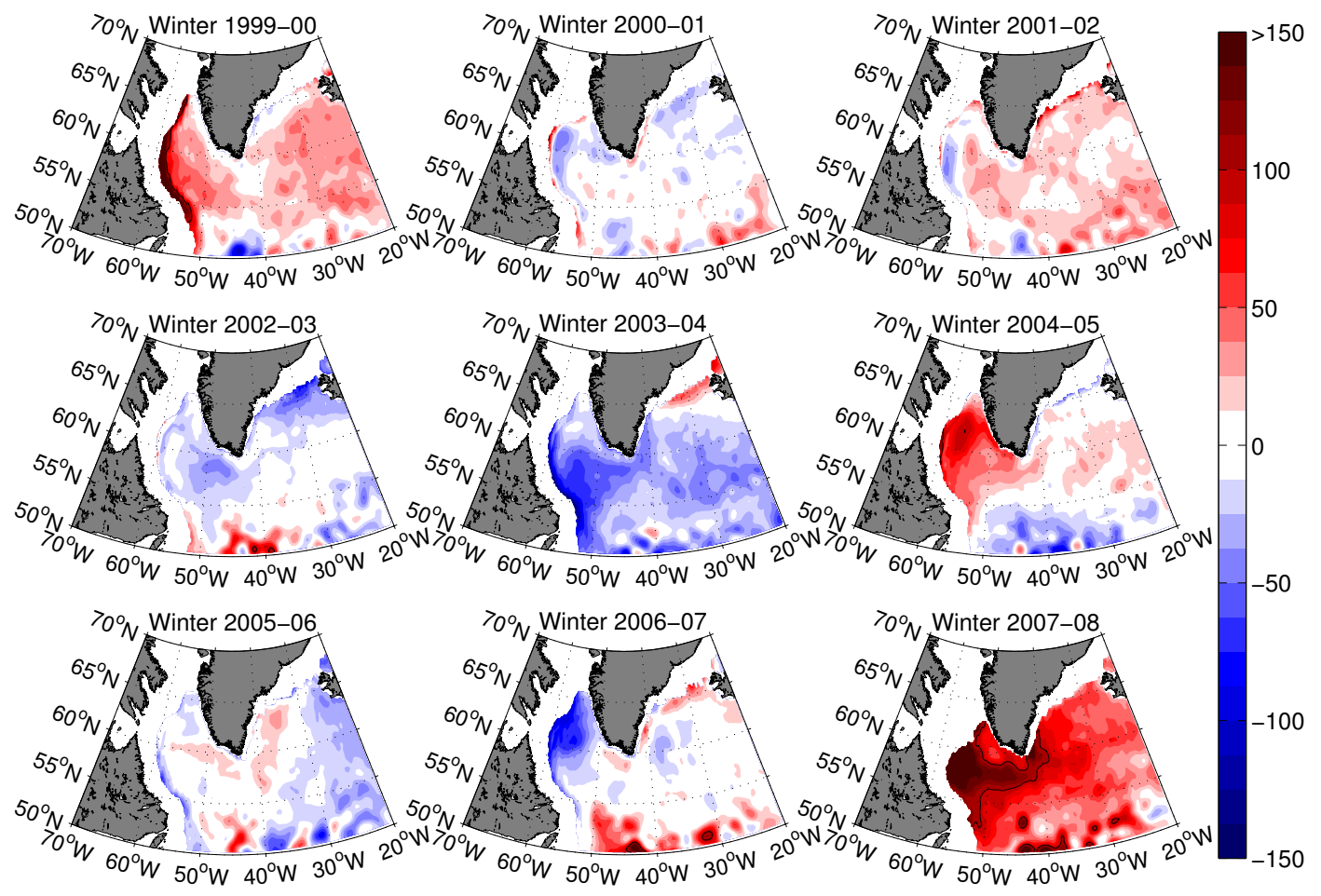

Figure 3-3: Interannual variability of wintertime air-sea heat flux. Each panel shows the mean December through February bulk heat flux anomaly field $\left(\mathrm{W} / \mathrm{m}^{2}\right)$ for the given winter relative to the $2000-07$ base period. The $100 \mathrm{~W} / \mathrm{m}^{2}$ isoline is contoured.

As seen in Figure 3-4, there is a clear relationship between the air temperature anomalies in the Labrador Sea in winter 2007-08 and the location of the ice edge. Here we 
define the ice edge as the location of $50 \%$ ice concentration (the results are not sensitive to this definition). In 2007-08 the edge of the pack-ice extended significantly farther into the Labrador Basin compared to the base period (compare the grey and brown lines in Figure 3-4). The largest air temperature anomalies, those exceeding $-6^{\circ} \mathrm{C}$, are found where the ice edge from winter 2007-08 extended past the ice edge from the base period. However, low air temperatures extended well beyond the ice edge across the basin into the southwest Irminger Sea. As seen below, this is because the anomalously large amounts of ice allowed the cold air emanating from the North American continent to remain largely unmodified by air-sea exchange as it passed eastward to the interior basin where convection occurred.
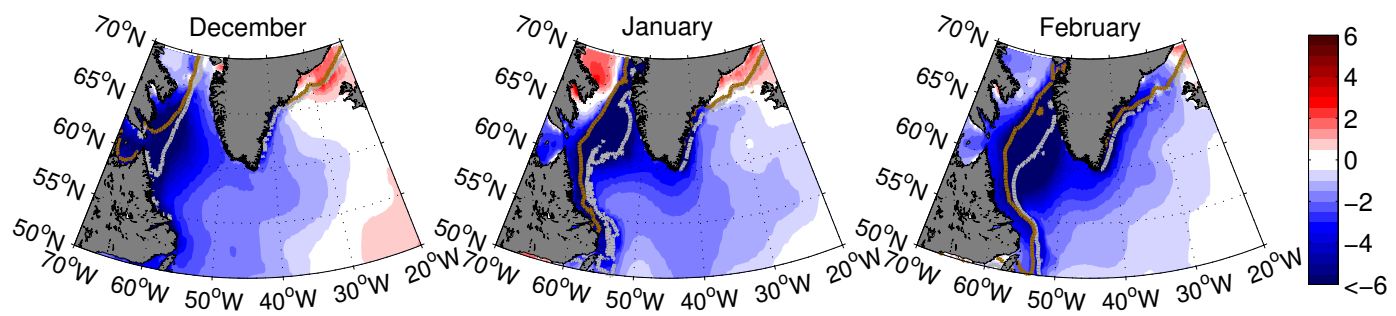

Figure 3-4: Relationship between air temperature and ice concentration in winter 2007-08. Monthly mean air temperature anomalies (colour) relative to the $2000-07$ base period are shown, overlain by the 50\% ice concentration limits from 2007-08 (grey contours), and mean $50 \%$ ice concentration limits for the base period (brown contours)

During most of the base period (the winters 2001-06) the NAO index was close to zero or negative, which is consistent with the fact that deep convection did not take place in the subpolar gyre during this time. By contrast, during the last two winters (2006-07 and 2007-08) the NAO index was above +2 , and, as is typical for such states, there were westerly winds throughout much of the western subpolar gyre. However, deep convection occurred only during the latter winter (the mixed layer depths recorded during winter 200607 were similar to the climatological values in Figure 3-2). Consideration of the winteraveraged surface wind field anomalies, relative to the base period, suggests why. As seen in Figure 3-5a, the wind vector anomalies in 2006-07 were generally from the east throughout most of the Labrador Sea. Furthermore, the anomaly pattern in the vicinity of southern Greenland for that winter is consistent with an atmospheric flow regime known as the reverse Greenland tip jet (Moore and Renfrew, 2005), which typically does not lead to 
deep mixing (Sproson et al., 2008).
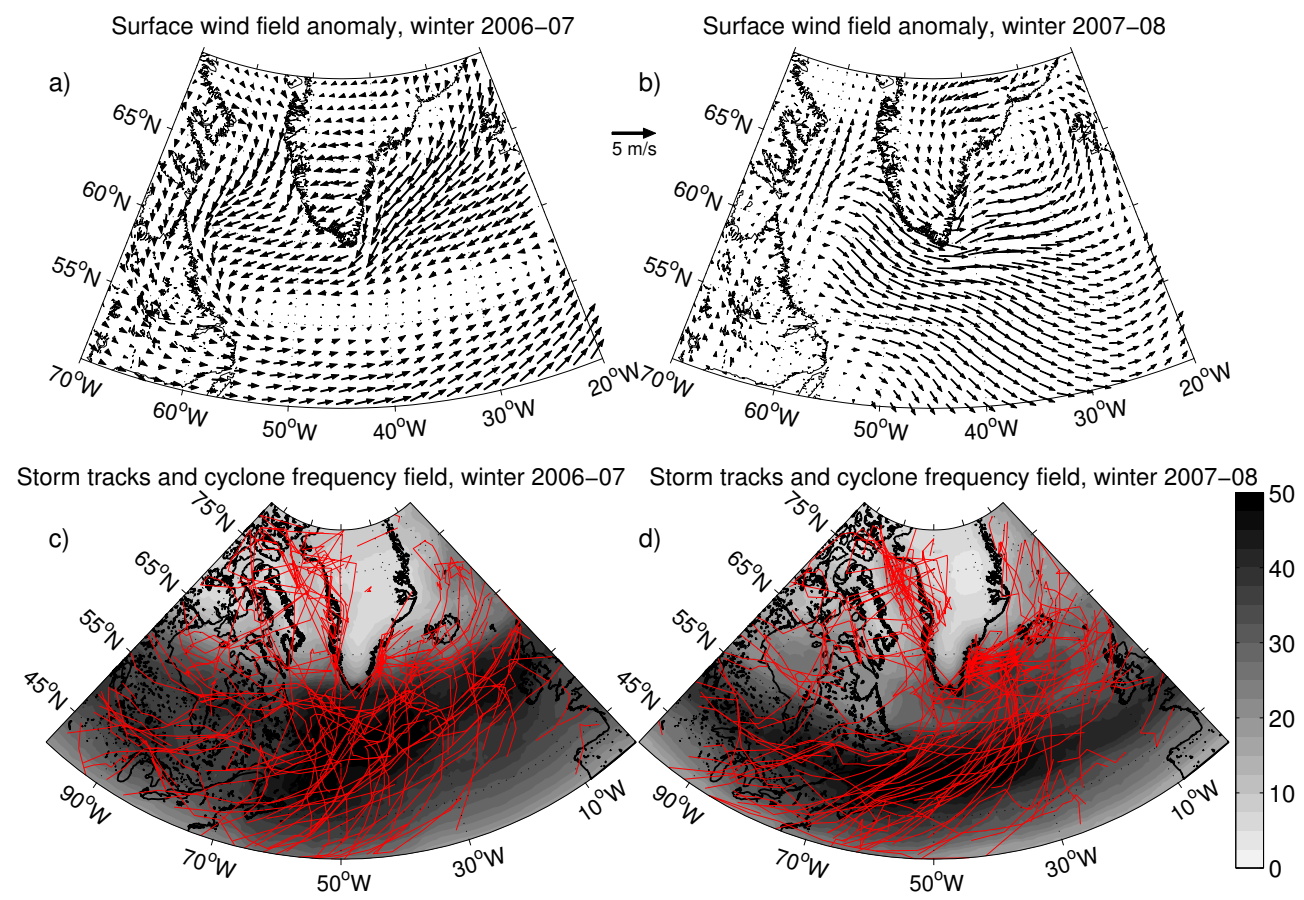

Figure 3-5: Wind anomalies and storm properties for the two high NAO winters of 200607 and 2007-08. Top row: NARR surface wind vector anomalies (m/s, every 21 st vector) relative to the 2000-07 base period. Bottom row: Storm tracks (red lines) and cyclone frequency field (grey shading).

In contrast, the surface wind field anomaly for winter 2007-08 shows very strong westerly winds off the Labrador ice edge (Fig. 3-5b), which, in light of Figure 3-4, boosted the advection of cold air toward the region of deep convection. In addition, the anomalously strong westerly winds south and east of Cape Farewell suggest that a larger number of forward Greenland tip jet events (Moore and Renfrew, 2005) took place during this winter. Tip jets are intense, small-scale wind phenomena that occur near the southern tip of Greenland (Doyle and Shapiro, 1999) and arise due to interaction between cyclones and the high local orography (Moore and Renfrew, 2005). The forward tip jet is known to force convection in the Irminger Sea (Pickart et al., 2003a; Våge et al., 2008). Indeed, using an objective empirical orthogonal function (EOF) method (Våge et al., 2008), we verified that more forward tip jets occurred during winter 2007-08 than in winter 2006-07. While the exact number of tip jets is sensitive to the chosen threshold wind speed, for the threshold used previously in the literature (Våge et al., 2008) there were 17 and 27 events for the 
extended winters (Nov-Apr) of 2006-07 and 2007-08, respectively. This is part of the reason why deep mixed layers were observed not only in the western Labrador Sea this past winter, but also south of Greenland and east of Cape Farewell (Fig. 3-2).

\subsection{Storm patterns}

In order to examine the relationship between the convective activity taking place on both sides of Greenland, we performed a statistical analysis of various metrics for each of the winters during this decade (2000-08). It was found that a significant correlation (-0.41 to -0.64) exists between the air temperature anomaly in the central Labrador Sea and the value of the forward tip jet EOF, with a time lag of 6-9 hours. This implies that tip jet events in the Irminger Sea often follow cold air outbreaks over the Labrador Sea. Inspection of the NARR fields reveals that the same storms that pull cold air off of eastern Canada into the Labrador Sea, tend to cause high winds in the lee of Cape Farewell as the low pressure systems progress eastward along the storm track. Therefore, conditions that favour deep convection in both basins often arise due to the same set of storms.

It still remains to be determined why there were such big differences in the wind field anomalies between the winters of 2006-07 and 2007-08, despite the fact that the NAO index was comparable for both years (stronger, in fact, for winter 2006-07). Analysis of the National Centers for Environmental Prediction (NCEP) sea level pressure data and calculated storm trajectories sheds light on this. Figure 3-5c,d (grey shading) show the

cyclone frequency field for the two winters, where cyclone frequency denotes how often a given grid point in the domain is contained within a cyclone (as defined in the Methods section) relative to the full period. In terms of the number and strength of low pressure systems passing through the domain, the two winters were similar. However, the tracks of the storms during winter 2007-08 tended to be shifted more to the south (Fig. 3-5, red lines). In particular, the cyclones followed a more well-defined track from the east coast of North America toward the Irminger Sea. While it is well known that changes in the North Atlantic storm track associated with positive versus negative states of the NAO index can have an impact on convection in the Labrador Sea (Dickson et al., 1996), the results 
presented here indicate that even moderate shifts in the storm track - within a high NAO regime - can have profound consequences.

\subsection{Preconditioning}

It is generally believed that preconditioning of the water column is conducive for the onset of deep convection, whether it be strengthening of the cyclonic circulation or the presence of remnant convected water from previous winters. In this regard, the return of deep convection to the Labrador and Irminger Seas in winter 2007-08 was a surprise. As seen in Figure 3-3, the air-sea heat flux in both seas was anomalously weak during the preceding winter, and the Argo floats showed relatively shallow mixed layer depths that winter. Furthermore, examination of the summer (May-Oct) Argo density data gives no indication of an enhanced gyre circulation. In particular, gridded lateral fields of isopycnal depth indicate that the density surfaces which eventually outcropped during winter 2007-08 in the Labrador and Irminger Seas were anomalously deep relative to the base period. This is consistent with the elevated sea surface height field compared to the period of deep convection in the early 1990s (updated through winter 2007-08, Sirpa Häkkinen, personal communication, Häkkinen and Rhines, 2004).

As detailed above, the large amount of pack ice in the northwest Labrador Sea this past winter played a major role in the onset of convection. Animations of sea ice motion using high resolution data from the Advanced Microwave Scanning Radiometer (AMSR-E) suggest that both local formation and export from Baffin Bay (Kwok, 2007) contributed to the heavy Labrador Sea ice cover. Values of liquid freshwater flux from 2004 to 2007, calculated using hydrographic data from the Davis Strait/Arctic Gateways project, show a trend of enhanced net freshwater flux into the Labrador Sea, with values of 96, 107, 133, and $13610^{3} \mathrm{~m}^{3} / \mathrm{s}$, respectively, relative to a salinity of 34.8 . (The trend is statistically significant at the 95\% confidence level.) Consistent with this, gridded Argo salinities in the upper $20 \mathrm{~m}$ reveal that the northern Labrador Sea was anomalously fresh in summer 2007 relative to the base period. By inhibiting mixed layer deepening through the fall, therefore causing increased cooling of the near-surface water column, this surplus of freshwater un- 
doubtedly contributed to the enhanced local ice formation during winter 2007-08. We note that the increased liquid and frozen freshwater flux into the Labrador Sea was likely tied to the large export of sea ice from the Arctic Ocean that contributed to the record minimum in sea ice extent observed in summer 2007 (Zhang et al., 2008). Ironically, this disappearance of Arctic sea ice, which has been linked to global warming, may have helped trigger the return of deep wintertime convection to the North Atlantic.

A similar sudden onset of deep convection in the Labrador Sea occurred during the extraordinarily cold winter of 1971-72 (Lazier, 1980), also associated with an increased flux of freshwater to the sea (the Great Salinity Anomaly, Dickson et al., 1988). However, the main source of freshwater at that time was the West Greenland Current, which is believed to be the dominant pathway of freshwater into the interior basin (Schmidt and Send, 2007). Hence the entire Labrador Sea (not just the northern part) was capped by low salinity water in 1971-72. By contrast, in summer 2007 the surface waters of the central basin were in fact salty compared to the base period. We note, however, that the 2007-08 AMSR-E animation indicated significant equatorward ice flux in the East Greenland Current all the way to Cape Farewell, which is likely the downstream response of the recent enhanced ice export through Fram Strait (Smedsrud et al., 2008). As this pathway from the Arctic Ocean to the Labrador Sea is longer, it could be expected that freshening of the interior Labrador Basin will occur in the near future. This means that next winter there may be the competing effects of a broad surface salinity cap (inhibiting deep convection) versus a preconditioned water column due to last year's remnant LSW (which is conducive for deep overturning).

The myriad of factors involving the atmosphere-ocean-ice system that led to the return of deep convection in winter 2007-08 highlights the complexity of the convective system in the North Atlantic, making it difficult to predict when deep mixing is likely to occur. A final notable aspect from last year was that the anomalously cold air temperatures over the subpolar North Atlantic in winter were not a local phenomenon. According to the Goddard Institute for Space Studies temperature anomaly timeseries (Hansen et al., 1999), the global temperature dropped $0.45^{\circ} \mathrm{C}$ between the winters 2006-07 and 2007-08. This decrease was particularly strong across northern North America, where the mean winter temperature was more than $3^{\circ} \mathrm{C}$ colder this past winter (Fig. 3-6). It is possible that the 
strong La Niña during winter 2007-08 may have contributed to this, suggesting that global atmospheric modes need to be considered as well when diagnosing convection in the North Atlantic.

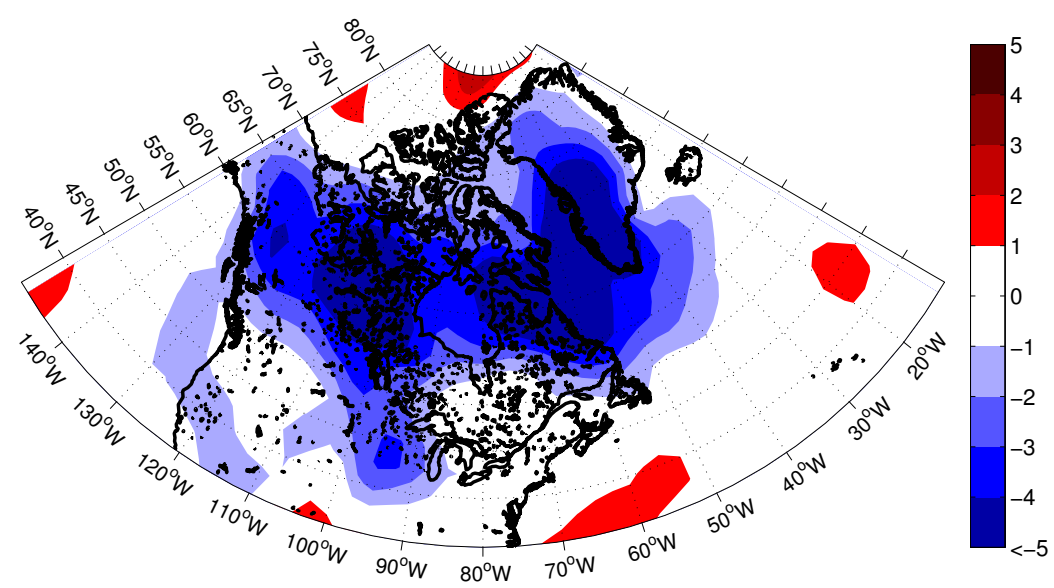

Figure 3-6: Hemispheric air temperature decrease in winter 2007-08. The difference in NCEP $2 \mathrm{~m}$ air temperature $\left({ }^{\circ} \mathrm{C}\right)$ over North America and Greenland between winters 200708 and 2006-07 is contoured.

\subsection{Methods}

The global program of profiling floats known as Argo has been in operation since 2000 . The floats typically drift at a depth of $1000 \mathrm{~m}$, and, every 10 days, profile between a depth of $2000 \mathrm{~m}$ and the surface providing measurements of temperature and salinity. Rudimentary quality control is performed before the data become public. For this analysis we used a combination of real-time and delayed-mode data, the latter having been corrected for drift in the conductivity and pressure sensors (Wong et al., 2003). Only profiles assigned a quality flag of 1 or 2 (indicating "good" or "probably good" data) were used, and a subset of profiles known to have been mis-calibrated (Willis et al., 2007) were excluded. Measurement uncertainties are expected to be less than $0.01^{\circ} \mathrm{C}$ and 0.03 for temperature and salinity, respectively. Late winter (Feb-Apr) mixed layer depths for the 2,023 profiles obtained between 2000-08 in the western subpolar gyre were estimated following a routine (Pickart et al., 2002) that involved manual inspection of each profile. An advantage of this procedure is that identification of mixed layers that have become isolated from the sea 
surface is possible. Both in the Labrador and Irminger Seas such isolated mixed layers are often observed during active convection (Pickart et al., 2002; Våge et al., 2008), either in the form of stacked multiple mixed layers or as early stages of restratification. Through inspection of the temporal evolution of the regional mixed layers and trends in stratification, we are confident that the isolated mixed layers were formed by local convection during a given winter.

Air-sea turbulent heat fluxes were computed using a bulk algorithm (Fairall et al., 2003) with the inputs of wind speed, humidity, air temperature and sea surface temperature (SST). For the wind data we used the multiple-satellite blended Sea Winds product (Zhang et al., 2006), which has a space and time resolution of $0.25^{\circ}$ and 6 hours, respectively. SST and ice concentration were acquired from an optimum interpolated, blended analysis of satellite and in-situ data provided once per day at $0.25^{\circ}$ spatial resolution (Reynolds et al., 2007). Humidity and air temperature were obtained from the high-resolution ( $32 \mathrm{~km}$ and 3 hours) NARR project (Mesinger et al., 2006). The bulk heat fluxes computed as such compare well with a newly released heat flux product (Yu and Weller, 2007) for the period of overlap (2000-06). Finally, storm tracks and cyclone field (defined as the area within the outermost closed $2 \mathrm{hPa}$ pressure contour of a low pressure system, Wernli and Schwierz, 2006) were computed, with global NCEP (Kalnay et al., 1996) reanalysis sea level pressure data used as input.

\subsection{Acknowledgments}

The authors wish to thank Tom Haine, Jamie Morison, Lisan Yu, Sirpa Häkkinen, Artem Sarafanov, Ignatius Rigor, Ron Kwok, Todd Mitchell, Harry Stern, and Olivia Martius for valuable suggestions. We thank Heini Wernli for providing the cyclone tracking algorithm and Roger Goldsmith for developing a Matlab tool to compute and analyze the tracks. Jim Hurrell kindly provided the NAO index timeseries. Argo data were obtained from the GODAE (www.usgodae.org) and Coriolis (www.coriolis.eu.org) data centers. The Sea Winds, OI SST, and NARR and NCEP reanalysis data sets were obtained from the NOAA National Climatic Data Center (www.ncdc.noaa.gov). The AMSR-E data were obtained 
from the National Snow and Ice Data Center (www.nsidc.org). We thank Jinbo Wang and Hendra Adiwidjaja for assistance with the reanalysis data. Support for this work was provided by the Ocean Sciences Division of the National Science Foundation. 


\section{Chapter 4}

\section{The Irminger Gyre: Circulation, convection, and interannual variability}

This chapter is written as an article that will be submitted to Deep-Sea Research.

\subsection{Abstract}

The Irminger Gyre (IG) is a narrow, cyclonic recirculation confined to the southwest Irminger Sea, east of southern Greenland. While its existence has been documented for many years, relatively little is known about its overall features, including its transport, vertical structure, forcing, and variability. Here we use 32 hydrographic transects between 1991 and 2007 from the vicinity of the WOCE A1E/AR7E section across the southern Irminger Sea to investigate different aspects of the gyre. From a combination of satellite and shipboard velocity measurements we have constructed vertical sections of absolute geostrophic velocity, which are analyzed in conjunction with the hydrographic sections and meteorological fields. The mean magnitude of the IG circulation was $6.8 \pm 1.8 \mathrm{~Sv}\left(1 \mathrm{~Sv}=10^{6} \mathrm{~m}^{3} / \mathrm{s}\right)$. While the upper-level subpolar gyre circulation declined during the 1990s, the magnitude of the IG transport increased at a rate of $4.3 S v$ per decade. This is true despite a reduction in the local winds and air-sea buoyancy fluxes, and was presumably due to influx of increasingly buoyant water from the Irminger Current (IC) leading to enhanced restratification in the eastern Irminger Basin and a steeper sea level gradient across the Irminger 
Gyre. Although the upper layer IC transport decreased over the study period, due to the emergence of a second deep extension of the surface-intensified IC, the full-depth IC transport increased. The mean full-depth IC transport was estimated to $20 \pm 3 S v$. The mean net full-depth transport of the Western Boundary Current (WBC) was $-32 \pm 4 S v$ (this is the equatorward throughput, as the southward limb of the IG has been subtracted out). For the Deep WBC $\left(\sigma_{\theta}>27.80 \mathrm{~kg} / \mathrm{m}^{3}\right)$ we determined a mean net transport of $-9.6 \pm 1.3 \mathrm{~Sv}$, also increasing through the study period. Weakly stratified water in the density range of Labrador Sea Water (LSW) was observed in the Irminger Sea. Examination of the temporal evolution of the LSW layer thickness across the section suggests that local convection formed deep LSW during the early 1990s within the Irminger Gyre. In contrast, LSW appeared outside of the gyre in the eastern part of the Irminger Sea with a time lag of 2-3 years, consistent with transit from a remote source in the Labrador Sea.

\subsection{Introduction}

From a climatic perspective, the Irminger Sea is a region of particular importance (Fig. 4-1). Here the dense overflows from the Nordic seas merge to form the Deep Western Boundary Current (DWBC, Dickson and Brown, 1994), much of the freshwater export from the Arctic first meets the subpolar North Atlantic (Dickson et al., 2007) and wintertime convection may result in a second region of Labrador Sea Water (LSW) formation (Pickart et al., 2003b). To some extent these phenomena are linked. Freshwater from the Arctic carried into the sea along the coast of Greenland can be fluxed offshore by winds or instabilities (Pickart et al., 2005) or be retroflected off the Greenland shelf (Holliday et al., 2007) and impact ventilation in the interior. This in turn can influence the properties of the intermediate water masses entrained into the DWBC (Yashayaev, 2007).

Over the last two decades significant and well-documented changes have taken place in the subpolar North Atlantic, influenced largely by the North Atlantic Oscillation (NAO). This is the dominant mode of atmospheric variability in this region, and the NAO index (Fig. 2-4) describes the normalized difference in sea level pressure between the regions of the Icelandic Low and the Azores High (e.g. Hurrell, 1995). A positive value is as- 


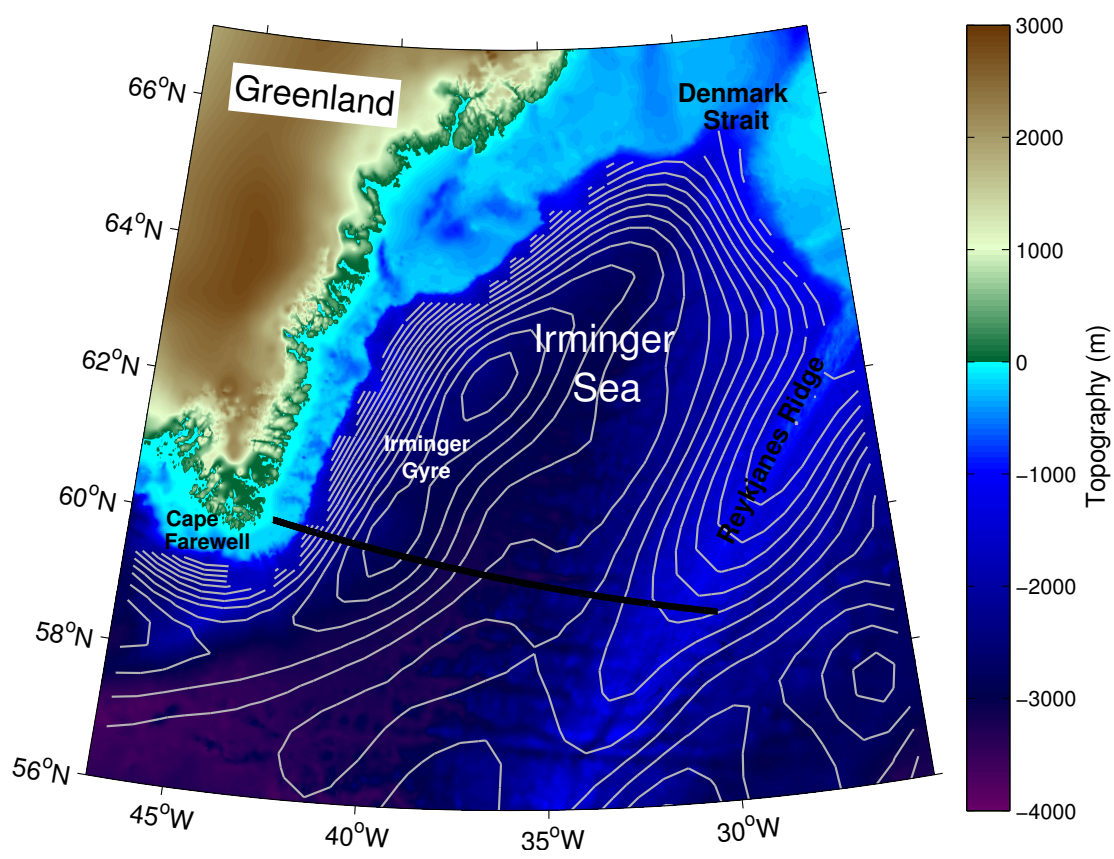

Figure 4-1: Topography of southeast Greenland and the Irminger Sea from the Etopo2 2-minute elevation data base. The black line identifies the least squares regression line onto which all insitu data have been projected (see Section 4.3). The gray lines are contours of objectively mapped geostrophic pressure at $700 \mathrm{db}$, from Lavender et al. (2000). The closed contours in the western Irminger Sea reveal the location of the Irminger Gyre.

sociated with anomalously strong westerly winds, a northward shift of the winter storm track (Rogers, 1990), and an increased occurrence of cyclones in the North Atlantic (Serreze et al., 1997). Together this results in a greater probability of deep convection in the Labrador Sea (Dickson et al., 1996). The late 1980s and early 1990s were characterized by an especially high NAO index, and the coldest and densest LSW on record was formed during this period (Yashayaev, 2007). In the winter of 1995-96 the NAO index dropped precipitously and has not since fully returned to its previous levels. The consequent decrease in wind and air-sea buoyancy forcing led to a significant reduction of deep LSW formation (Lazier et al., 2002; Avsic et al., 2006; Yashayaev, 2007). At the same time the subpolar gyre circulation has slowed and contracted (Häkkinen and Rhines, 2004; Hátún et al., 2005; Bersch et al., 2007). Sarafanov (2009) demonstrated how an increasing influence of warm and salty subtropical waters on the eastern North Atlantic associated with the contraction of the gyre has reversed the intermediate and deep freshening trend of the preceding four decades (Dickson et al., 2002; Curry et al., 2003). An alternative hypothe- 
sis for the weakening of the subpolar gyre de-emphasizes the role of the NAO-modulated atmospheric forcing in favor of an unstable ocean state (Lohmann et al., 2009).

\subsubsection{Circulation}

Figure 4-2 shows a schematic of the boundary currents of the Irminger Sea along with transport estimates in Sverdrups $\left(1 S v=10^{6} \mathrm{~m}^{3} / \mathrm{s}\right)$ from Pickart et al. (2005). These values are in general agreement with more recent synoptic estimates (Holliday et al., 2009). Using surface drifters and satellite altimetry, Flatau et al. (2003) found that the surface flow in the boundary currents intensified during winter and NAO-positive years. As outlined in the figure, warm and salty Atlantic-origin water is carried northwards by the Irminger Current (IC) along the Reykjanes Ridge. The current bifurcates near Denmark Strait: One branch continues northward through the strait to form the Icelandic Irminger Current, and the other branch recirculates to the south to flow alongside the East Greenland Current (EGC), which carries cold and fresh Arctic-origin water equatorward near the shelfbreak. The IC and EGC are difficult to distinguish in terms of velocity, but a sharp hydrographic front is present at the boundary between the two water masses. On the inner shelf the East Greenland Coastal Current (EGCC) advects a combination of Arctic-origin water and coastal runoff to the south. Sutherland and Pickart (2008) argue that the EGCC is predominantly a bifurcated branch of the EGC, and that the combined EGC/EGCC transport is approximately $2 S v$. Seaward of the shelfbreak, on the mid to deep continental slope, resides the DWBC.

Offshore of the boundary, in the southwest interior Irminger Sea, there is a narrow, closed cyclonic recirculation (Fig. 4-1). This feature is referred to here as the Irminger Gyre. Such a recirculation (though larger in zonal extent) was first postulated by Knudsen (1899) in order to maintain the hydrographic properties of the interior Irminger Sea. However, the first direct evidence of the Irminger Gyre was only recently presented by Lavender et al. (2000) who mapped its subsurface flow using float trajectories (Fig. 4-1). The gyre circulation is not readily detected in hydrographic data because of its predominantly barotropic nature and lack of geostrophic shear (Pickart et al., 2003b). The interior of the 


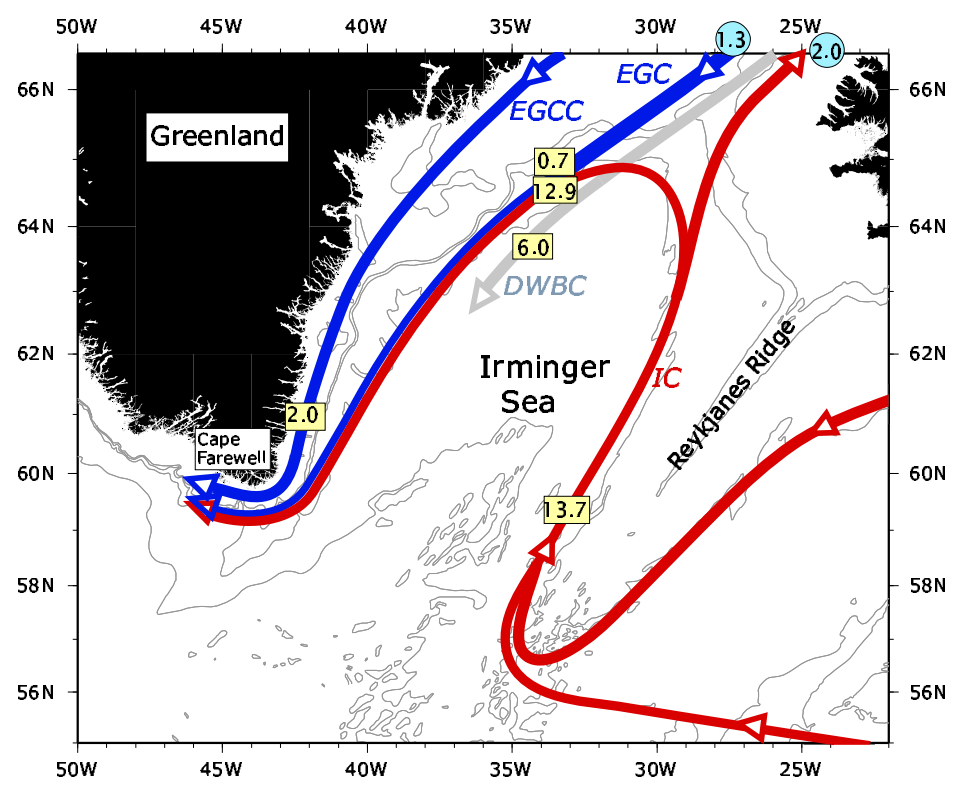

Figure 4-2: The boundary currents of the Irminger Sea, from Pickart et al. (2005). The acronyms are: $\mathrm{IC}=$ Irminger Current; EGC $=$ East Greenland Current; EGCC $=$ East Greenland Coastal Current; DWBC = Deep Western Boundary Current. Red (blue) arrows indicate upper-layer transport of warm (cold) water, and the numbers are transport estimates. The 500, 1000, 2000, and $3000 \mathrm{~m}$ isobaths are plotted.

gyre is a region of low eddy kinetic energy (e.g. Knutsen et al., 2005). As shown by Lavender et al. (2000), a band of low geostrophic pressure extends around Cape Farewell (the southern tip of Greenland, Fig. 4-1) into the southeast Labrador Sea. The flow on the seaward side of this band represents a pathway for LSW to travel from the Labrador Sea to the Irminger Sea (Talley and McCartney, 1982; Straneo et al., 2003; Faure and Speer, 2005).

\subsubsection{Forcing}

The atmospheric circulation in the vicinity of the Irminger Gyre is affected by the high topography of Greenland (e.g. Renfrew et al., 2008). Intense, small-scale wind events often arise from the impact of the topography upon cyclones that pass nearby along the North Atlantic storm tack. This is the main reason why the region near Cape Farewell is the windiest area of the World Ocean (Sampe and Xie, 2007). These small-scale winds may have an important impact on the circulation and wintertime mixing in the Irminger Sea (Pickart et al., 2008; Straneo et al., 2009). Of particular importance for the Irminger Gyre is a strong, 
but narrow and intermittent wind pattern called the westerly Greenland tip jet (Doyle and Shapiro, 1999, Fig. 1-3). Tip jets are predominantly a wintertime phenomenon formed in the lee (eastern side) of Greenland, either by conservation of the Bernoulli function during orographic descent down the lee side of Greenland (Doyle and Shapiro, 1999) or by acceleration through deflection around the southern tip of Greenland (Moore and Renfrew, 2005; Våge et al., 2009b). The tip jets often develop when a low-pressure system moves into the region northeast of Cape Farewell (Pickart et al., 2003a), and a greater (smaller) number of tip jet events tends to occur when the NAO index is high (low) and the Icelandic low is shifted towards the north (south) (Bakalian et al., 2007; Våge et al., 2009b). Mean wind speeds up to $30 \mathrm{~m} / \mathrm{s}$ generating heat fluxes approaching $600 \mathrm{~W} / \mathrm{m}^{2}$ are generally sustained for less than one day, but many such events can occur over the course of a winter (on average $13 \pm 5$ events, Våge et al., 2009b).

Tip jets have been linked with the oceanic circulation (Pickart et al., 2003a; Spall and Pickart, 2003) and convection (Pickart et al., 2003a,b; Våge et al., 2008) in the Irminger Sea. Spall and Pickart (2003) noted that the strong wintertime wind stress curl east of Greenland (see also Chelton et al., 2004) would induce upwelling, consistent with a cyclonic recirculation. The enhanced wind stress curl is mainly caused by the sharp northward gradient in zonal wind speed associated with the tip jet (Pickart et al., 2003a). Using an idealized hydrostatic, primitive equation general circulation model (GCM) driven by such a wintertime wind stress curl pattern, Spall and Pickart (2003) reproduced many of the circulation features observed by Lavender et al. (2000, 2005), including the Irminger Gyre. The circulation persisted throughout the summer - when the wind forcing was absent - maintained by a combination of weak stratification and sloping bathymetry under the forcing region. Hence there was only a weak seasonality of the Irminger Gyre. Spall and Pickart (2003) argue that baroclinic Rossby waves interact with the bottom and slow the circulation during winter when the forcing is present, and maintain the circulation during the rest of the year when there is no forcing. An earlier model study by Käse et al. (2001) suggests that wind forcing, bathymetry and the Denmark Strait overflow all play important roles for the mid-depth recirculations in the Labrador and Irminger seas. 


\subsubsection{Convection}

Deep convection in the open ocean can occur when a set of oceanic and atmospheric conditions are satisfied. These are (i) strong atmospheric forcing that removes buoyancy from the surface waters, (ii) a preconditioned water column containing weakly stratified water and (iii) a cyclonic circulation that isolates the water subjected to the forcing and causes doming of the isopycnal surfaces, which brings the weakly stratified water close to the surface (Marshall and Schott, 1999). Consequently there are only a limited number of locations in the World Ocean where deep overturning occurs. One such site is the Labrador Sea, where the intermediate water mass known as Labrador Sea Water (LSW) originates. Cold, dry continental air is advected from the Canadian land mass over the Labrador Sea by low-pressure systems following the winter storm track. Large heat fluxes result when the air reaches the ice-free ocean (Renfrew et al., 2002). The retention of water from the previous winters' deep overturning provides a preconditioned state (Lazier et al., 2002), and a cyclonic recirculation gyre in the western Labrador Sea (Lavender et al., 2000) isolates the water, resulting in exposure to the atmospheric cooling for an extended period of time.

It has been argued that LSW is also formed by deep convection in the Irminger Sea (Pickart et al., 2003a,b; Bacon et al., 2003; Álvarez et al., 2004; Falina et al., 2007; Våge et al., 2008). This is in fact not a new idea. Nansen (1912) suggested almost a century ago that the dense overflows were insufficient to supply all of the bottom water of the North Atlantic, and that deep convection must therefore take place in the subpolar gyre. From a limited number of early spring hydrographic stations that had surface water properties matching those of the bottom water, Nansen (1912) postulated that deep convection takes place in the Irminger Sea. Subsequent winter expeditions to the Irminger Sea were largely motivated by a desire to verify this hypothesis (Defant, 1936). Evidence of deep convection was found (Wattenberg, 1938; Sverdrup et al., 1942; Wüst, 1943), but the idea was largely forgotten by the oceanographic community as the discovery of deep convection in the Labrador Sea put an increased emphasis on that basin.

The notion of deep convection in the Irminger Sea was revisited by Pickart et al. 
(2003b). They showed that the three criteria for deep overturning were satisfied in that basin as well. Existence of cyclonic recirculation was demonstrated by Lavender et al. (2000, Fig. 4-1), and, because of density compensation, the warmer and saltier water in the central Irminger Sea can be as weakly stratified as the corresponding water column in the Labrador Sea to a depth of $1500 m$ (Pickart et al., 2003b). Moreover the observed tracer distribution in the western North Atlantic is inconsistent with the Labrador Sea being the sole source of LSW (Pickart et al., 2003b). Although the atmospheric forcing of the Irminger Sea is weaker compared to the Labrador Sea, the Greenland tip jet events in the southwest Irminger Basin are capable of locally enhancing the heat removal from the ocean to the atmosphere. The tip jet is poorly captured in low-resolution global atmospheric reanalysis data (Moore and Renfrew, 2005; Våge et al., 2009b), but its non-negligible effect on the seasonal evolution of the mixed layer was demonstrated by Våge et al. (2008). They found good correspondence between a timeseries of mixed layer depths obtained from a moored profiler in the central Irminger Sea for the winters of 2002-04 and a one-dimensional mixed layer model (Price et al., 1986) forced by heat-flux timeseries that include the enhancing influence of the tip jets.

Weaker atmospheric forcing and increasing oceanic stratification followed the decline of the NAO index in the early 2000s, and typical mixed layer depths of only $300-400 \mathrm{~m}$ were observed during that time period, in agreement with concurrent float data (Centurioni and Gould, 2004; Louarn et al., 2009). However, application of the 1-D model to the winter of 1994-95, near the end of the high-NAO period of the early 1990s, resulted in a final mixed layer depth exceeding $1700 \mathrm{~m}$, which is in good agreement with hydrographic measurements obtained the following summer. Numerical simulations by Pickart et al. (2003a,b) also resulted in deep mixed layers. Given the important influence of intense, small-scale wind events, the processes governing convection in the Irminger Sea are clearly different than those leading to ventilation in the Labrador Sea.

Despite the evidence to date, there is not an overall consensus in the oceanographic community that formation of LSW can occur in the Irminger Sea. For example, Bersch et al. (2007) argued that a continuously present intermediate salinity maximum, which has its origin near the Reykjanes Ridge, indicates that there was no significant formation of 
LSW in the Irminger Sea after 1991. Central to this discussion is the pathway of LSW export into the Irminger Sea. Pickart et al. (2003b) argued that the deduced transit times of less than one year (Sy et al., 1997) imply unrealistically high current velocities from the Labrador Sea to the Irminger Sea, and that such an estimate is likely due to a misinterpretation of locally convected water. Yashayaev (2007) suggested instead that the rapid spreading was based on insufficient data to register the true arrival of LSW into the Irminger Sea, and presented observational evidence of LSW transit times being at least double that provided by Sy et al. (1997). While there were no wintertime measurements in the Irminger Sea during the high-NAO period of the early 1990s, direct observational evidence of deep mixed layers in the Irminger Sea was obtained during the high-NAO winter of 2007-08 from Argo float profiles (Våge et al., 2009a) and moored time series (Femke de Jong, personal communication, 2008). If there is a second site of LSW formation in the subpolar gyre, this would have important consequences for our understanding of the North Atlantic meridional overturning circulation, the modification of the dense overflow waters from the Nordic seas, and the stratification and ventilation of the interior North Atlantic.

The main objectives of this chapter are (i) to quantify the structure, transport and interannual variability of the Irminger Gyre and (ii) to investigate the importance of the Irminger Sea as a source region for LSW. We use a collection of 32 of hydrographic transects across the southern Irminger Sea along with satellite and shipboard velocity measurements and meteorological fields to investigate these objectives. The data sets and methods used are presented in Section 4.3. We describe the mean state and interannual variability of the Irminger Sea in Sections 4.4 and 4.5. Transports across the regression line (Fig. 4-1) will be quantified in Section 4.6. We will show that the circulation of the Irminger Gyre intensified through the observed period, despite a general reduction of the atmospheric forcing. Then we present evidence that there is a distinct signal of locally versus remotely formed LSW in the Irminger Sea, which clarifies the contributions of the two basins in ventilating the mid-depth North Atlantic in Section 4.7. In the last two sections our main results are discussed and summarized. 


\subsection{Data and methods}

\subsubsection{Hydrography}

Since 1991, hydrographic transects in the vicinity of the World Ocean Circulation Experiment (WOCE) A1E/AR7E section across the southern Irminger Sea between Greenland and the Reykjanes Ridge (Fig. 4-3) have been performed up to several times every year with the exceptions of 1993 and 1998. Table 4.1 and Figure 4-4 lists all 32 occupations. Apart from the April 1991 and November 1994 transects, all of the sections were conducted during the summer half-year period May through October (hereafter referred to as summer), mainly between June and August ( $72 \%$ of the sections). The hydrographic data generally meet the standards described in the WOCE operations manual (accuracies of $0.002^{\circ} \mathrm{C}$, 0.002 and $3 d b$ for temperature, salinity, and pressure respectively). The median station spacing was $36 \mathrm{~km}$, and the measurements at each station generally covered the full depth of the water column. The radius of deformation is about $10 \mathrm{~km}$ (e.g. Chelton et al., 1998).

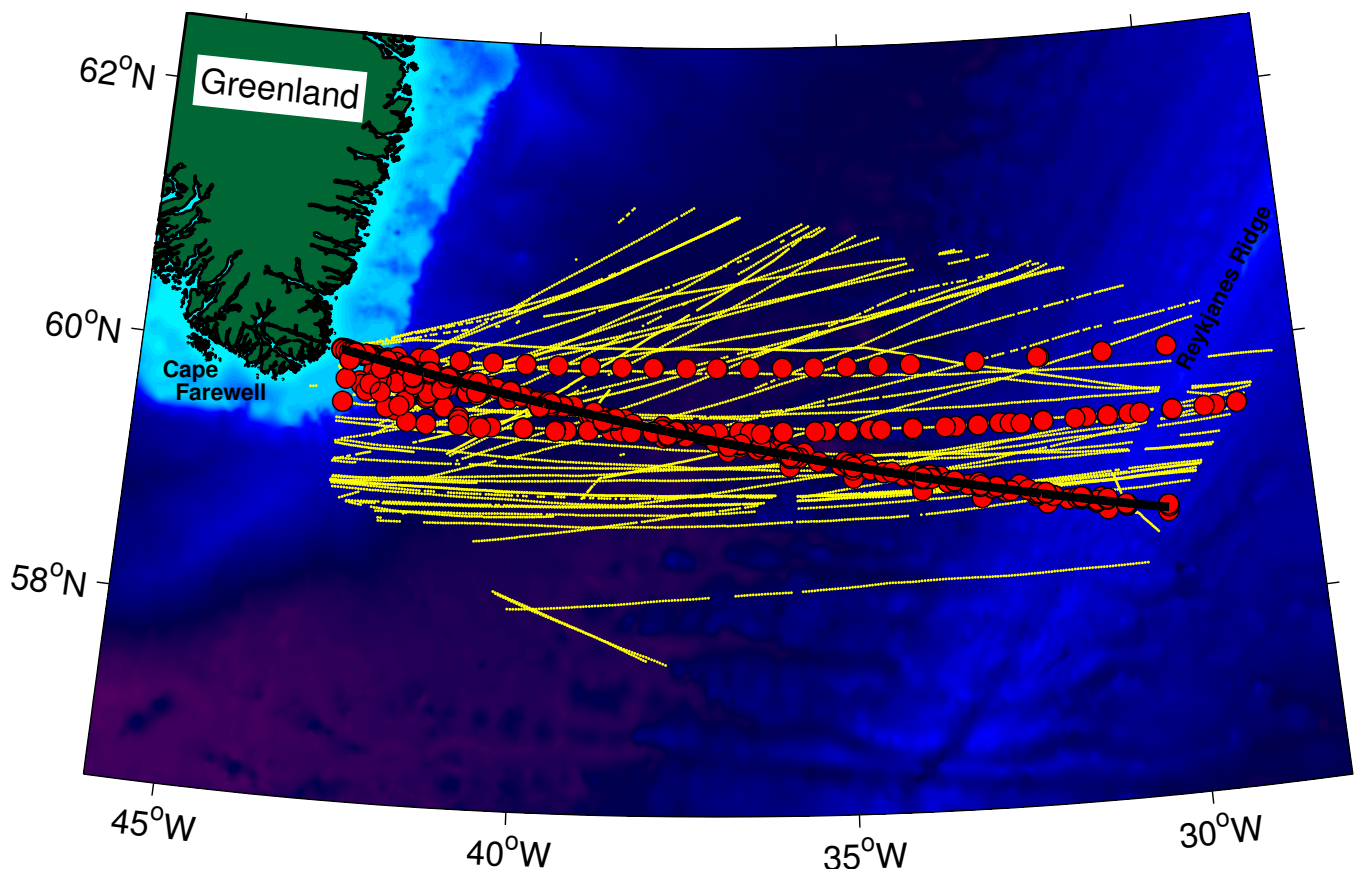

Figure 4-3: Topography of southeast Greenland and the Irminger Sea from the Etopo2 2-minute elevation data base. The black line identifies the least squares regression line onto which all of the in-situ data have been projected. The red circles and yellow points mark locations of hydrographic and direct velocity measurements, respectively. 


\begin{tabular}{l|l|l}
\hline Date & PI & Ship/Country \\
\hline Apr 1991 & van Aken & Tyro/NL \\
Aug 1991 & Gould & Charles Darwin/GB \\
Sep 1991 & Meincke & Meteor/DE \\
Sep 1992 & Sy & Valdivia/DE \\
Nov 1994 & Meincke & Meteor/DE \\
Jun 1995 & Bersch & Valdivia/DE \\
Aug 1996 & Bersch & Valdivia/DE \\
Aug 1997 & Sy & Meteor/DE \\
Oct 1997 & Sokov & Professor Shtokman/RU \\
May 1999 & Bersch & Valdivia/DE \\
Aug 1999 & Meincke & Meteor/DE \\
Aug 2000 & Hübner & Poseidon/DE \\
Oct 2000 & van Aken & Pelagia/NL \\
Jun 2001 & Holfort & Meteor/DE \\
Aug 2001 & Pickart & Oceanus/US \\
Jun 2002 & Holfort & Poseidon/DE \\
Jun 2002 & Mercier & Thalassa/FR \\
Jul 2002 & Bersch & Alexander von Humboldt/DE \\
Aug 2002 & Morozov & Akademik Mstislav Keldysh/RU \\
Aug 2002 & Pickart & Oceanus/US \\
Jul 2003 & Mortensen & Meteor/DE \\
Jul 2003 & Sokov & Akademik Ioffe/RU \\
Jul 2003 & Pickart & Oceanus/US \\
Sep 2003 & van Aken & Pelagia/NL \\
Jun 2004 & Huck & Thalassa/FR \\
Jun 2004 & Pisarev & Akademik Ioffe/RU \\
Jul 2004 & Pickart & James Clark Ross/GB \\
Aug 2004 & Quadfasel & Alexander von Humboldt/DE \\
Jun 2005 & Pisarev & Akademik Ioffe/RU \\
Sep 2005 & van Aken & Pelagia/NL \\
Jul 2006 & Sokov & Akademik Ioffe/RU \\
Jul 2007 & Sokov & Akademik Ioffe/RU \\
\hline
\end{tabular}

Table 4.1: Hydrographic transects across the southern Irminger Sea. 


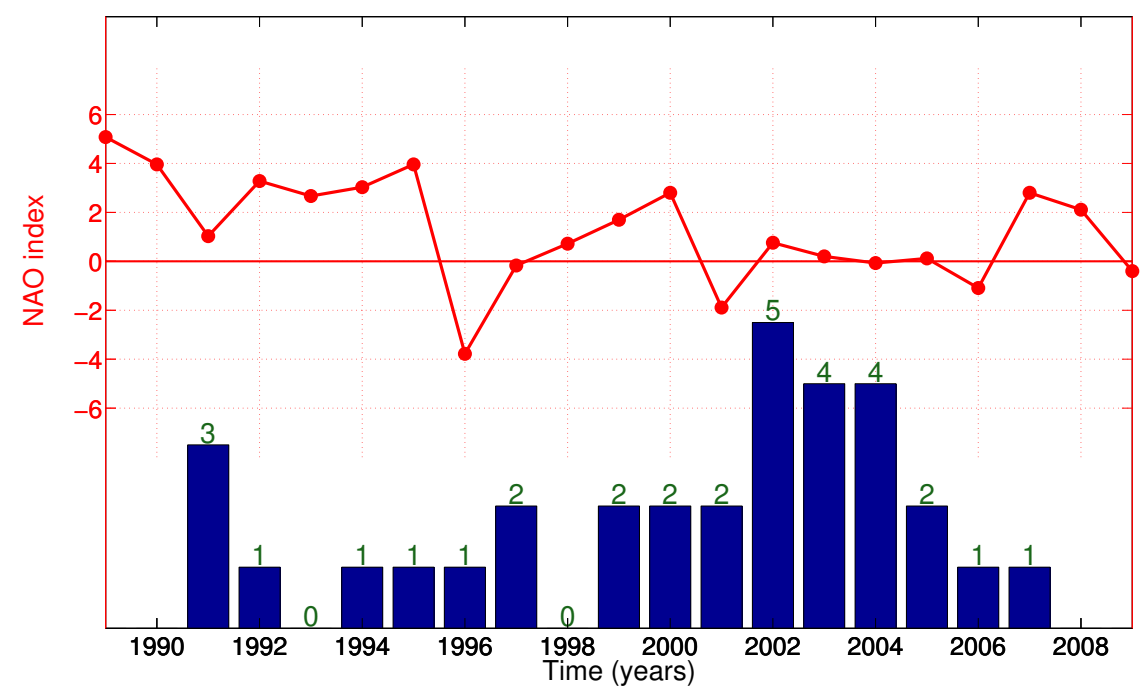

Figure 4-4: Number of hydrographic sections per year (blue bars) and December-March NAO index from Hurrell (1995, red).

\subsubsection{Shipboard velocities}

The container vessel Nuka Arctica operates on a three-week schedule from spring to fall between Denmark and Greenland. In 1999 it was outfitted with a $150 \mathrm{kHz}$ acoustic Doppler current profiler (ADCP). The objective was to obtain enough observations of the upper ocean circulation in the subpolar northeast Atlantic to construct robust ensemble averages, thereby permitting investigation of the total velocity field and its variation (Knutsen et al., 2005). From 1999 to 2002 nearly 50 crossings took place during the months of AprilDecember (Fig. 4-5), with the majority of them occurring between June and August (52\% of the transects). The data have been manually edited and de-tided ( $\varnothing$. Knutsen, personal communication, 2007). The Nuka Arctica continued to record ADCP data beyond 2002, but problems with data management and the logging system have prevented the data set from being updated (T. Rossby, personal communication, 2009). Additionally, for three of the hydrographic transects occupied between 1999 and 2002, concurrent shipboard ADCP measurements were obtained.

\subsubsection{Satellite altimetry}

In this study we use absolute dynamic ocean topography (DOT) and geostrophic velocities provided by Archiving, Validation, and Interpretation of Satellite Oceanographic data 


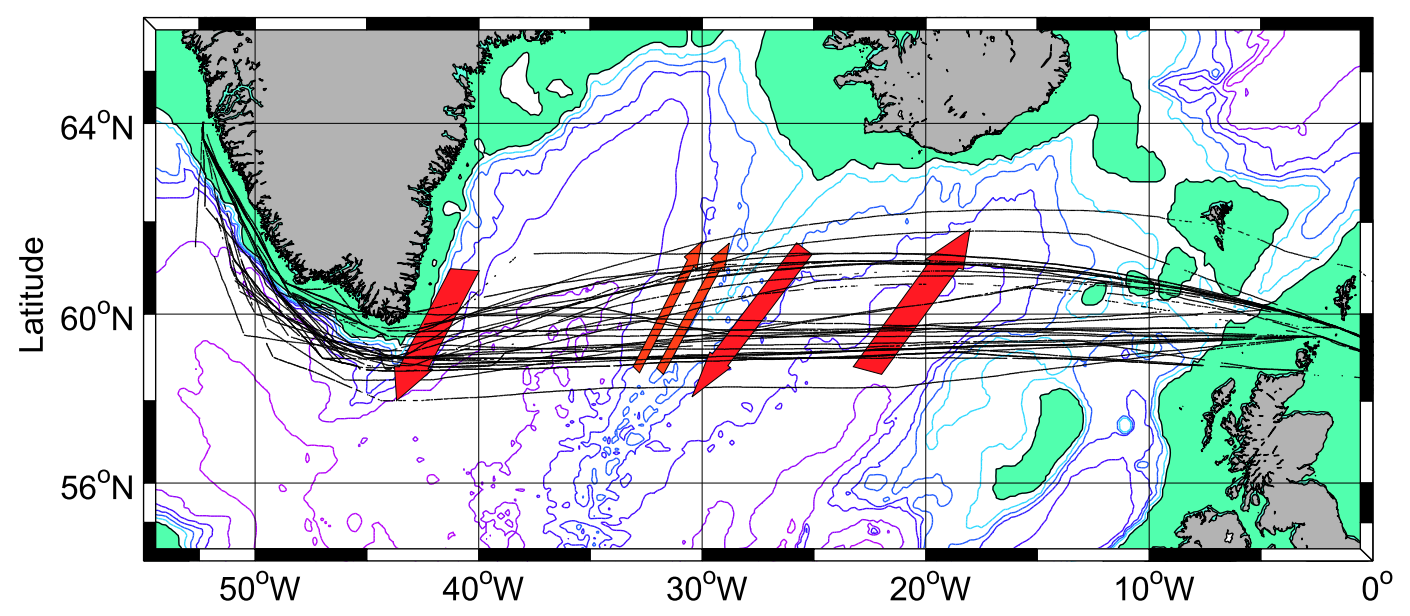

Figure 4-5: Nuka Arctica transects between 1999 and 2002, from Knutsen et al. (2005). The green areas are shallower than $500 \mathrm{~m}$, and depth is contoured with $500 \mathrm{~m}$ increments. The arrows represent from west to east: the EGC, two peaks of the IC (discussed further below), southward flow on the eastern side of the Reykjanes Ridge, and the North Atlantic Current.

(AVISO). Since October 1992 sea surface height (SSH) anomalies from multiple satellite altimeter missions have been consistently combined using sophisticated merging techniques and mapped onto a $1 / 3^{\circ}$ grid at weekly temporal resolution (Fig. 4-6, Ducet et al., 2000; Le Traon et al., 2003). Standard corrections to the altimeter data to take into account instrument noise, orbit error, atmospheric attenuation, sea state bias, and tides were applied by AVISO. Absolute dynamic topography was obtained from a combination of the SSH anomalies and a mean dynamic topography, which was computed from altimetry, in situ data, and a geoid model (Rio and Hernandez, 2004). Due to land contamination effects, the presence of ice, errors in the tide model, and limitations of the geoid estimate, the absolute dynamic topography is not expected to be very accurate near the coast or on lateral scales shorter than about $200 \mathrm{~km}$ (R. Ponte, personal communication, 2009). Limitations and error bars associated with the use of the AVISO data set in the present analysis are discussed below.

\subsubsection{Atmospheric reanalysis}

Monthly mean wind vectors and latent and sensible heat fluxes were obtained from the high-resolution North American Regional Reanalysis project (NARR, Mesinger et al., 


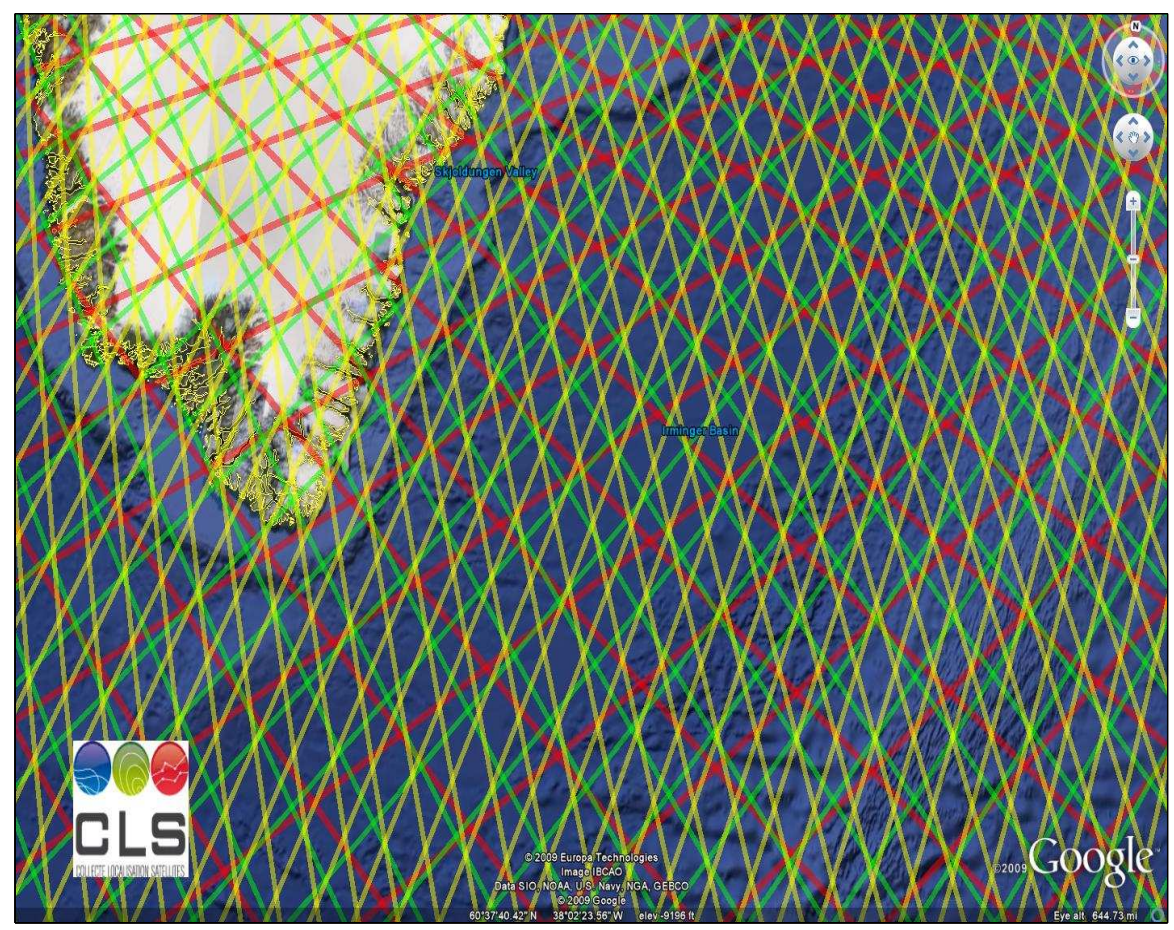

Figure 4-6: Satellite altimeter ground tracks provided by AVISO and plotted in Google Earth. The red tracks belong to Topex/Poseidon and Jason (9.1 day repeat cycle), the yellow tracks to ERS and Envisat (35 days repeat cycle), and the green tracks to GFO (17 days repeat cycle).

2006). From the monthly mean winds we computed wind stress curl using the method of Milliff and Morzel (2001). The spatial resolution of the NARR fields is $32 \mathrm{~km}$. The increased resolution relative to the regular global reanalysis products (e.g. NCEP) is important for a more realistic rendition of the tip jet (Jung and Rhines, 2007).

\subsubsection{Projection and gridding}

In order to facilitate the analysis and enable the use of quantitative techniques such as empirical orthogonal functions (EOFs), the hydrographic sections were first interpolated onto a standard grid in the $x-z$ plane. This was accomplished as follows. A least squares regression line was fit through the locus of the hydrographic station positions (stations from the sections along $59.5^{\circ} \mathrm{N}$ and $60^{\circ} \mathrm{N}$ were excepted). As the majority of the sections followed the WOCE A1E/AR7E line closely, the regression line is nearly identical to the WOCE line, and the regression line will hereafter be referred to simply as AR7E. A bathymetry profile along AR7E was extracted from Etopo2 (Fig. 4-1). A second bathymetry profile 
was estimated from the maximum depth of each station under the assumption that the measurements ended $10 \mathrm{~m}$ above the bottom (e.g. Pickart, 2004). Overall there was very good agreement between the two resulting depth curves. The final bathymetry profile is a smoothed combination of the Etopo2 and station-based depth estimates, with the deeper profile prevailing at each distance interval (Fig. 4-7).

Every station was subsequently projected onto the AR7E line. To the west of the center of the Irminger Basin the location of each station along AR7E was tentatively determined by minimizing the distance between its original position and the AR7E line. In the cases where the discrepancy between the station's original ${ }^{1}$ and projected depths exceeded a set tolerance criterion (5\%), the projected location was moved along the AR7E line until its original depth matched the bathymetry profile within the set tolerance. In the eastern part of the Irminger Basin the northward shoaling of the Reykjanes Ridge towards Iceland presented a complication. As the topography of the Reykjanes Ridge has an important dynamical effect on the flow (see for instance Fig. 4-5), it was decided that the distance of each station from the center of the Reykjanes Ridge must be maintained under the projection. Thus in the eastern part of the Irminger Basin each station was first projected onto the AR7E line such that the projected distance was minimized. Subsequently the station was moved along the line until its distance from the center of the ridge was preserved. The requirement of conservation of distance from the ridge was linearly relaxed between the center of the basin and the ridge such that the projection was completely determined by distance from the ridge near the ridge and completely determined by minimum projected distance near the center of the basin.

In total, 519 stations from the 32 sections were projected onto AR7E. In the same fashion each ADCP measurement was projected onto the AR7E line. The only difference between these procedures was that the original depth of each ADCP measurement was solely determined by Etopo2. Measurements from locations requiring a projection in excess of $200 \mathrm{~km}$ were discarded. As most of the hydrographic stations were located in the vicinity of AR7E, the distance of projection was less than $5 \mathrm{~km}$ for $73 \%$ of the stations and only

\footnotetext{
${ }^{1}$ The station's original depth was taken as the deepest of maximum measurement depth plus $10 \mathrm{~m}$ and Etopo2 interpolated to the position of the station
} 
$15 \%$ of the stations were moved more than $25 \mathrm{~km}$ from their original locations (Fig. 4-7). In summary, measurements from the western side of the Irminger Basin were projected along isobaths onto the AR7E line, while in the eastern half of the basin the distance from the Reykjanes Ridge was taken into account.

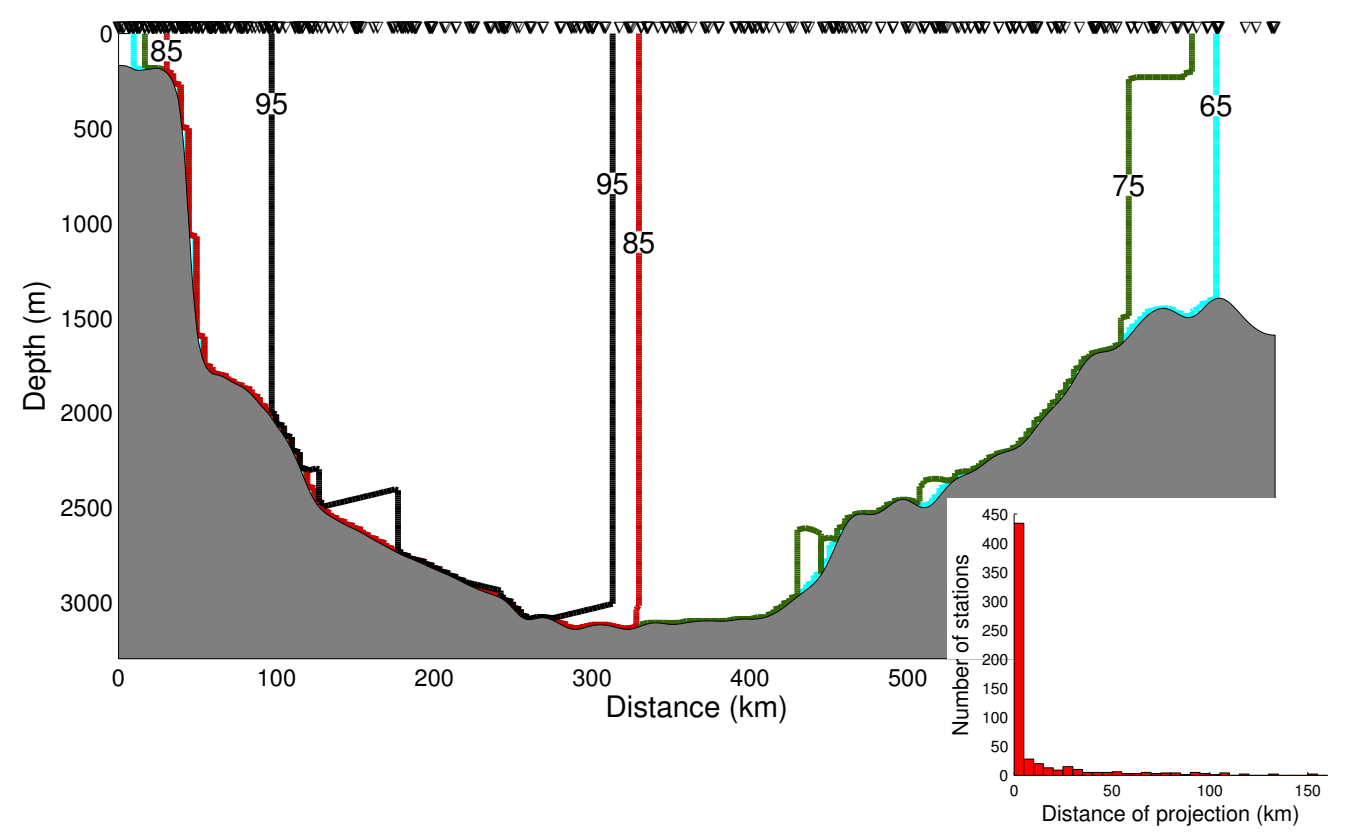

Figure 4-7: Bathymetry profile and hydrographic data coverage (in percent). The black triangles indicate station locations along AR7E. The inset histogram shows the distribution of distances of projection.

The hydrographic and direct velocity data from individual sections were then interpolated onto a standard $5 \mathrm{~km}$ by $10 \mathrm{~m}$ grid using a Laplacian-spline interpolator (see Pickart and Smethie, 1998, for details of this procedure). The data coverage along the standard grid is shown in Fig. 4-7. The western half of the Irminger Basin was sampled during the majority of the occupations, while hydrographic measurements were conducted across the entire basin from the Greenland shelf to the Reykjanes Ridge during $75 \%$ of the occupations. The collection of gridded sections will be used throughout the rest of the study.

\subsubsection{ADCP-referenced geostrophic velocities}

Absolute geostrophic velocities along the AR7E section were computed two ways: using the shipboard ADCP velocity data in the upper part of the water column, and using the 
AVISO gridded surface velocities. Since the time period covered by AVISO (1993-2007) is much greater than that sampled by the Nuka Arctica container vessel (1999-2002), in order to meaningfully investigate interannual variability it is necessary to use the former product. As such, the ADCP-referenced absolute velocities were used only to demonstrate the accuracy of the AVISO-referenced velocities.

For the Nuka Arctica time period, a weighted mean ADCP section over the depth interval 50 to $350 \mathrm{~m}$ was computed. The weights are inversely proportional to the distance of projection (projection distances shorter than $25 \mathrm{~km}$ were given equal weight). The weighting scheme was implemented because of the change in direction of the current flowing along the western boundary as it starts to curve around Cape Farewell, and the Greenland slope is also the only region where the weighted and unweighted mean vertical ADCP sections differed significantly (Fig. 4-8). The absolutely-referenced geostrophic flow was computed following the procedure of Pickart et al. (2005). In particular, each of the eleven gridded vertical sections of temperature and salinity for the time period 1999-2002 was used to calculate the dynamic height, from which relative geostrophic velocities were computed. The individual sections were then re-mapped onto the standard grid and averaged to create a mean thermal wind section. Finally, this section was referenced by matching the vertically averaged relative and ADCP velocities at each horizontal grid node (the difference between a vertically averaged match and a least squares best fit was minimal). Although the de-tided ADCP velocity field still contains ageostrophic motion, good agreement between the mean ADCP and mean absolute geostrophic velocities (not shown) indicate that the ageostrophic components were to a great extent averaged out and had little influence on the result. Below we compare the near-surface ADCP-referenced geostrophic velocities to the AVISO product for the 4-year period of overlap.

\subsubsection{AVISO-referenced geostrophic velocities}

The mean absolute geostrophic velocities computed from the subset of 11 hydrographic and the 47 direct velocity sections provide a realistic estimate of the flow across the AR7E line during the 1999-2002 period. However, to examine the evolution of the flow throughout 

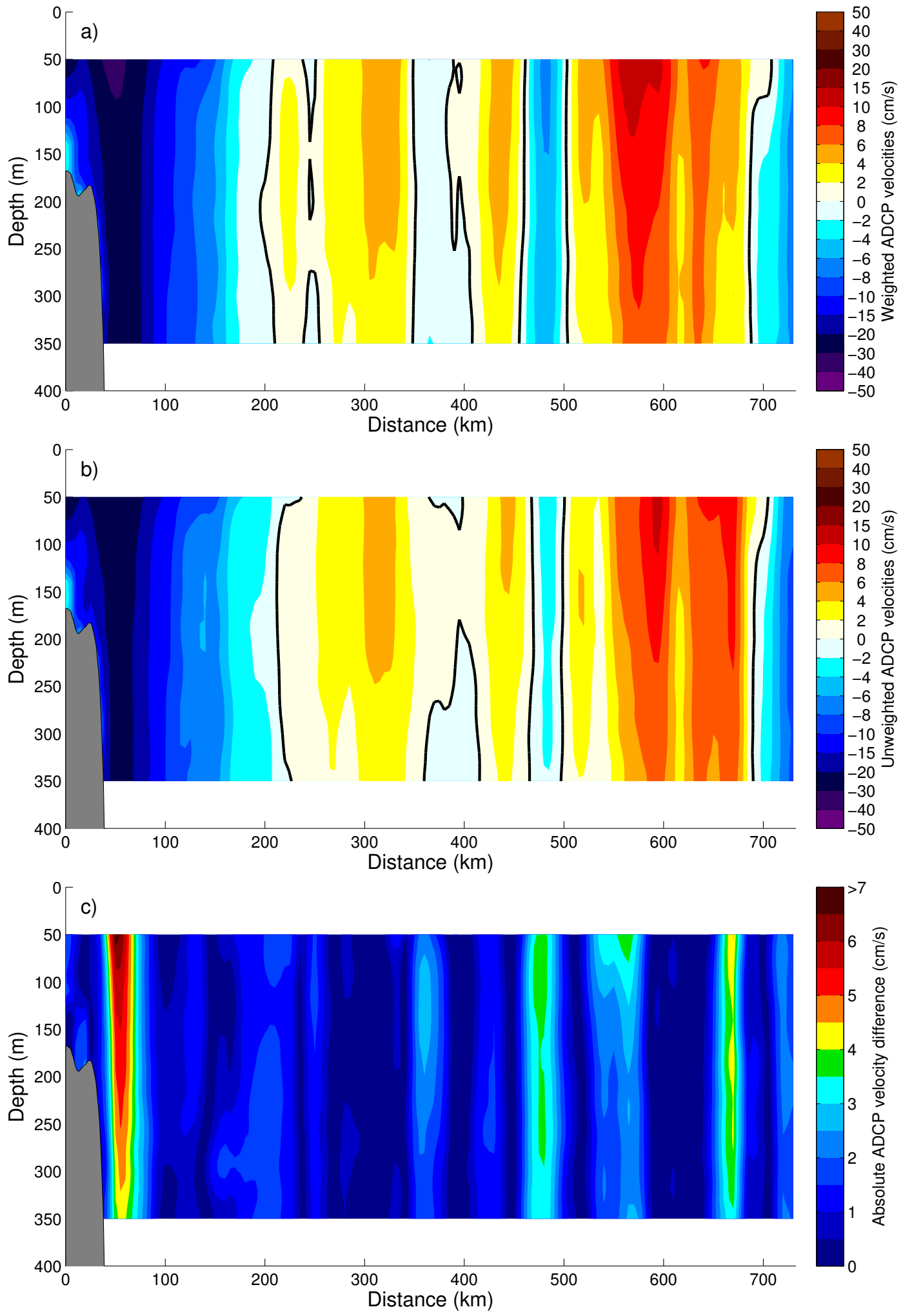

Figure 4-8: Comparison of ADCP velocities across AR7E for the period 1999-2002. a) Weighted mean velocities, b) unweighted mean velocities, and c) absolute difference between a) and b). 
the entire sampled period (1991-2007), additional reference velocity information is needed. Global sea surface height has continuously been measured by multiple satellite altimeters since October 1992. We examined the merged AVISO geostrophic surface velocity product to see how it compares against our independently computed ADCP-referenced surface geostrophic velocities. The mean 1999-2002 AVISO surface velocity field (for the months of April through December, to coincide with the period of hydrographic and direct velocity measurements) was interpolated onto the AR7E line and the velocity component normal to AR7E determined. The resulting AVISO velocity curve (green line) and the near-surface absolute geostrophic velocities from the ADCP-referenced field (10-50 $\mathrm{m}$ vertically averaged, blue line) are displayed in Figure 4-9a. Although the AVISO curve is smoother, the agreement between the AVISO- and ADCP-referenced surface geostrophic velocities is striking, with a root-mean-square (RMS) deviation of less than $3.0 \mathrm{~cm} / \mathrm{s}$. Both curves display the primary circulation features of the Irminger Sea: the Western Boundary Current (WBC, approximately 0-200 km), the northward branch of the Irminger Gyre (IG, approximately 200-350 km), and the Irminger Current (IC, approximately 500-700 km). We note that the AVISO product has smoothed out the two surface peaks of the IC that were pointed out by Knutsen et al. (2005) using the Nuka Arctica ADCP data.

Another pair of surface velocity curves computed from independent mean DOT products were evaluated for possible use as reference velocities with the geostrophic calculation (Fig. 4-9b). These would need to be coupled to the AVISO velocity anomaly fields in order to provide time-varying reference information. The GRACE-based DOT estimate of Tapley et al. (2003, orange line) is best suited for applications with wavelengths greater than $500 \mathrm{~km}$, and does not properly resolve the scales of interest in this study. Thompson et al. (2009, red line) used terrestrial and altimeter-derived gravity data to add high wave number detail to their regional DOT of the northwest Atlantic. They were able to resolve oceanographic features with length scales of order $100 \mathrm{~km}$ such as the Mann Eddy, and do also capture the primary features of interest in the Irminger Sea (the WBC, the IG, and the IC). However, the magnitudes of the surface flow in both the WBC and the northward branch of the IG are unrealistically high, and the peak of the IC is shifted eastward by about $100 \mathrm{~km}$ compared to our ADCP-referenced geostrophic surface velocities (Fig. 4-9b). A follow-up 

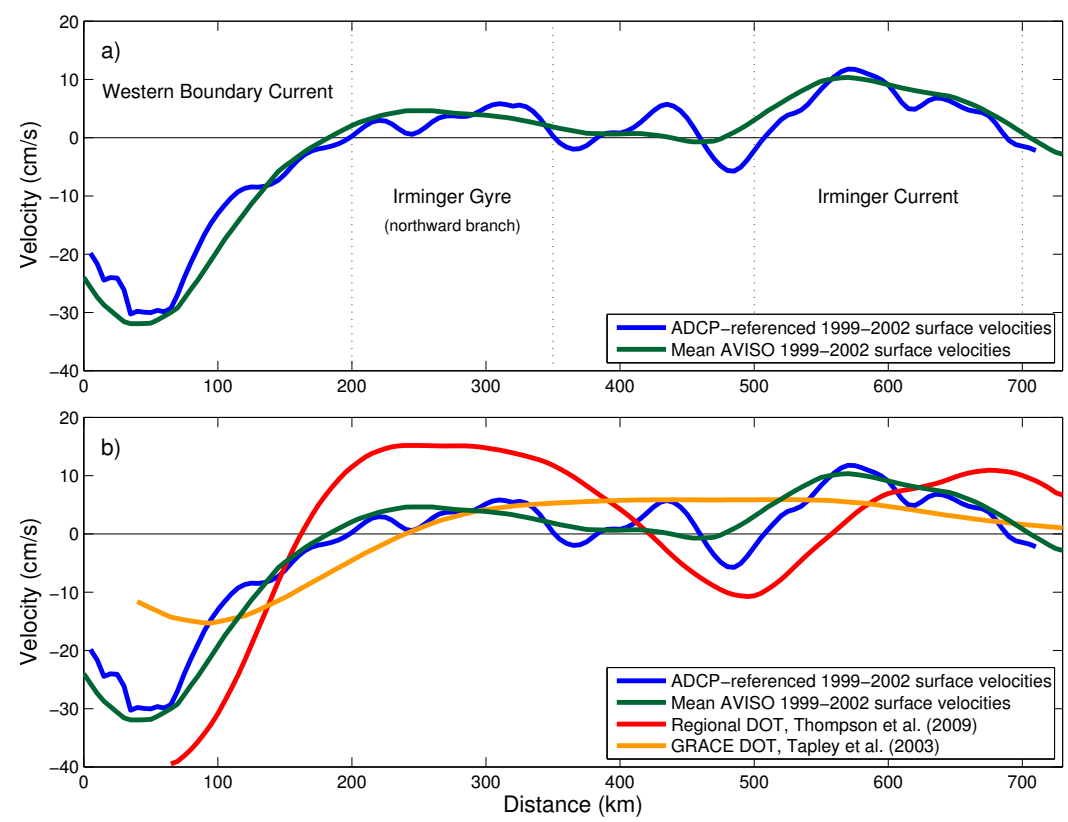

Figure 4-9: Comparison of surface velocities across the AR7E line. a) The blue line is a trace of the mean 1999-2002 near-surface absolute geostrophic velocities. The green line shows the mean 1999-2002 AVISO surface velocities. The approximate locations of the primary circulation features (discussed in the text) are indicated. b) The additional red and orange lines are mean surface velocities computed from the dynamic ocean topographies (DOT) of Thompson et al. (2009) and Tapley et al. (2003), respectively.

study in which additional high-quality terrestrial gravity data from the Irminger Sea area are included will be conducted within the next few months (K. Thompson, personal communication, 2009). Despite the above mentioned shortcomings (lack of accuracy for flow on the shelf and on short scales), the AVISO absolute geostrophic surface velocities calculated using the DOT of Rio and Hernandez (2004) are obviously the best choice at present for referencing our geostrophic velocity sections over the full time period. The scales of the primary features of interest (the WBC, IG, and IC) appear to be properly resolved, and the Greenland shelf area will not be included in our transport estimates.

In order to investigate the time-varying nature of the flow in the Irminger Sea, we chose to consider annual averages, or, more precisely, summer averages (May-Oct). The rationale was to reduce the effects of mesoscale activity as well as altimeter data uncertainty, and the majority of the hydrographic sections were occupied during these months. Accordingly, a single composite AVISO velocity curve was computed for each year (May through October, 26-27 realizations) for the period 1993-2007 (Fig. 4-10a). These surface velocity 
curves were then used to reference the annually-averaged thermal wind sections calculated from the AR7E occupations. AVISO only extends back to October 1992, which is not sufficient to provide reference velocity information for the 1991 and 1992 hydrographic sections. However, the early 1990s was a period of uniformly strong atmospheric forcing, as witnessed by the consistently high NAO index (Fig. 4-4), and, perhaps not surprisingly, there was little difference in the reference velocity curves from 1993 to 1996 . This provided motivation to extend the timeseries back in time to 1991 via linear extrapolation under the assumption that the circulation in 1991 and 1992 was similar in character to the succeeding years (Fig. 4-10b) ${ }^{2}$. This is admittedly a big assumption, and the resulting transport estimates for 1991 and 1992 should be considered as less certain.
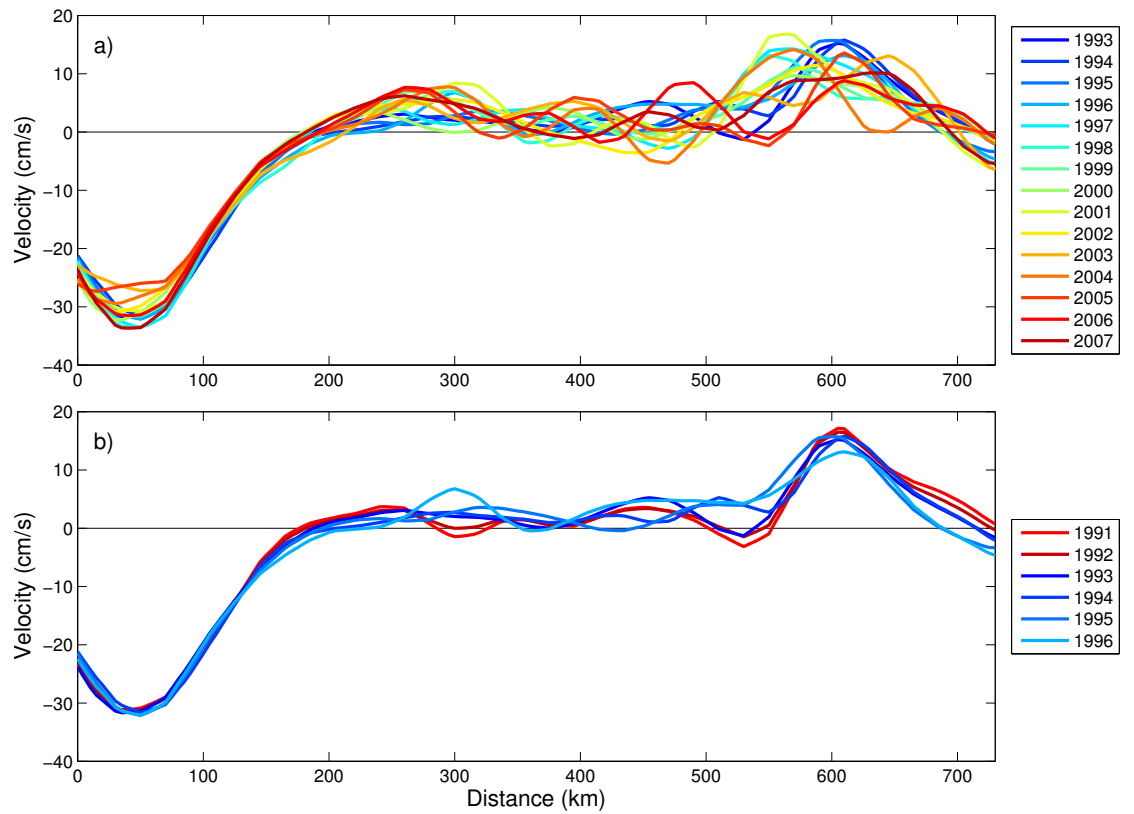

Figure 4-10: Annually (May-Oct) averaged AVISO reference velocity curves. a) 1993-2007. b) 1993-1996 (blue lines) and 1991-1992 extrapolated surface velocities (red lines).

\subsubsection{Absolute geostrophic velocity errors}

It is important to assess the errors associated with the calculation of absolute geostrophic velocities referenced by AVISO surface velocities. The uncertainties originate both from

\footnotetext{
${ }^{2}$ Though the atmospheric state had shifted by 1996, the surface circulation had not yet adjusted to make it significantly different from the preceding years, and it was included as the most recent end point of the extrapolation.
} 
the altimeter and the hydrographic data.

One important difficulty in using altimetry-derived surface velocities as reference values for full-depth geostrophic calculations is the uncertainty of the marine geoid, in particular for areas in the vicinity of land and for scales shorter than about $500 \mathrm{~km}$ (e.g. Tapley et al., 2003). In spite of this we found very good correspondence between the 4-year mean surface velocities derived from the geostrophic calculation referenced by direct velocity measurements (ADCP) and the AVISO absolute velocities (Fig. 4-9). This indicates that, averaged over a sufficient amount of time, the AVISO surface velocities provide a reasonable representation of the directly observed surface flow across the AR7E line. From this comparison we estimate an error associated with the geoid based on the RMS difference between the ADCP-referenced and AVISO geostrophic surface flows. The mean RMS difference is $3.0 \mathrm{~cm} / \mathrm{s}$, with the greatest values found over the Greenland shelf and slope and smallest values in the region of the Irminger Gyre. A curve of RMS differences calculated from a running mean filter with a window of $200 \mathrm{~km}$ provides an estimate of the uncertainty of the geoid at each nodal point.

Standard errors were computed for each of the summer averaged AVISO reference velocity curves (Fig. 4-10a) using the bootstrap technique, which is a procedure that involves random sampling with replacement from the dataset and does not require any assumptions about the underlying probability distribution. The mean standard error was $1.2 \mathrm{~cm} / \mathrm{s}$, and varied between approximately $0.8 \mathrm{~cm} / \mathrm{s}$ in the $\mathrm{WBC}$ and $1.6 \mathrm{~cm} / \mathrm{s}$ in the IC. The largest standard errors were generally found near the center of the basin and in the IC. We assigned a much larger error to the extrapolated 1991 and 1992 reference velocity curves estimated from the sum of the range and mean standard error of the 1993-1996 curves that served as the basis for the extrapolation.

Density gradients cannot be directly measured below the deepest common level of neighboring hydrographic stations (i.e. the "bottom triangle"). The extrapolation resulting from our Laplacian-spline gridding technique filled these bottom triangles, but the difference between the extrapolated grid points and the real ocean is unknown. To estimate an error associated with flow through the bottom triangles we first determined the median distance between stations $(36 \mathrm{~km})$ and the median slope of the bathymetry over this distance 
$(4.1 \mathrm{~m} / \mathrm{km})$ to obtain a "standard bottom triangle area". In the vicinity of steep bathymetry this area would tend to be larger. But, as a matter of routine, station spacing is typically decreased to compensate for the increased bottom triangle area under such conditions, thereby reducing the impact of steep bathymetry on the velocity error. The resulting standard bottom triangle area is equivalent to a uniform layer of thickness $74 \mathrm{~m}$ situated directly above the bottom. Combining the standard deviation of the absolute geostrophic velocities within this layer and the area of a standard bottom triangle, we obtain a transport error estimate of $0.18 S v$ associated with the data gap. Naturally this error affects only transport estimates of currents extending to the bottom. With a bottom depth of $2300 \mathrm{~m}$ (the average depth of the Irminger Basin) and a median distance of $36 \mathrm{~km}$ between stations, this error is comparable to a barotropic flow of $0.22 \mathrm{~cm} / \mathrm{s}$. For swift, bottom-trapped currents such as the DWBC, the bottom triangles may locally represent a much larger uncertainty.

An error will also result from the projection and gridding. Given the short distance over which most of the stations were projected ( $85 \%$ less than $25 \mathrm{~km}$ ) we do not expect a significant contribution to the total error resulting from the projection. The error arising from the gridding procedure was estimated from a comparison between the observed data and the gridded data interpolated to the locations of the original observations (e.g. Nikolopoulos et al., 2009). Below $250 \mathrm{~m}$ the median RMS difference between actual observations and gridded maps were $0.012^{\circ} \mathrm{C}$ and 0.0021 for temperature and salinity, respectively. The temperature RMS difference exceeds the observational error by a factor of 6 . In the worst case scenario, where one station would consistently be biased towards colder, saltier conditions by the above RMS differences compared to a neighboring station separated by the median distance of $36 \mathrm{~km}$, the geostrophic velocity error would reach $2 \mathrm{~cm} / \mathrm{s}$ at $3000 \mathrm{~m}$. This extreme case is highly unrealistic due to the random component of the gridding error. The greatest RMS difference between observed and gridded data occurred on the Greenland shelf, both because of strong gradients in temperature and salinity as well as large differences in the station spacing between the various cruises. This is not an important issue for our study, since the Greenland shelf is not considered.

Finally there is a statistical error associated with use of the synoptic density structure as a proxy for a summertime mean density. In the Labrador Sea this error is negligible below 
$1500 m$ (Han and Tang, 2001), which is likely the case for the Irminger Sea as well. This error is of course reduced for the years when multiple transects are available (Fig. 4-4). We have not attempted to quantify this statistical error. Instead our annual mean sections may be considered synoptic representations for each given year smoothed by the summer averaged AVISO reference velocities.

We found above the hydrographic uncertainties to be negligible compared to the errors associated with the temporally averaged AVISO absolute surface velocities that were used for referencing, with the possible exception of swift, bottom-trapped currents near steep bathymetry (e.g. the DWBC) where the error arising from transport through the bottom triangles may become more important. The total uncertainty of the reference velocity curve for each year was determined as the root of the sum of the squares of the two dominant contributions (geoid and standard errors). The transport errors in Section 4.6 are estimated from the impact of the reference velocity errors on the geostrophic calculations. Velocities exceeding $\pm 2 \mathrm{~cm} / \mathrm{s}$ may in general be considered significant for any pentadal or longer average.

\subsection{Mean structure}

We first examine the overall (1991-2007) mean hydrographic and absolute velocity fields, which are displayed in Figure 4-11. Following previous studies (e.g. Holliday et al., 2009) we split the water column into shallow, intermediate, and deep water masses.

Throughout most of the shallow layer $\left(\sigma_{\theta}<27.70 \mathrm{~kg} / \mathrm{m}^{3}\right)$ is a warm, saline Atlanticorigin water mass called Irminger Sea Water that is mainly supplied by the Irminger Current (IC). The IC is a branch of the North Atlantic Current, and enters the Irminger Sea as a northward flow along the western side of the Reykjanes Ridge. In the mean it is a surfaceintensified flow roughly $200 \mathrm{~km}$ wide, with a deep extension reaching the $1500 \mathrm{~m}$ isobath (Figure 4-11). The major fraction of the IC (up to 85\%, Pickart et al., 2005) flows around the Irminger Basin (Fig. 4-2) and continues south along the Greenland slope. Here a sharp hydrographic front separates the Irminger Sea Water from the cold, fresh Arctic-origin water carried by the East Greenland Current. We are unable to distinguish the boundary 
between the southward flow of the East Greenland Current and the IC. This was the case as well in studies farther to the south (Fratantoni and Pickart, 2007). We will hereafter refer to the combined southward flow along the Greenland slope as the Western Boundary Current and the northward flow along the Reykjanes Ridge as the Irminger Current.

The intermediate layer $\left(27.70 \mathrm{~kg} / \mathrm{m}^{3}<\sigma_{\theta}<27.80 \mathrm{~kg} / \mathrm{m}^{3}\right)$ is dominated by Labrador Sea Water, which is identifiable by a mid-depth minimum of salinity and potential vorticity (e.g. Talley and McCartney, 1982). The low potential vorticity signifies weak stratification, which may be traced to the convective origin of LSW resulting in a nearly homogeneous water mass. The most pure LSW in the Irminger Sea is found in the western half of the basin (note the doming and deepening 27.70 and $27.80 \mathrm{~kg} / \mathrm{m}^{3}$ isopycnals, respectively). The warmer and saltier water mass occupying the same depth as LSW predominantly in the vicinity of the Reykjanes Ridge is called Icelandic Slope Water (van Aken and de Boer, 1995; Read, 2001).

Two distinct water masses are found in the deep layer $\left(\sigma_{\theta}>27.80 \mathrm{~kg} / \mathrm{m}^{3}\right)$, both of which contribute to the DWBC and originate from the dense Nordic seas overflows. Near the bottom the cold and fresh signature of the Denmark Strait Overflow Water (DSOW) is evident. Directly above this the Iceland-Scotland Overflow Water (ISOW) is identifiable by the deep salinity maximum. This water mass is often referred to as North East Atlantic Deep Water (NEADW), and its greater salinity results largely from entrainment of saline Atlantic-origin waters primarily in the vicinity of the Iceland-Scotland sills (Fogelqvist et al., 2003). The boundary separating ISOW and DSOW is usually taken to be the 27.88 $\mathrm{kg} / \mathrm{m}^{3}$ isopycnal (e.g. Dickson and Brown, 1994), and we adopt this definition as well. Collectively DSOW, ISOW, and LSW form the major fraction of the DWBC, and are referred to as North Atlantic Deep Water (NADW), a water mass that constitutes a significant fraction of the World Ocean (Johnson, 2008) and plays an important role in the Meridional Overturning Circulation.

The strongest velocity signature in the mean section is the boundary current system. The IC flows northward on the western side of the Reykjanes Ridge, and returns as a surface-intensified flow in the upper part of the WBC. The enhanced southward flow at the bottom of the WBC is the DSOW, which has a "tail" extending offshore to roughly the 


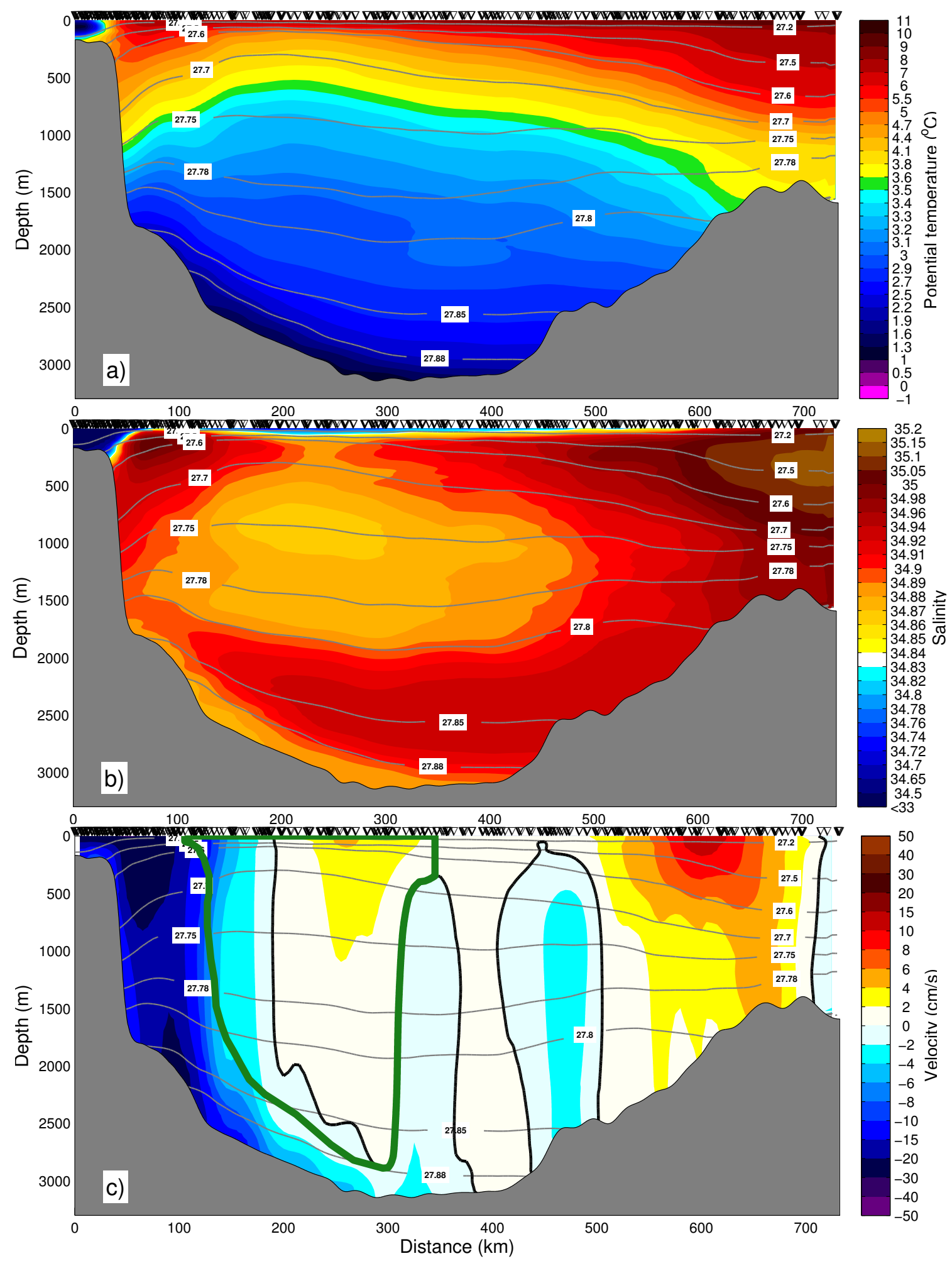

Figure 4-11: Vertical sections of a) potential temperature $\left({ }^{\circ} \mathrm{C}\right)$, b) salinity, and c) absolute geostrophic velocity (positive to the northeast, $\mathrm{cm} / \mathrm{s}$ ) averaged over the period 1991-2007. The grey lines are contours of constant potential density, and the black and green lines in c) are the zero velocity contour and the Irminger Gyre boundary. The black triangles indicate station locations. 
$3000 \mathrm{~m}$ isobath. This feature is seen in synoptic sections as well (Pickart et al., 2005). As previously noted (e.g. Lherminier et al., 2009), in the central Irminger Basin there is little density shear through most of the water column, which results in a large depth-independent component to the flow. The northward flow of the Irminger Gyre (IG) is seen clearly in the mean section, consistent with current meter data collected at this location (Våge et al., 2008). We defined the southward limb of the gyre as the seaward part of the WBC necessary to balance the northward transport at each density level in the water column. The boundary of the IG is depicted in Figure 4-11c by the thick green line. We note that earlier studies have referred to the Irminger Gyre as the cyclonic circulation across the full width of the Irminger Basin (e.g. Flatau et al., 2003; Lherminier et al., 2007). We strictly denote the Irminger Gyre as the narrow cyclonic recirculation in the western Irminger Basin. This feature was first mapped by Lavender et al. (2000) and is displayed in Figure 4-1. The recirculating component of the WBC forming the southward limb of the gyre will be removed from our estimates of net equatorward WBC transport.

\subsection{Temporal variability}

Significant changes have taken place across the Irminger Basin in concert with the changing atmospheric conditions represented by the NAO index (Fig. 4-4). To document these changes we first focus on two pentads, the early 1990s (1991-95) and the early 2000s (2001-05), that represent distinctly different modes of the atmospheric circulation as represented by the NAO index. Following this we relate results from an EOF analysis using hydrographic, altimetric, and atmospheric reanalysis data to the NAO index and the subpolar gyre index of Häkkinen and Rhines (2004, 2009). The goal is to understand how these changes were interrelated.

\subsubsection{Contrasting the early $1990 \mathrm{~s}$ to the early $2000 \mathrm{~s}$}

The early 1990s (1991-95) was a period of consistently high NAO index. It was characterized by stormy and severe winters, and the formation of a large volume of LSW in the Labrador Sea (Lazier et al., 2002; Yashayaev, 2007). The resulting LSW class, the coldest 
and densest on record, has been referred to as lower LSW (ILSW) or LSW 1994 . Following this, the NAO index dropped precipitously to a strongly negative value in 1996, and the formation of ILSW ceased. In the early 2000s (2001-05) the NAO index fluctuated between weakly positive and weakly negative. The atmospheric forcing at the beginning of the period (winter 1999-00) was sufficient to cause renewed formation of LSW, although a less dense class of LSW was formed, called upper LSW (uLSW) or $\mathrm{LSW}_{2000}$ (Yashayaev, 2007; Yashayaev et al., 2007a).

To illustrate the changes that took place between these vastly different periods of atmospheric forcing, we display in Figures 4-12 and 4-13 mean vertical sections for the early 1990s and early 2000s. The most dramatic change in the hydrography of the Irminger Sea occurred in the intermediate layer (Figs. 4-12 and 4-13). A large pool of cold, fresh, and weakly stratified ILSW filled most of the western and central Irminger Basin between the 27.75 and $27.80 \mathrm{~kg} / \mathrm{m}^{3}$ isopycnals in the early 1990s. By the early 2000s the ILSW dome had all but collapsed, and warmer, saltier, and more stratified waters permeated the basin. As the formation of ILSW ceased in the mid-1990s, the water mass became completely isolated from the surface. Mixing with warmer and saltier waters along the margins eroded the salinity minimum and led to restratification and flattening of the isopycnals (e.g. Lazier et al., 2002). In the early 2000s there was still a trace of ILSW identified by the deep salinity minimum above the $27.80 \mathrm{~kg} / \mathrm{m}^{3}$ isopycnal. The shallower salinity minimum above the $27.75 \mathrm{~kg} / \mathrm{m}^{3}$ isopycnal is associated with uLSW. These large-scale changes in the lower and upper LSW volumes throughout the subpolar gyre are readily detectable in chlorofluorocarbon inventories (e.g. Kieke et al., 2007). The local salinity maximum separating the two LSW modes is referred to as Icelandic Slope Water (Holliday et al., 2009). The weak stratification in the vicinity of the Reykjanes Ridge is also a signature of this water mass (Read, 2001), and is not related to LSW. The importance of local formation of LSW in the Irminger Sea versus import from the Labrador Sea will be discussed in Section 4.7. Warming and salinification took place in the deep layer as well, and has been quantified by previous authors (Sarafanov et al., 2007; Yashayaev et al., 2007a,b).

The declining buoyancy forcing and collapse of the ILSW dome during the 1990s resulted in a rising subpolar sea surface height and a spin-down of the subpolar gyre (Häkkinen 

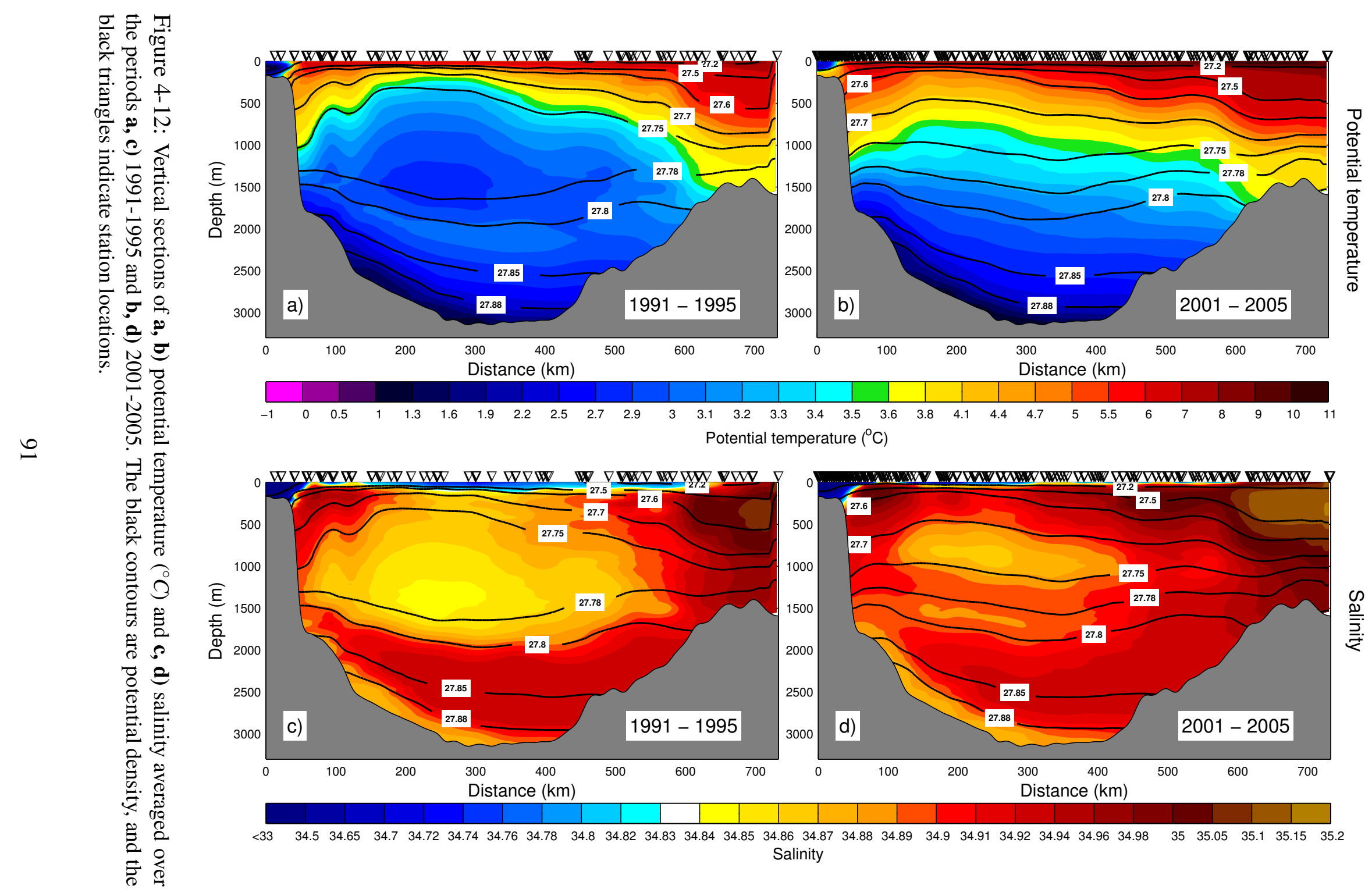

$\begin{array}{lllllllllllllllllllllllllllll}<33 & 34.5 & 34.65 & 34.7 & 34.72 & 34.74 & 34.76 & 34.78 & 34.8 & 34.82 & 34.83 & 34.84 & 34.85 & 34.86 & 34.87 & 34.88 & 34.89 & 34.9 & 34.91 & 34.92 & 34.94 & 34.96 & 34.98 & 35 & 35.05 & 35.1 & 35.15 & 35.2\end{array}$ Salinity 


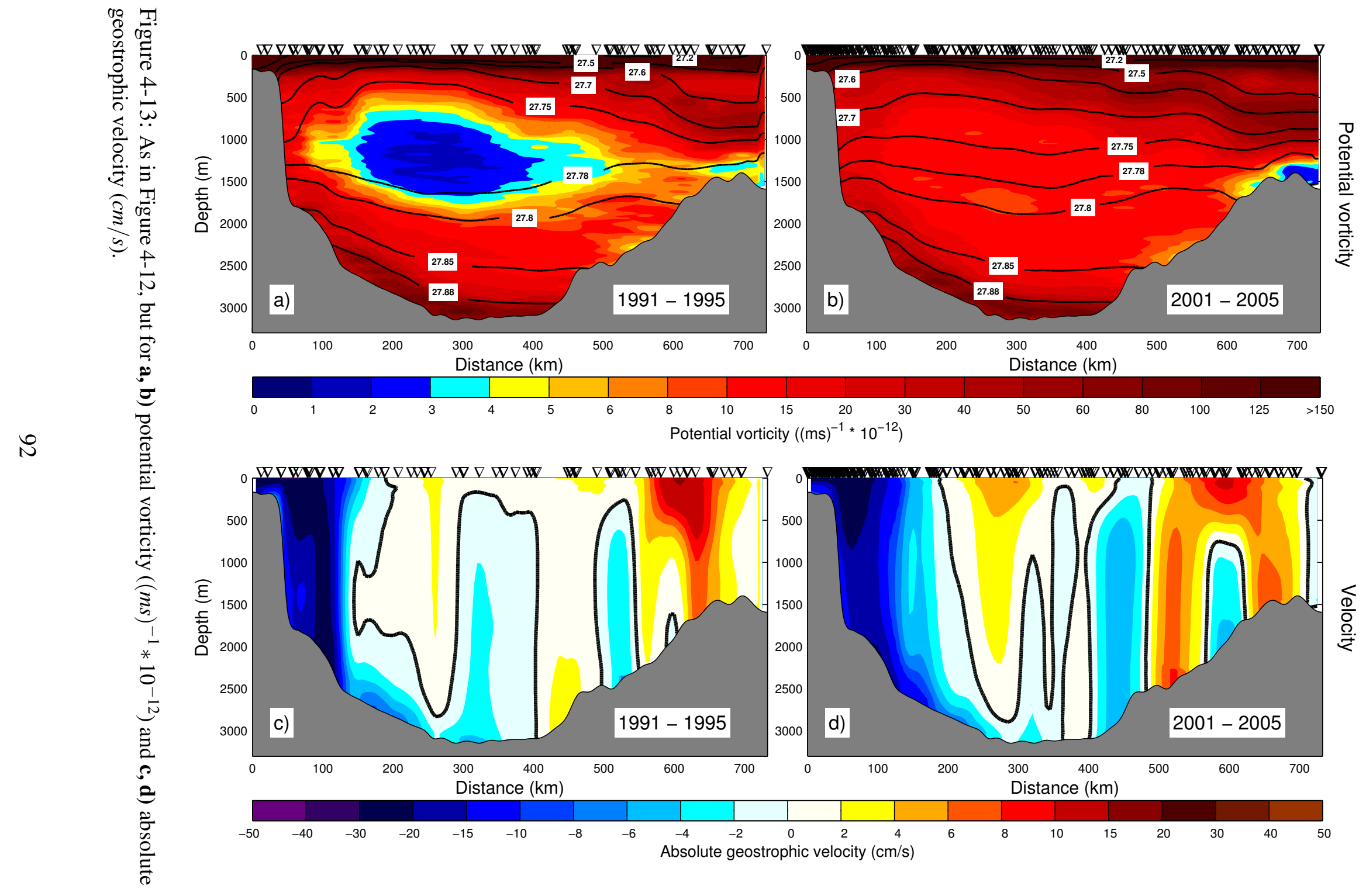


and Rhines, 2004). This is reflected in the changing structure of the boundary currents along the margins of the Irminger Sea. The shallow part of the IC weakened between the early 1990s and the early 2000s. The most notable change in the IC, however, is in its deep structure. During the latter pentad a second deep extension of the current developed, centered on the $2500 \mathrm{~m}$ isobath (there is a weak signature of this feature during the first pentad). The influence of this varying IC structure on the transport of the current will be quantified in Section 4.6, and possible reasons for the structural transformation will be discussed in Section 4.8. The magnitude of the WBC also declined between the early 1990s and the early 2000s, in particular in the shallow layer, consistent with the notion of a declining subpolar gyre. Interestingly there is a compensating effect in that the WBC became wider in the latter period. Timeseries of transport in the WBC will also be examined in Section 4.6. An unexpected change that occurred between the two periods is that the strength of the IG (located between approximately 150 and $350 \mathrm{~km}$ along AR7E) increased. This is surprising because both the wind stress and buoyancy components of the atmospheric forcing were significantly reduced over this time period (Fig. 4-14), and local wind stress curl and air-sea buoyancy exchange are thought to be the main forcing mechanisms of the IG (Spall and Pickart, 2003; Pickart et al., 2003a).

Examination of the AVISO DOT field (Fig. 4-15) provides an indication of what might have taken place. In agreement with the observations of Häkkinen and Rhines (2004) an increase in SSH is evident across the Irminger Sea (Fig. 4-15a). More detailed scrutiny reveals, however, that the increase was not uniform. The extent of sea level rebound was greater in the eastern half of the Irminger Basin than in the western. As a result, the SSH gradient in the central Irminger Sea steepened. This effect is particularly evident when examining the DOT along AR7E in Figure 4-16. Consequently, the northward flow of the IG, which is largely barotropic, increased. This is consistent as well with the AVISO surface geostrophic velocity field (Fig. 4-15c, d), where enhanced northward velocities across AR7E in the region of the IG is evident in 2001-05 relative to 1992-95. The velocity difference field (not shown) shows increased velocities in most of the interior Irminger Sea north of AR7E. Increased surface flow is also evident along parts of the IC (although not at the AR7E line as discussed above), which is surprising given the general decline of the 

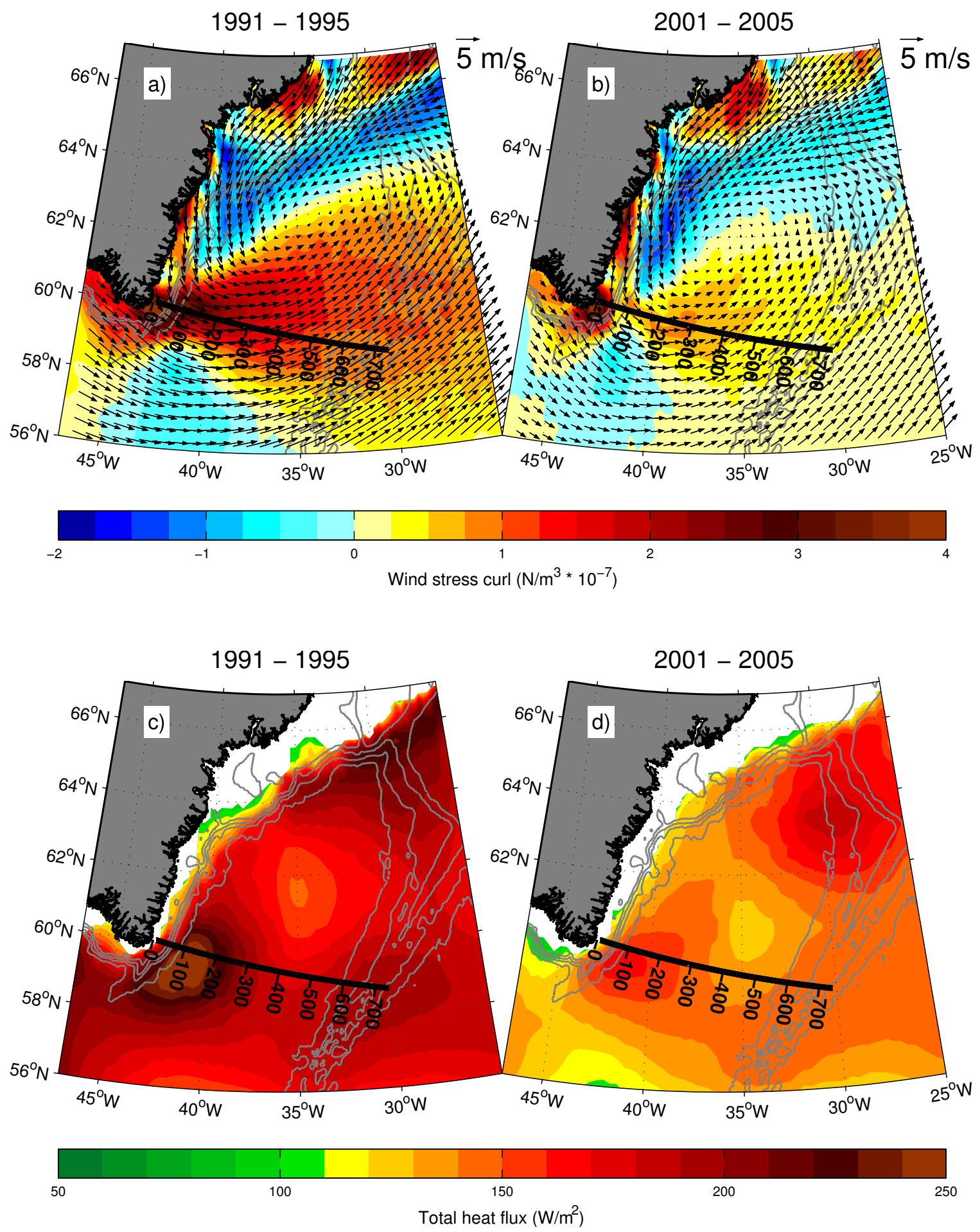

Figure 4-14: Maps of NARR winter a, b) wind stress curl $\left(\mathrm{N} / \mathrm{m}^{3} * 10^{-7}\right)$ and wind vectors $(\mathrm{m} / \mathrm{s})$ and c, d) total turbulent heat flux $\left(\mathrm{W} / \mathrm{m}^{2}\right)$ averaged over the periods a, c) 1991-1995 and b, d) 20012005. The black line and numbers indicate the AR7E line and distance (in $\mathrm{km}$ ), depth is contoured with $500 \mathrm{~m}$ increments starting at $500 \mathrm{~m}$. 
subpolar gyre circulation. The WBC surface flow declined as expected from Häkkinen and Rhines (2004). The apparent paradox of a strengthening IG circulation under weakening atmospheric forcing will be discussed further in Section 4.8.

\subsubsection{Decadal variability}

Häkkinen and Rhines (2004) used empirical orthogonal functions (EOFs) ${ }^{3}$ to study the North Atlantic sea level anomalies. Interestingly, the subpolar gyre center of action in the spatial pattern of their leading EOF mode is situated in the Irminger Sea. Häkkinen and Rhines (2004) speculate that this may be a reflection of changes in local convective activity. Too much emphasis should perhaps not be attached to the exact location of the center of action considering the low amount of variance in the altimeter data set explained by their leading mode (11\%) and the southern Irminger Sea's close proximity to the geographical center of the subpolar gyre.

We investigated the decadal variability with a more local focus, and performed an EOF analysis using a wider variety of oceanic and atmospheric data from the Irminger Sea region. In particular, we computed EOFs using the AR7E hydrographic data, altimetric data, and NARR atmospheric data. We performed both individual and coupled EOFs, including one calculation with all of the fields. The leading modes of all of the calculations are similar in character and represent the major evolution that took place between the early 1990s and the early 2000s. We present only the PC timeseries and not the spatial patterns, which are better represented by the pentadal averages presented above (Figures 4-12 to 4-15).

For the hydrographic EOF we used as input the annually-averaged potential temperature, salinity, and potential vorticity from the intermediate layer in the IG region to emphasize the LSW. The resulting PC timeseries explains 38\% of the variance and is expressed by the black crosses in Figure 4-17a. The other timeseries in the figure are the NAO index (blue line) and the subpolar gyre index (the PC timeseries from Häkkinen and Rhines (2004, 2009), red line). We note immediately the high level of agreement between the

\footnotetext{
${ }^{3}$ Performing an EOF analysis of a data set implies decomposing it into basis functions orthogonal to each other, chosen such that the variance accounted for by each is maximized. Timeseries and spatial patterns for each basis function are both produced by the analysis.
} 

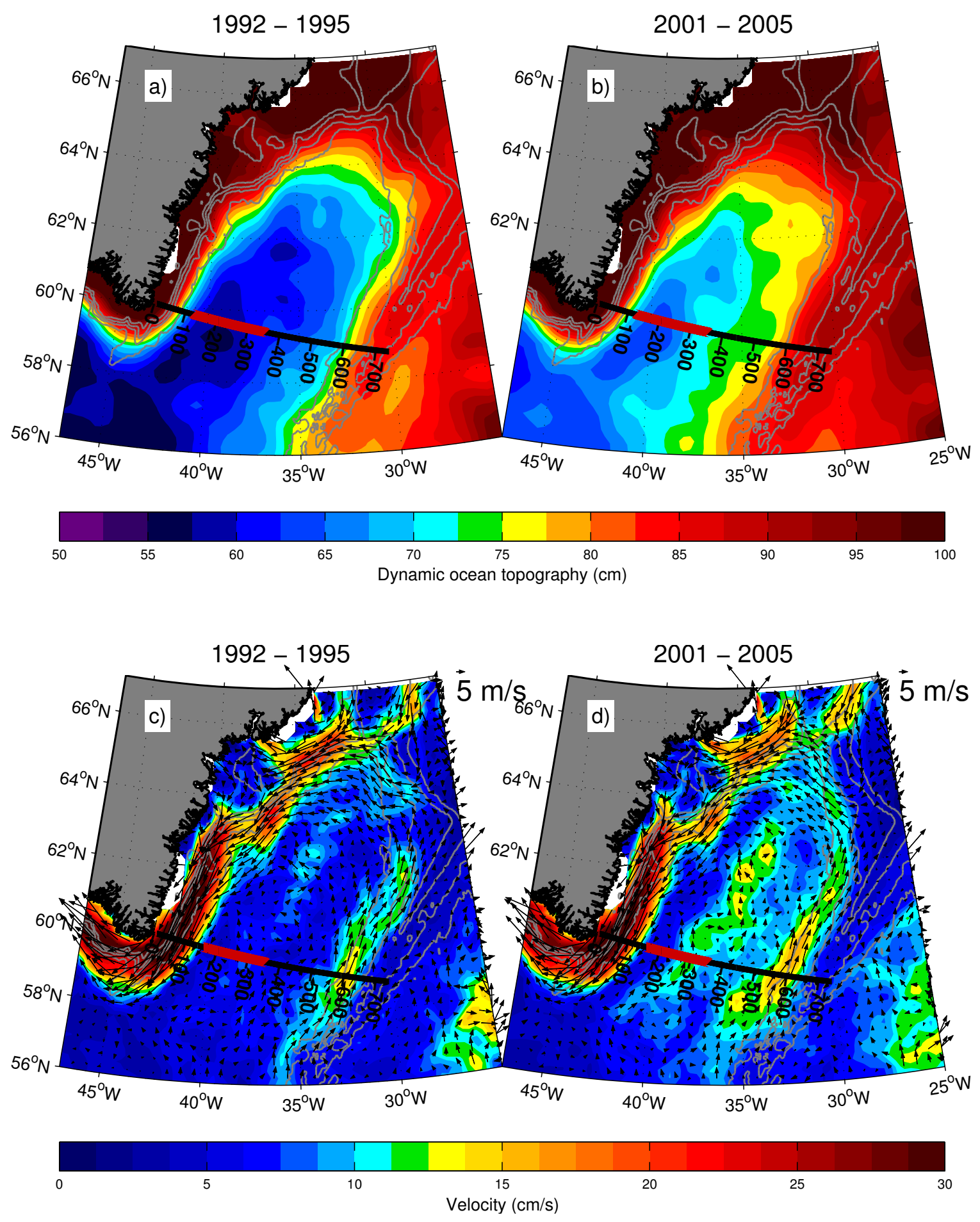

Figure 4-15: As Figure 4-14, but for AVISO summer absolute a, b) dynamic ocean topography $(\mathrm{cm})$ and $\mathbf{c}$, d) surface geostrophic velocity $(\mathrm{cm} / \mathrm{s})$. The red segment along AR7E indicates the width of the IG, shown also in Fig 3-15. 


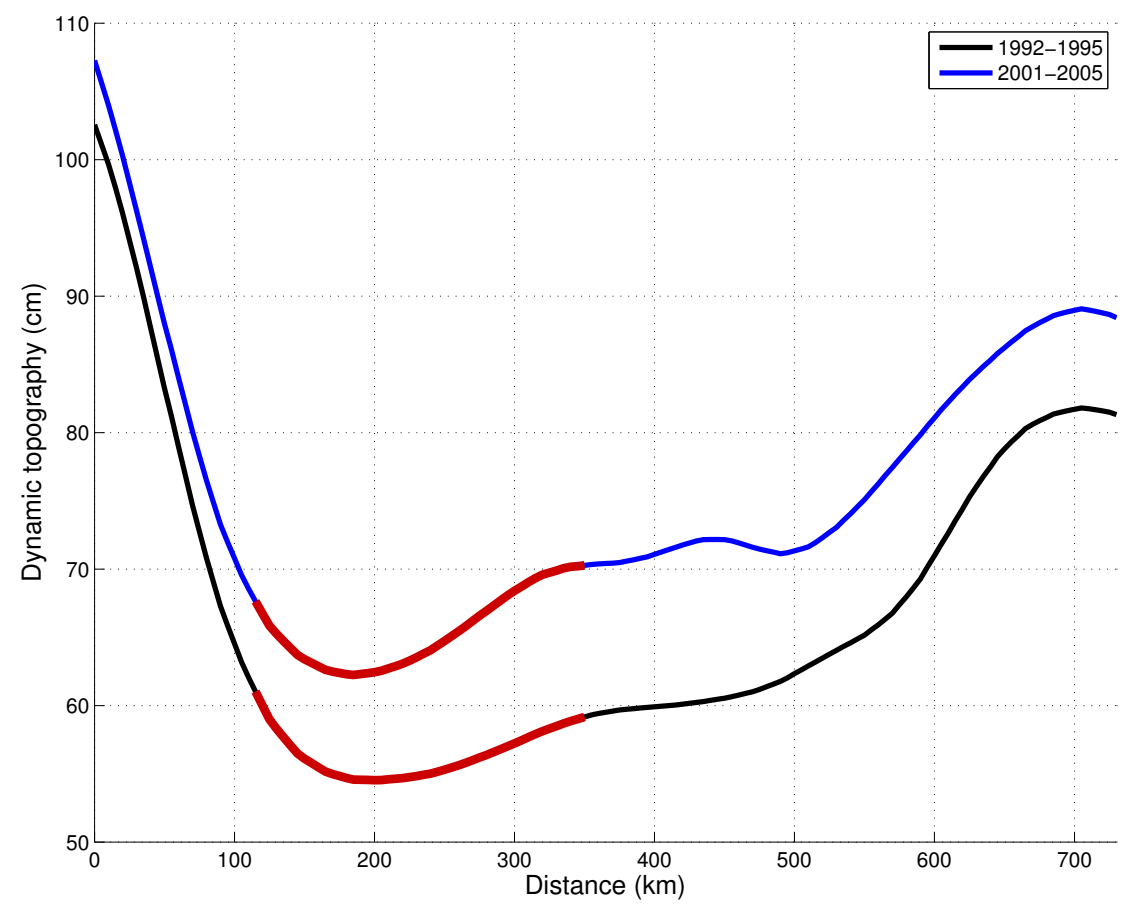

Figure 4-16: AVISO DOT ( $\mathrm{cm}$ ) along AR7E for the early 1990s and the early 2000s. The width of the IG is indicated by the red segment.

PC timeseries and the gyre index. The correlation between the two timeseries is 0.95 . It is rather remarkable that the evolution of the gyre index, which represents the large-scale circulation in the North Atlantic, so closely reflects the variability of the Irminger Sea hydrography as seen in the AR7E sections. The precise timing of the mid-1990s maximum is the only discrepancy between the timeseries. The gyre index peaked in early 1994, while the PC timeseries peaked around 1995. The difference between the two years, on the other hand, is probably insignificant, and the missing data from 1993 would likely have had an effect on the hydrographic EOF analysis. With the exception of the absolute geostrophic velocity field, which as discussed earlier behaved contrary to expectations in terms of the IG circulation, various other combinations of hydrographic data produce similar results. The highest correlation with the gyre index (0.97) was obtained when computing the EOF from potential vorticity alone, and the greatest amount of variance explained (53\%) was achieved when considering potential temperature alone. Expanding the domain from the intermediate layer in the IG to the full width and depth of the Irminger Sea led to a marginal increase in coherence with the gyre index, but a significant decrease in amount of variance 
accounted for. Since only $75 \%$ of the sections extended across the entire Irminger Basin, fewer data points were available from the full domain.

Next we considered an altimetric EOF using the summer mean dynamic ocean topography and surface geostrophic velocity fields. The resulting PC timeseries (Fig. 4-17b) explains $28 \%$ of the variance. Although the EOF is computed from a limited domain (the Irminger Sea deeper than $1000 \mathrm{~m}$, north of $57^{\circ} \mathrm{N}$, and between $45^{\circ} \mathrm{W}$ and the Reykjanes Ridge), the input data express essentially the same signal as the sea level anomalies used by Häkkinen and Rhines (2004, 2009), and the high correlation (0.95) between the PC timeseries and the gyre index is not surprising. The coherence is greater still when considering only the velocity field, while most variance is explained by the first DOT EOF mode.

The leading atmospheric EOF mode of winter mean turbulent heat fluxes and wind stress curl from the NARR atmospheric reanalysis project (same domain as above) explains $29 \%$ of the variance in the data set. Inspection of the PC timeseries (Fig. 4-17c) shows a high degree of coherence with the NAO index, which indicates that the NAO index is useful as a representation of the wintertime atmospheric forcing in this region. The strongest signal is found directly east of Cape Farewell (Fig. 4-14), which is a testament to the importance of the tip jet on this region (e.g. Pickart et al., 2003a). As noted above there is also a positive correlation between the NAO index and the number of tip jet events per winter. The region influenced by the atmospheric variability represented by the NAO index extends well beyond the Irminger Sea. Though the NAO index displays a substantial amount of short-term fluctuations, the spin-down and contraction of the subpolar gyre is likely a reflection of a long-term decline in the NAO index from its maximum in the early 1990s (see for example Figure 1d in Sarafanov, 2009). This is not very evident from the temporally limited PC timeseries in Figure 4-17, but it should not be surprising that the ocean and the atmosphere operate on different time scales.

\subsection{Transports}

Transports of the three primary features of interest, the Irminger Gyre, the Irminger Current, and the Western Boundary Current, have been estimated using the annually averaged 

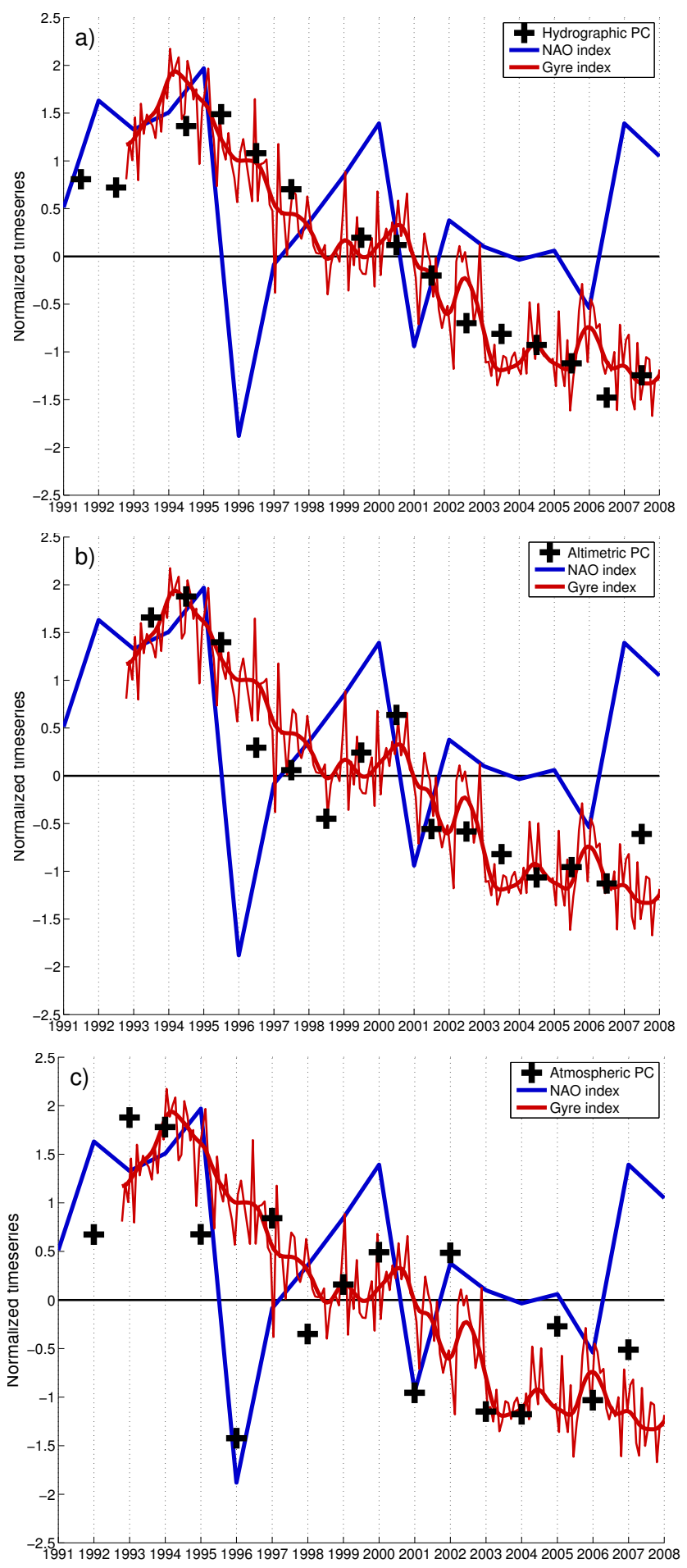

Figure 4-17: Principal components timeseries of the first EOF mode computed from a) annual mean hydrographic data (potential temperature, salinity, and potential vorticity), b) summer mean altimeter data (dynamic ocean topography and surface geostrophic velocity), and c) winter mean atmospheric reanalysis data (turbulent heat fluxes and wind stress curl). The blue and red timeseries are the NAO index and the gyre index of Häkkinen and Rhines (2004, 2009), respectively. 
absolute geostrophic velocity sections described above. In the following figures (Figs. 418 to 4-21) the black error bars represent the full uncertainty. This is a combination of the geoid error estimate and the AVISO reference velocity standard error, which are the two dominant error terms (Sec. 4.3.8). The geoid error is constant in time. ${ }^{4}$ The blue error bars represent only the AVISO standard error, which does vary from year to year, and hence is the only dominant error term that will directly impact the trend. The reader should keep in mind the extrapolation used to produce absolute geostrophic velocity sections for 1991 and 1992, and hence the increased uncertainty of the resulting transports.

\subsubsection{The Irminger Gyre}

The Irminger Gyre was typically located between 150 and $350 \mathrm{~km}$ along the AR7E line (Fig. 4-11c). Although it was present every summer, there was considerable interannual variability in terms of its width and magnitude. The transport was estimated from the northeasterly return flow to the east of the center of the gyre (assuming an equal return flow in the WBC). The resulting transport timeseries of the Irminger Gyre is presented in Figure 4-18. As noted above in Section 4.5 the magnitude of the gyre circulation increased through the observational period, which is confirmed by the trend of increasing transport at a rate of $4.3 S v$ per decade. The significance of the trend was found to be greater than $99 \%$ using the reverse arrangements test of Bendat and Piersol (1986). ${ }^{5}$ The mean Irminger Gyre transport through the full 17-year period was $6.8 \pm 1.8 S v$. An alternative way to compute the mean transport of the IG is directly from the temporally averaged absolute geostrophic velocity (Fig. 4-11c) instead of from the transport timeseries. The resulting mean transport estimate is lower, only $4.0 \pm 1.9 \mathrm{~Sv}$. This discrepancy exists because the location of the gyre changes from year to year as well as its strength. Hence the average of the individual timeseries values can be thought of as a "stream coordinate" mean.

\footnotetext{
${ }^{4}$ The geoid error will appear to have temporal variability as the width of the feature under consideration was not constant; for the same transport a broad and sluggish current will have a greater uncertainty than a narrow and swift current.

${ }^{5} \mathrm{~A}$ reversal in a sequence of observations of the variable $x$ occurs when $x_{i}>x_{j}$ for $i<j$. The reverse arrangements test is used to evaluate the significance of a trend based on how many such reversals take place relative to the number expected from pure chance with no trend.
} 


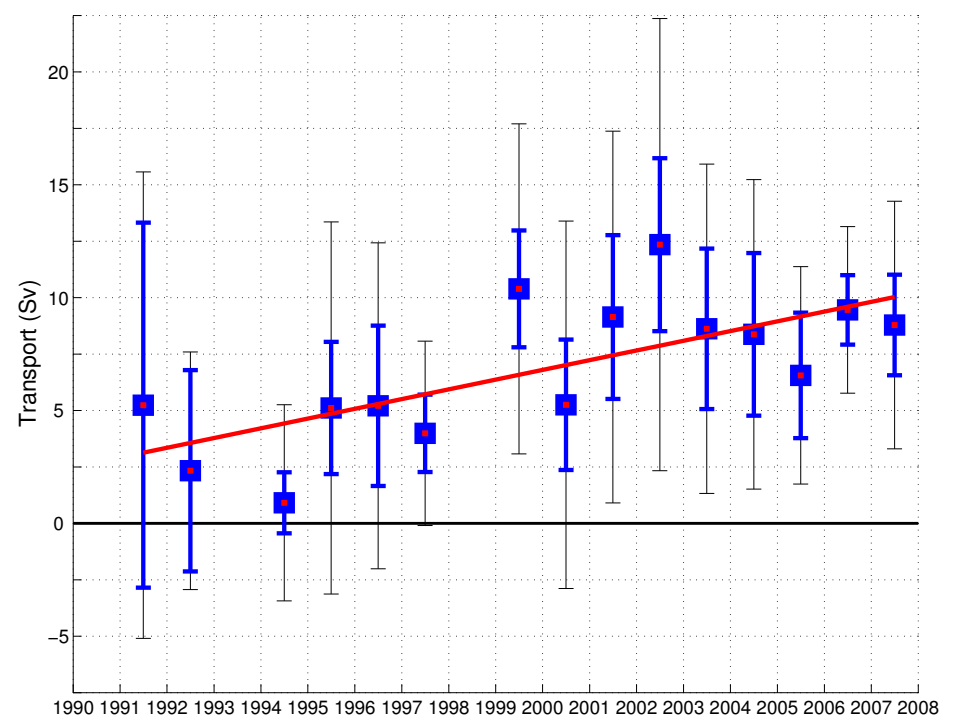

Figure 4-18: Irminger Gyre transport in $S v$. The black error bars indicate the total error, while the blue error bars show the AVISO standard error only. The red line is the least squares best fit through the data.

\subsubsection{The Irminger Current}

The Irminger Current is steered by the topography of the Reykjanes Ridge, and was typically found between 500 and $700 \mathrm{~km}$ along AR7E (Fig. 4-11c). The full-depth IC transport timeseries is displayed in Figure 4-19a. Surprisingly, we found a trend of increasing IC transport, which is contrary to the notion of a declining subpolar gyre circulation. There is, however, considerable interannual variability, and the $3.4 \mathrm{~Sv}$ per decade trend is significant only at the 92\% level. Removal of the high-uncertainty transport estimates from 1991 and 1992 referenced by extrapolated surface velocities does little to improve the significance of the trend. Closer inspection reveals that the positive trend is caused by a transport increase at depth. In fact, the transport in the upper $500 m$ decreased into the 2000s (Fig. 4-19b), consistent with the conclusions of Häkkinen and Rhines (2004, 2009). ${ }^{6}$ The deep transport increase in the IC (Fig. 4-19c) is largely the result of the emergence of the second deep extension of the IC noted in Section 4.5. The changing structure of the deep IC will be discussed more extensively in Section 4.8, including possible causes.

The mean of the full-depth IC transport timeseries was $20 \pm 3 \mathrm{~Sv}$. For comparison with

\footnotetext{
${ }^{6}$ Both the weakening trend of upper-layer transport and the strengthening trend of the deep transport were significant at better than the $95 \%$ confidence level.
} 

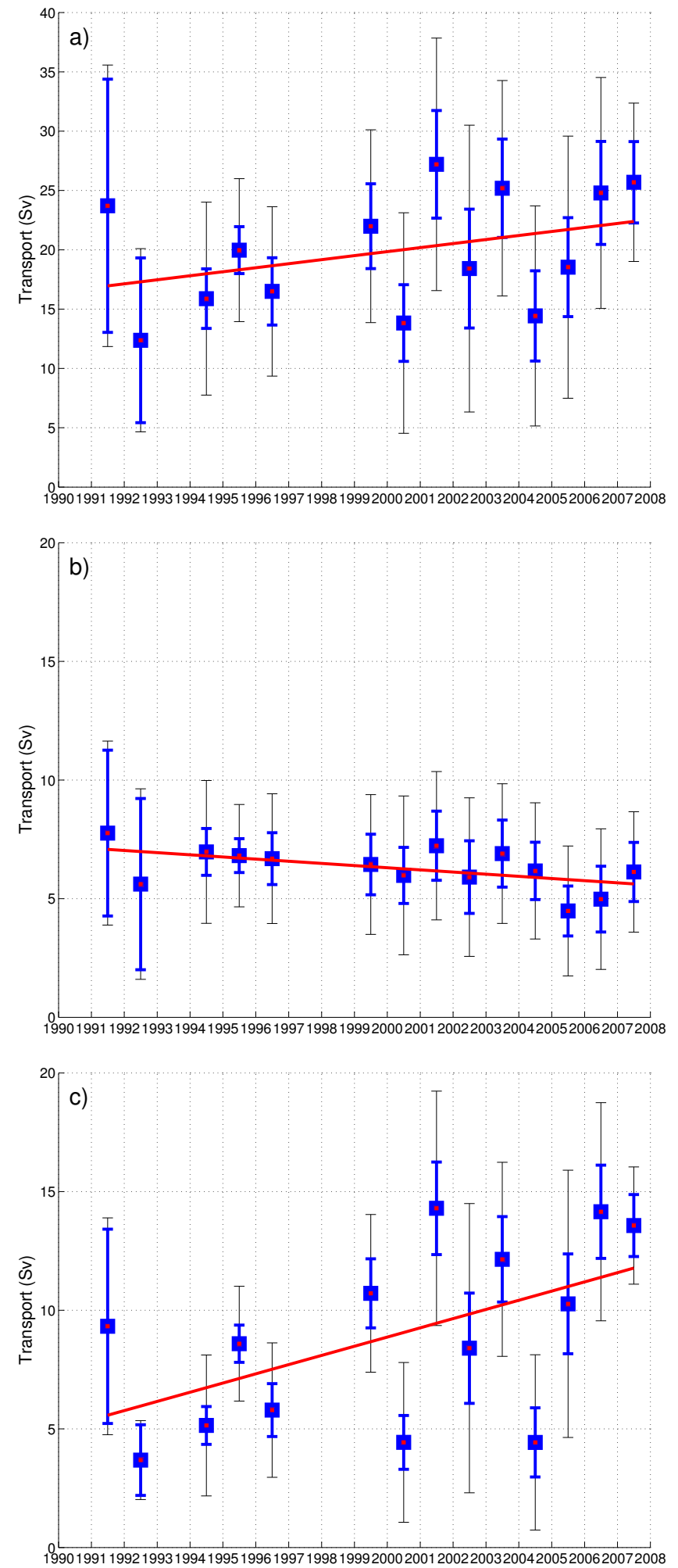

Figure 4-19: As Figure 4-18, but for the Irminger Current. a) Full IC transport, b) IC transport above $500 \mathrm{~m}$, and c) IC transport below $1000 \mathrm{~m}$. Note the different vertical scale in b) and c). 
previous estimates we also computed the transport of waters less dense than $\sigma_{\theta}=27.76$ $\mathrm{kg} / \mathrm{m}^{3}$ whose average value was $12 \pm 2 \mathrm{~Sv}$. The corresponding synoptic transport reported by Pickart et al. $(2005)^{7}$ for their August 2001 occupation was 13.7 Sv. While this is a bit larger than our average value, it compares well with our 2001 estimate of $14 \pm 6 \mathrm{~Sv}$. IC transports were also provided by Bacon (1997): $9 \mathrm{~Sv}\left(\sigma_{2}<36.873 \mathrm{~kg} / \mathrm{m}^{3}\right.$ in 1991) and Lherminier et al. (2009): $11 \pm 2 S v\left(\sigma_{2}<36.94 \mathrm{~kg} / \mathrm{m}^{3}\right.$ in both 2002 and 2004).

The IC transport computed directly from the temporally averaged vertical section of absolute geostrophic velocity (Fig. 4-11c) is $14 \pm 3 S v$. As was the case for the IG transports, this value is reduced compared to the temporal average of the discrete estimates presented above. In the IC case, however, meandering of the current is not the cause of this reduction; rather, it is due primarily to the significant changes in the current's deep structure, where pentadal flow reversals tend to reduce the deep northward transport (compare Figures 4-13 $c$ and d).

\subsubsection{The Western Boundary Current system}

We consider the Western Boundary Current (WBC) to be the southward flow bounded by the Greenland shelfbreak to the west (30 km along AR7E) and the deepest part of the Irminger Gyre in the east (typically located around $280 \mathrm{~km}$, see Fig 3-10). The bottom of the Irminger Gyre (sometimes it extended all the way to the bottom) is close to the deepest point of the Irminger Basin, and thus our definition of the WBC is in general agreement with that of Holliday et al. (2009), although they also included the outer part of the Greenland shelf in their calculations. In 1995 the section did not extend farther onshore than to 50 $\mathrm{km}$. To compensate for the missing part of the WBC transport that year, the mean transport between 30 and $50 \mathrm{~km}(-3.2 \mathrm{~Sv})$ was added to the 1995 estimate, and the error was increased by the standard deviation of the mean transport within the given interval $(1.9 S v)$. As the DWBC does not extend inshore of $50 \mathrm{~km}$, it is not affected by the modification to the 1995 velocity section.

Traditionally, all of the southward flow on the western side of the Irminger Basin is

\footnotetext{
${ }^{7}$ Pickart et al. (2005) also provides a list of previous, unreferenced IC transport estimates, none of which exceed $10 \mathrm{~Sv}$.
} 
taken into account in estimates of WBC transport. For comparison with previous results we have computed WBC transports in the same fashion, hereafter called southward WBC transport. We will, however, emphasize timeseries of WBC transport with the IG return flow removed, which is referred to as the net WBC transport. The net WBC transport is the throughput of the boundary current system, hence the more appropriate quantity to consider.

The net surface to bottom WBC average transport (Fig. 4-20) was $-32 \pm 4 S v$ (keep in mind that southward transports are negative). There is a slight indication of weakening of the $\mathrm{WBC}$, but the trend is not significant. The range of interannual variability was $15 \mathrm{~Sv}$. When considering the southward WBC transport, the average transport is larger, $-39 \pm 4$ $S v$. Interestingly, there was a significant trend of increasing southward WBC transport of $-3.0 S v$ per decade. However, this is predominantly because the Irminger Gyre spun up over this time period (by $4.3 S v$ per decade, see above). Hence there was little or no trend in net transport. In the case of the WBC there was good agreement between the mean transport computed from the transport timeseries and from the temporally averaged vertical section of absolute geostrophic velocity (-37 \pm 3 Sv, Fig. 4-11c). This was expected given the lack of WBC spatial variability and changing structure, unlike the IG and IC cases above.

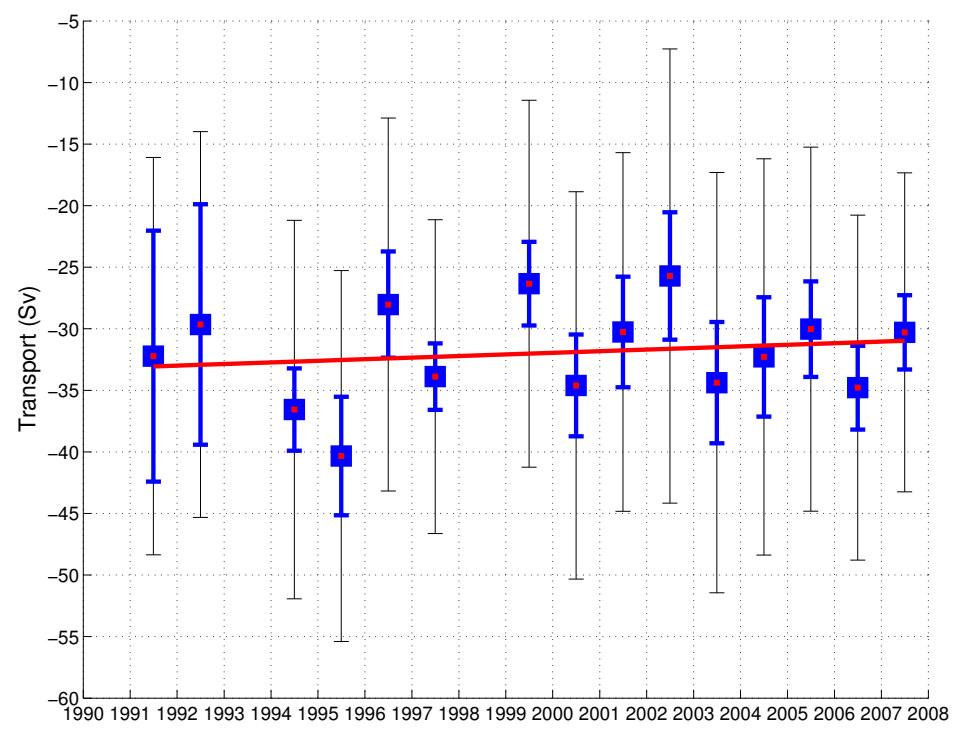

Figure 4-20: As Figure 4-18, but showing net Western Boundary Current transports.

Our southward WBC transport $(-39 \pm 4 S v)$ compares well with a recent estimate 
by Holliday et al. (2009), who reported a transport of $-40.5 \pm 8.1 S v$ in August-September 2005. Earlier surface to bottom estimates from the southern Irminger Sea and Cape Farewell region include: -33.5 Sv (2-month current meter records from 1978, Clarke, 1984), -32.2 $S v$ (ADCP-referenced synoptic section from 1991, Bersch, 1995), -26.5 Sv (inverse model constrained by ADCP data from 1991, Bacon, 1997), and -39.0, -31.6, and -34.9 Sv (also an inverse model constrained by ADCP data, from 1997, 2002, and 2004, respectively, Lherminier et al., 2007, 2009). Our result is in the upper range of the previous transport estimates.

\subsubsection{The Deep Western Boundary Current}

Given its importance to the MOC, we have considered the DWBC component $\left(\sigma_{\theta}>27.80\right.$ $\mathrm{kg} / \mathrm{m}^{3}$ ) of the WBC, which is composed of the DSOW and ISOW. To compensate for the bottom triangle error (see Section 4.3.8), we have added 0.3 and $1.4 S v$ to the total errors of the ISOW and DSOW layers, respectively (estimated from the average $0.18 \mathrm{~Sv}$ per $36 \mathrm{~km}$ bottom triangle error and the mean distance over which each layer is in contact with the bottom). As in the case of the WBC we emphasize net transports (although for the DSOW layer, into which the IG only sporadically reached, the difference between southward and net transports is minimal).

The net DWBC average transport (Fig. 4-21) was $-9.6 \pm 1.3 \mathrm{~Sv}$. This can be split into $-7.3 \pm 1.0 S v$ and $-2.4 \pm 0.4 S v$ for the ISOW and DSOW components, respectively. During the 17-year observational period the net DWBC transport increased at a rate of -1.4 $S v$ per decade (the trend was significant at a level higher than 95\%). Using southward DWBC transport estimates relative to a level of no motion at $1000 \mathrm{~m}$, Sarafanov et al. (2009a) found a similar significant trend of increasing baroclinic transport over the same time period. Combining altimetry-derived surface velocities and baroclinic velocities from hydrographic data Sarafanov et al. (2009b) determined that the absolute DWBC transport increased as well between the mid-1990s and the mid-2000s, consistent with our results. A trend of increasing DWBC transport in the Labrador Sea from the late 1990s to the early 2000s was reported by Dengler et al. (2006). Extending their timeseries using equiv- 
alently computed baroclinic transports from Bacon (1998), a robust negative correlation between DWBC transport anomalies and LSW thickness anomalies was detected, such that decreasing LSW thickness is associated with enhanced DWBC transport. This relationship was found farther south (west of the Grand Banks of Newfoundland) as well by Pickart et al. (1999). Sarafanov et al. (2009a,b) hypothesize that complex and coherent oceanic responses to the NAO-modulated atmospheric forcing that influences (among other things) the convective activity and subpolar gyre circulation may regulate the relationship between LSW thickness and DWBC transport.

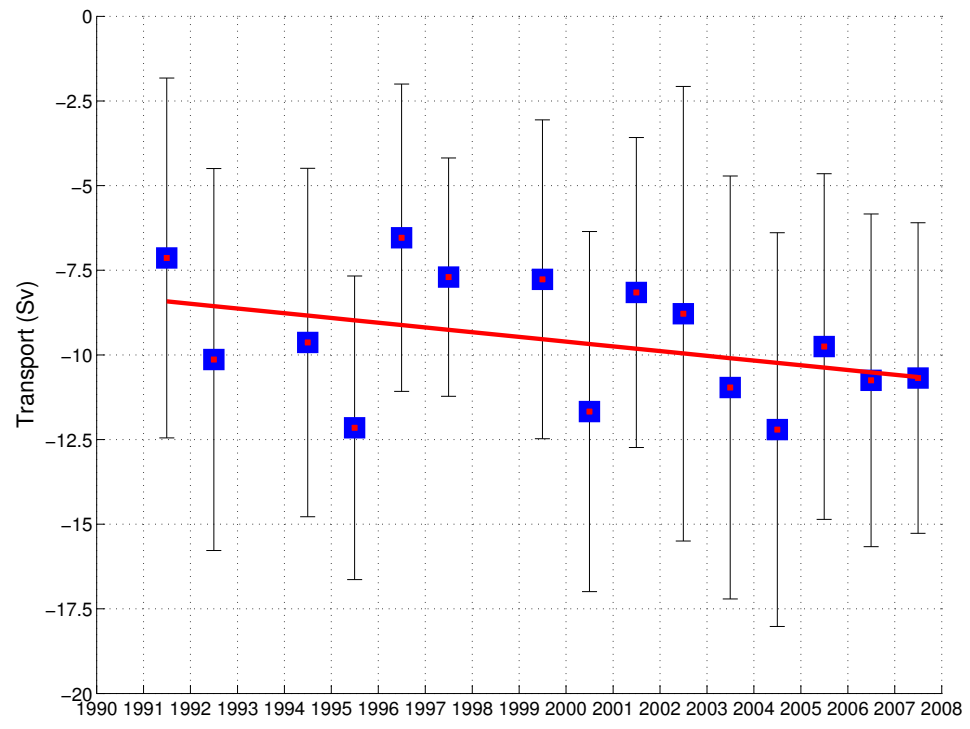

Figure 4-21: Net Deep Western Boundary Current transport in $S v$. The black error bars indicate the total error (including estimated bottom triangle error), and the red line is the least squares best fit through the data.

For the full DWBC we obtain a mean southward transport of $-11.4 \pm 1.2 \mathrm{~Sv}$. This estimate is well within the range of previous synoptic absolute DWBC transports of -7.3 to -13.3 Sv for the southern Irminger Sea and Cape Farewell region (e.g. Clarke, 1984; Dickson and Brown, 1994; Bersch, 1995; Lherminier et al., 2007, 2009; Holliday et al., 2009). 


\subsection{Convection}

The traditional hypothesis describing the LSW formation process, proposed by McCartney and Talley (1982), argues that LSW is the end-product of "subpolar mode waters" that are continuously densified via air-sea interaction within the cyclonic flow around the subpolar gyre. This culminates with deep convection in the Labrador Basin, forming the weakly stratified LSW. In contrast, a growing body of evidence shows that deep convection can also take place in the Irminger Sea during particularly severe winters, leading to a second location of LSW formation (e.g. Pickart et al., 2003a,b; Bacon et al., 2003; Falina et al., 2007; Våge et al., 2008, 2009a). These studies have underscored the importance of small-scale oceanic (the Irminger Gyre) and atmospheric (the westerly Greenland tip jet) features that conspire to provide conditions favorable for deep convection in the southwestern Irminger Sea, and suggest that high spatial resolution may be necessary to understand the convective process in this region.

Despite this body of evidence, recent studies argue that the LSW signature in the Irminger Basin is principally due to advection from the Labrador Sea on the time scale of $\sim 2$ years, with little or no local convection east of Greenland. One such study (Bersch et al., 2007) presents evidence that there has been an intermediate salinity maximum layer continuously present in the Irminger Sea since 1991, implying that deep overturning could not have occurred during this time period. In the present section we examine this issue using the collection of AR7E sections. To further elucidate the issue of local versus remote ventilation, we use a volumetric T-S approach applied by Yashayaev (2007) to the Labrador Basin. We find strong evidence that deep convection occurred in the Irminger Basin during the early 1990s. Furthermore, we identify a separate signal of remotely-formed LSW advected into the Irminger Sea from the west.

\subsubsection{Intermediate salinity maximum layer}

One of the pieces of evidence used to discount the notion of local convection in the Irminger Sea stems from the recent analysis of Bersch et al. (2007). They used time series obtained from a subset of the AR7E hydrographic sections averaged between $34-41^{\circ} \mathrm{W}$ (i.e. the full 
width of the deep Irminger Basin, Fig. 4-3) to investigate changes in the characteristics and distribution of LSW in the Irminger Sea. Computing the temporal changes of salinity relative to $1991\left(\Delta S_{91}\right)$, they found a layer of positive $\Delta S_{91}$ at a density of approximately $\sigma_{1}=32.38 \mathrm{~kg} / \mathrm{m}^{3}\left(\sigma_{1.5}=34.655 \mathrm{~kg} / \mathrm{m}^{3}\right.$, between 600 and $\left.1200 \mathrm{db}\right)$ that was continuously present since 1991 (Fig. 4-22, right). This layer coincides with the Icelandic Slope Water intermediate salinity maximum that separated the lower and upper LSW water masses of the 2001-05 pentad (Fig. 4-12d, see also Holliday et al., 2009). Bersch et al. (2007) interpreted this as evidence that there was no significant formation of the densest class of LSW in the Irminger Sea, even during the high-NAO period of the early 1990s. They argued that, had there been convection, fresh surface water would have penetrated the $\sigma_{1}=32.38 \mathrm{~kg} / \mathrm{m}^{3}$ isopycnal causing an interruption of the positive $\Delta S_{91}$ layer.
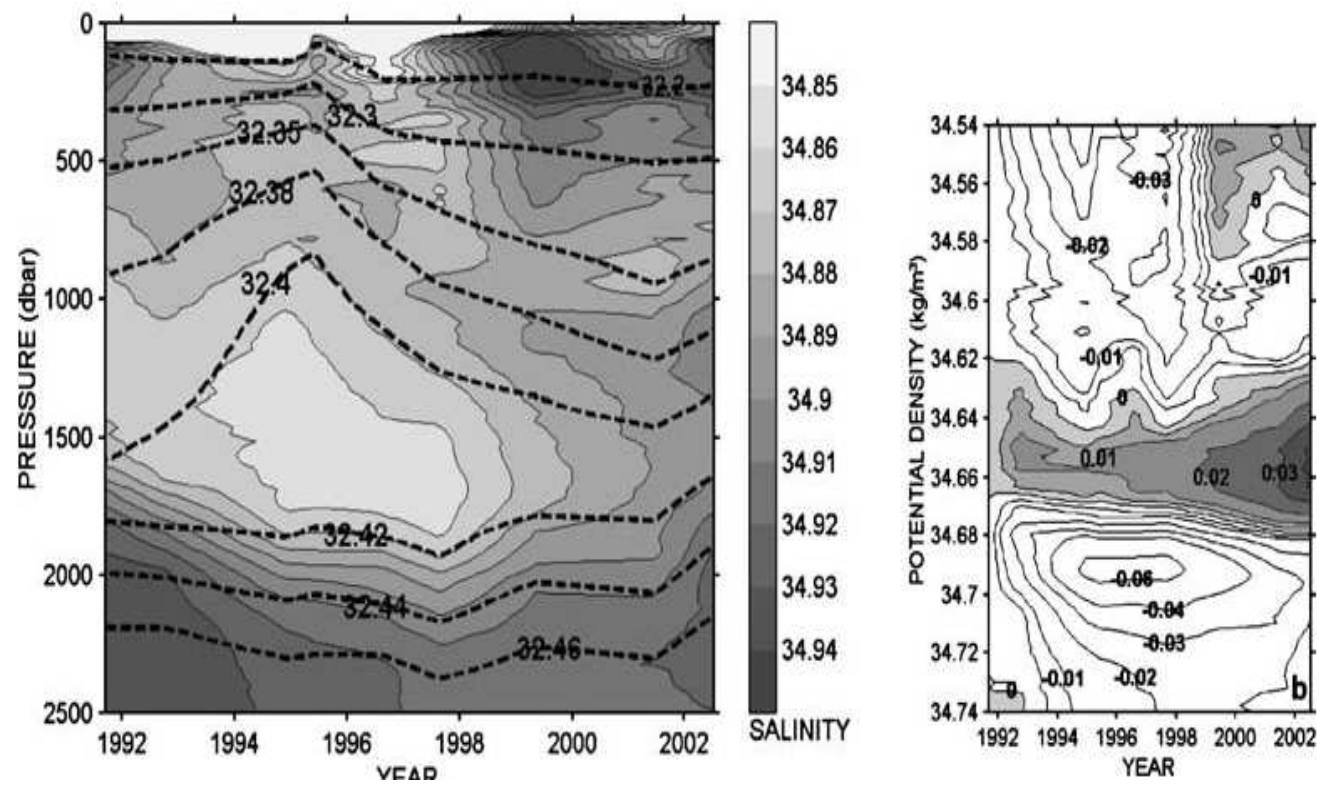

Figure 4-22: Temporal changes (left) of salinity (shaded) and density ( $\sigma_{1}$, contours) and (right) salinity relative to 1991 (positive values are shaded) on density surfaces $\left(\sigma_{1.5}\right)$. Both figures are based on data averaged between $33-41^{\circ} \mathrm{W}$, and have been copied from Bersch et al. (2007).

It is important to note that Bersch et al. (2007) averaged properties over the entire deep Irminger Basin, from the base of the Greenland continental slope to the western flank of the Reykjanes Ridge (Fig 4-3). However, if deep convection occurs in the Irminger Sea, it is likely to take place primarily within the southwestern portion of the basin (Pickart et al., 2003a,b; Centurioni and Gould, 2004). This region is under direct influence of the 
cyclonic Irminger Gyre and the Greenland tip jet, and is the part of the Irminger Sea where the oceanic and atmospheric conditions are most favorable for deep overturning. With this in mind, we re-did the calculation of Bersch et al. (2007) using hydrographic data confined to the location of the IG along AR7E $(150-350 \mathrm{~km}$, see Fig 3-10c; the results are not very sensitive to the exact limits).

A different result from Bersch et al. (2007) is obtained when the data are confined geographically as such. Figure 4-23a shows the temporal evolution of salinity and potential density. In agreement with Bersch et al. (2007), the peak of the LSW dome occurred in 1995. By 2001 it had collapsed (see also Fig. 4-12d). However, when considering only the western portion of the Irminger Basin within the IG, the isopycnal doming was much more pronounced (compare Figures 4-22, left, and 4-23a). In particular, the $\sigma_{1.5}=34.63 \mathrm{~kg} / \mathrm{m}^{3}$ contour that, according to Bersch et al. (2007), delimits the density of locally formed water masses reached a minimum pressure of approximately $230 \mathrm{db}$ in 1995 . Keep in mind that the data used here were collected in summer. It is highly unlikely that the mixed layer depth in this region did not exceed $230 d b$ during the winter of 1994-95 (during the high-NAO period). This suggests strongly that the ILSW layer was locally ventilated. Mixed layers deeper than $400 \mathrm{db}$ were routinely observed by profiling floats ${ }^{8}$ and moorings during the winters of the early 2000s, which, unlike the early 1990s, were characterized by a low NAO index and a well-stratified water column (Centurioni and Gould, 2004; Våge et al., 2008, 2009a; Louarn et al., 2009). Furthermore, our calculation of $\Delta S_{91}$ using hydrographic data from within the IG does indeed show an interruption of the positive $\Delta S_{91}$ layer between 1994 and 1996, which again suggests that ILSW was formed during this period. This calculation reinforces the arguments made to date that, under strong atmospheric forcing, deep convection can occur in the Irminger Sea. It also illustrates some of the subtleties involved in investigating convection in that basin.

\subsubsection{Labrador Sea Water layer thickness}

Encouraged by the above results showing that deep convection likely occurred in the western Irminger Sea in the early 1990s, but realizing that LSW was also likely advected out of

\footnotetext{
${ }^{8}$ Argo floats were not present in the early 1990 s.
} 

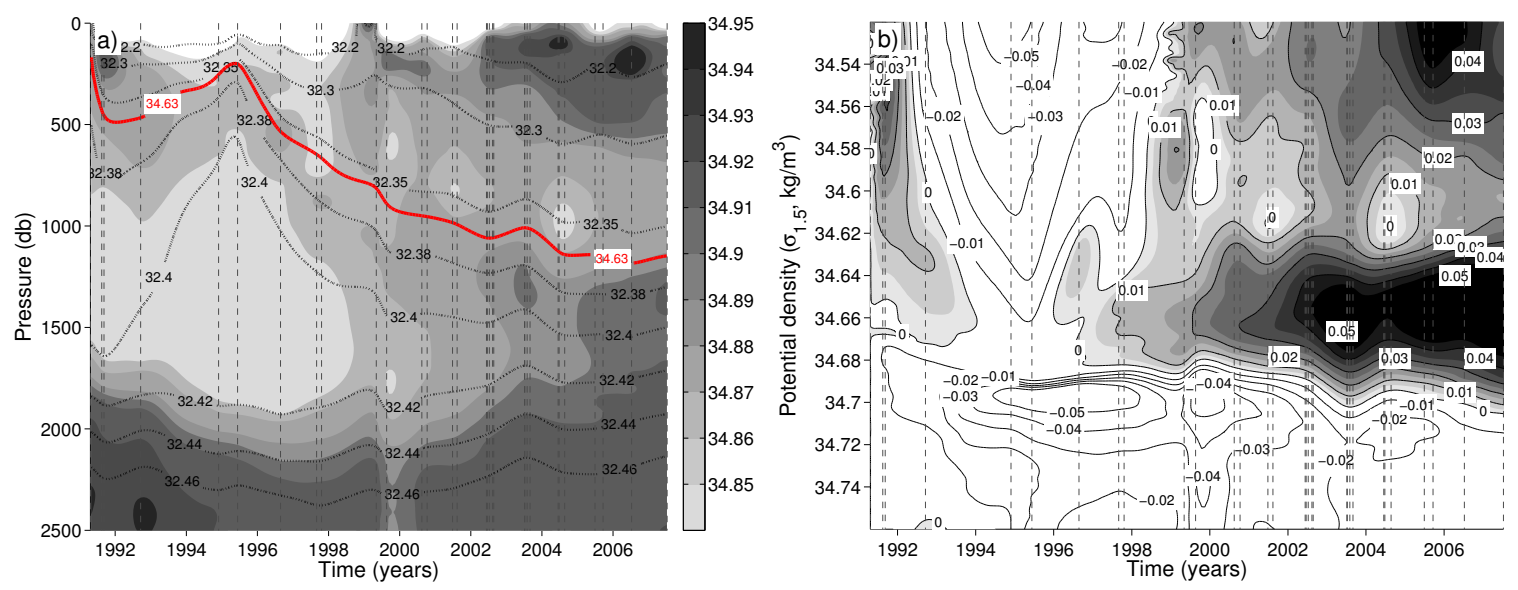

Figure 4-23: As in Figure 4-22, but based on data from within the IG. The dashed lines indicate when measurements were made. The $\sigma_{1.5}=34.63$ contour is highlighted in red.

the Labrador Sea to the east, we studied in greater detail the evolution of the LSW inside and outside of the Irminger Gyre. The LSW core was identified following the volumetric density layer approach of Yashayaev (2007). The method involves calculation of the thickness of a continuum of potential density $\left(\sigma_{2}\right)$ layers. A mean vertical density profile for each section within the chosen lateral boundaries was first determined. The vertical extent (thickness) of every layer of width $\Delta \sigma_{2}=0.01 \mathrm{~kg} / \mathrm{m}^{3}$ was then computed. Individual layers were separated by $0.002 \mathrm{~kg} / \mathrm{m}^{3}$. The LSW core was then easily identified by the density layer of largest thickness. An advantage of this method is its ability to take into account changes in water mass properties since it does not rely on time-invariant hydrographic bounds to identify the water mass.

The spreading of LSW from the Labrador Sea was investigated by Pickart et al. (2003b) using the advective-diffusive model of Straneo et al. (2003), which was based on a realistic flow field determined from float measurements containing the interior recirculations in the Labrador and Irminger seas (Lavender et al., 2000). In agreement with recent observationally based estimates (e.g. Yashayaev, 2007; Falina et al., 2007), the time for LSW to travel from the Labrador Basin to the central Irminger Basin was approximately 2 years. Once inside the Irminger Sea, the model tracer was observed to wrap around the Irminger Gyre (Straneo et al., 2003), taking another year to penetrate to the gyre's center (Pickart et al., 2003b). The LSW formed in the Labrador Basin is in general colder, fresher, and denser than the LSW formed locally in the Irminger Sea (Pickart et al., 2003b). Hence 
we expect that the arrival of the remote LSW will present an unmistakable signal in the Irminger Sea LSW timeseries derived from the volumetric approach. Furthermore, the strongest remotely-formed LSW signal should occur outside of the gyre (i.e. to the east of the northward limb of the gyre).

As a first calculation we applied the volumetric method to the center of the Irminger Gyre, between 200 and $300 \mathrm{~km}$ along AR7E. These narrow bounds (on average the gyre was located between 150 and $350 \mathrm{~km}$ ) were chosen to avoid contamination from LSW outside of the gyre, but the outcome is not very sensitive to this particular choice. The resulting average layer thickness versus time and density is shown in Figure 4-24.

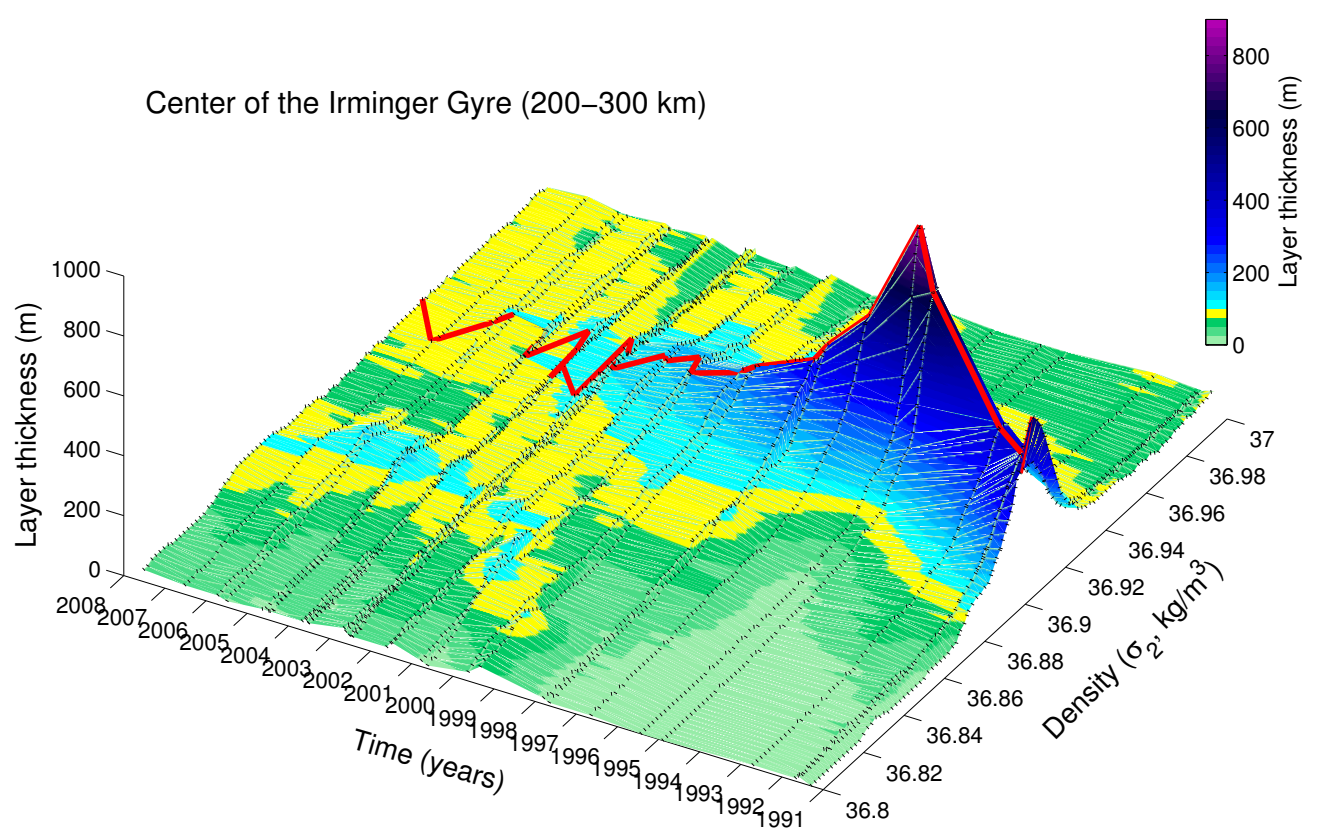

Figure 4-24: Average thickness (in $m$ ) of potential density layers within the Irminger Gyre (100$200 \mathrm{~km}$ along AR7E) in relation to potential density $\left(\sigma_{2}, \mathrm{~kg} / \mathrm{m}^{3}\right)$ of the given layer and time (years). The vertical extent of each overlapping layer was $0.01 \mathrm{~kg} / \mathrm{m}^{3}$, and individual layers were separated by $0.002 \mathrm{~kg} / \mathrm{m}^{3}$. The red line follows the crest of the thickness ridge and hence identifies the lLSW core in each section. The dashed lines indicate when individual sections were made.

The most notable feature in Figure 4-24 is the LSW dome that reached its greatest volume in 1995 (in good agreement with Figure 4-23a and Bersch et al., 2007). As previously mentioned, this agrees well with the modeled mixed layer depth in the winter of 1994-95 exceeding $1700 \mathrm{~m}$ (Våge et al., 2008). Indeed, the bottom of the thickest $1995 \sigma_{2}$ level was found at a depth of $1730 \mathrm{~m}$ in summer 1995 (Fig. 4-25b). In contrast, the densest water 
in the ILSW class was formed in the Labrador Sea in the winter of 1993-94 (Yashayaev, 2007), although ILSW formation did not shut down until after the following winter (e.g Avsic et al., 2006). Had the LSW observed inside the Irminger Gyre been ventilated remotely in the Labrador Sea, one would expect to see the thickest LSW layer at the center of the gyre at the earliest three years later, in 1997. At this time, however, the Irminger Gyre ILSW dome was already collapsing. Timeseries of ILSW core properties within the Irminger Gyre are shown in Fig. 4-25. One sees a single extremum in the layer thickness, salinity, and temperature. (We note that even though the layer thickness started declining immediately in 1996, the temperature and salinity remained low for one more year, perhaps due to some amount of remotely-formed LSW penetrating the gyre.)
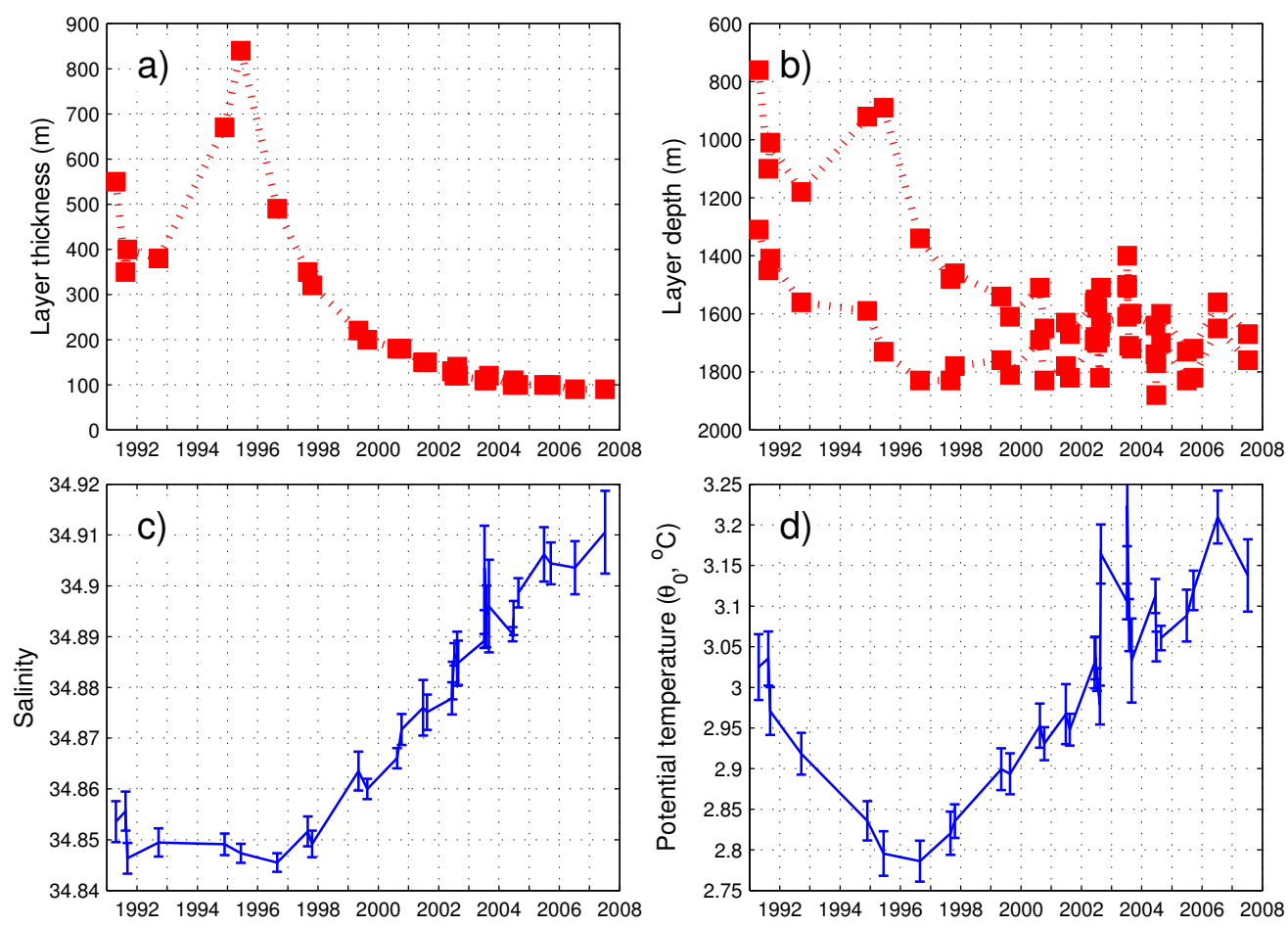

Figure 4-25: Timeseries of core ILSW properties. a) Layer thickness $(m)$. b) Upper and lower bounds of the layer in a). c) Salinity. d) Potential temperature $\left({ }^{\circ} \mathrm{C}\right)$. One standard deviation is indicated by the error bars.

Note also the arrival of the shallower LSW mode around 2000. While not as prominent as in the Labrador Sea (see Figure 6a in Yashayaev, 2007), some uLSW evidently formed also within the Irminger Gyre. The thickness of the uLSW layer appears to have increased substantially between 2004 and 2005, perhaps due to arrival of uLSW from the Labrador 
Sea.

Now we contrast the results from the volumetric density layer calculation within the Irminger Gyre to that outside of the gyre. Figure 4-26 corresponds to Figure 4-24, but is obtained using data from the eastern part of the Irminger Basin, between 400 and $500 \mathrm{~km}$ along AR7E. The bounds were chosen such that the domain was well outside the Irminger Gyre, while still to the west of the Irminger Current. The difference between the two figures is striking. The ILSW dome is much smaller in magnitude (the maximum ILSW thickness was about $500 \mathrm{~m}$ compared to more than $800 \mathrm{~m}$ inside the gyre), but now there is a second peak in 1997. This is seen more clearly in the timeseries of layer thickness, salinity, and temperature outside of the gyre (Fig. 4-27). In contrast to the center of the gyre, there are now two extrema in these properties. The timing of the second peak (1997) is consistent with a 2-3 year time lag from the Labrador Sea. Furthermore, the second peak is colder, fresher, and deeper, consistent with the more extreme properties of the LSW formed in the Labrador Basin. Finally, the mean absolute velocity section for the pentad of the early 1990s (Fig 4-13c) shows northeastward flow in the region outside of the gyre (between 400 and $500 \mathrm{~km}$ ), consistent with a remote pathway from the Labrador Sea. We note that the earlier LSW peak implies some degree of local convection outside of the gyre, which was observed in winter 2007-08 (Femke de Jong, personal communication, 2008).

To summarize, we have demonstrated that inside of the Irminger Gyre there was no mid-depth salinity maximum layer that indicated a limit to the depth of local convection in the early 1990s. Instead there was a single peak of ILSW in 1995, too early to be a remote signal from the maximum convection year in the Labrador Sea (1994). However, outside of the gyre there were two maxima. The timing and properties of the latter peak are indeed only reconcilable with a remote Labrador Sea source, and consistent as well with the velocity field.

\subsection{Discussion}

We found above that the Irminger Gyre circulation had intensified between the early 1990s and the early 2000s, with the transport increasing at a rate of $4.3 S v$ per decade. This 


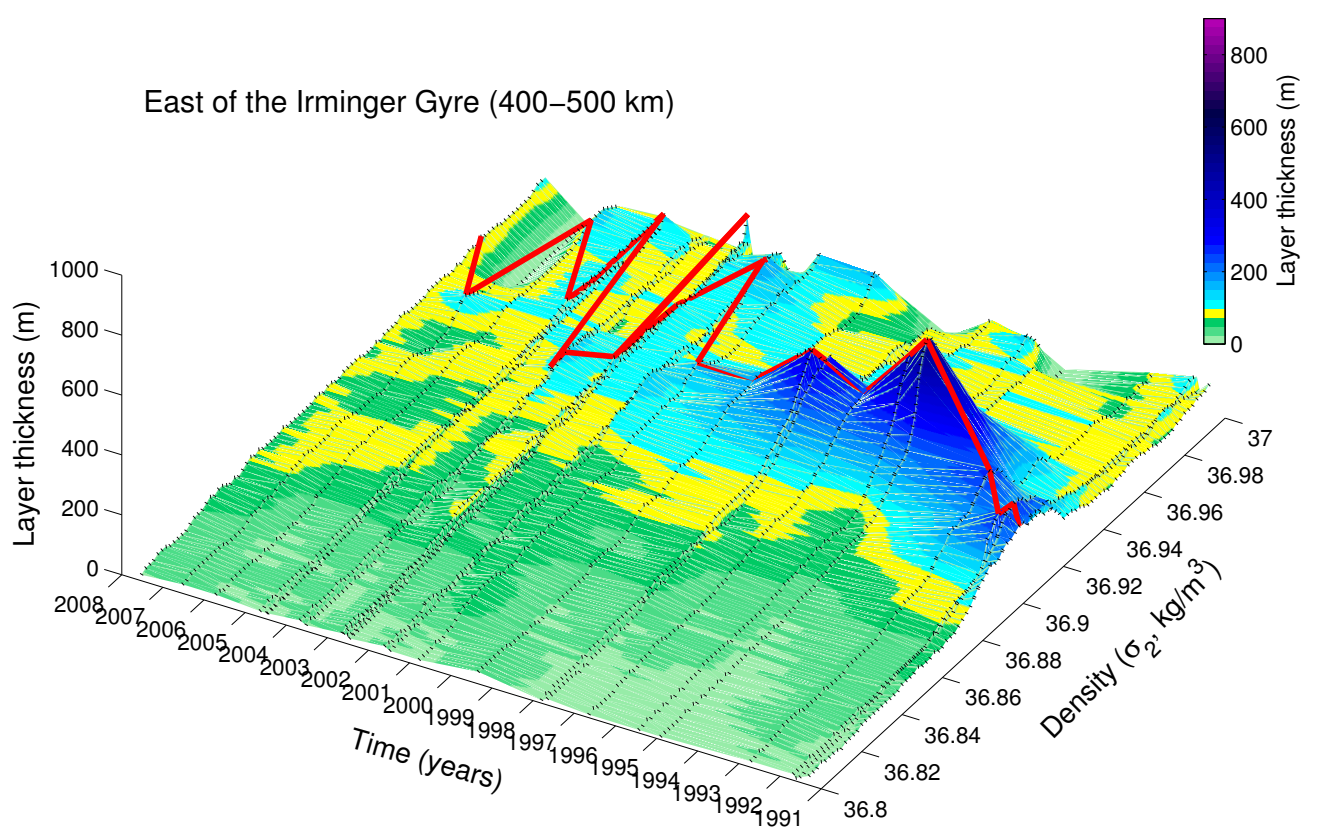

Figure 4-26: As Figure 4-24, but for the region east of the Irminger Gyre between 400 and $500 \mathrm{~km}$ along AR7E.
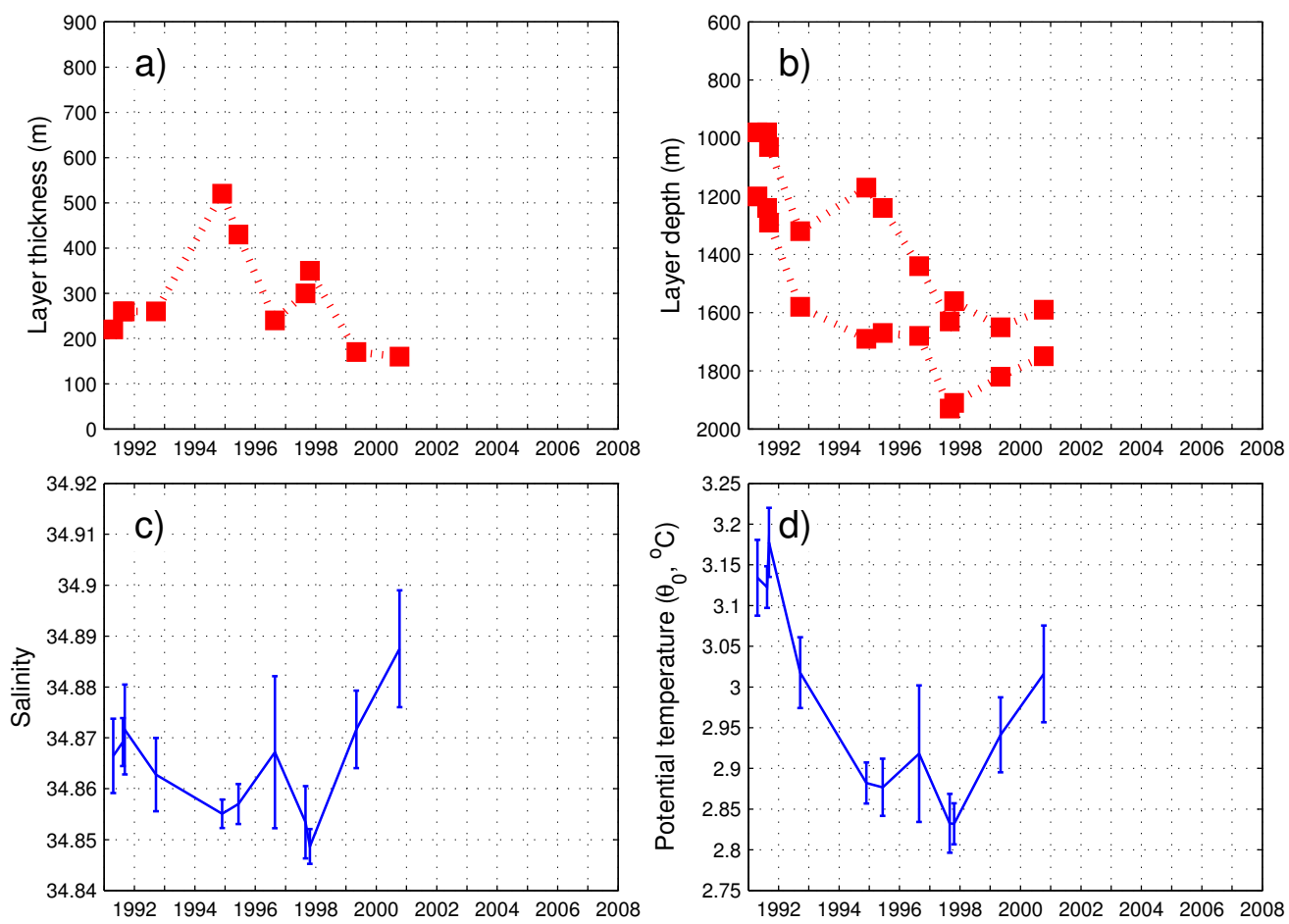

Figure 4-27: As Figure 4-25, but for the region east of the Irminger Gyre between 400 and 500 $\mathrm{km}$ along AR7E. The timeseries were cut before 2001 since reliable detection of the ILSW was no longer feasible (the noisy 2000s signal is evident in Figure 4-26). 
was unexpected given the general decline in atmospheric forcing that occurred through the period of observations. Inspection of the AVISO dynamic ocean topography field revealed that the general increase in SSH across the entire subpolar gyre was not uniform within the Irminger Sea, but that the eastern half of the basin rebounded to a greater degree than the western, leading to a steeper gradient across the IG and hence the stronger circulation (Fig. 4-16). Analysis of the AR7E hydrographic data indicate that part of the SSH change was due to steric height differences. In particular, from the early 1990s to the early 2000s the steric height in the eastern part of the Irminger Basin increased more rapidly than in the western part, consistent with the evolution of absolute SSH. This suggests that the restratification process leading to the collapse of the ILSW dome was more pronounced on the eastern side of the basin, which is not surprising due to the presence of the buoyant Irminger Current next to the Reykjanes Ridge.

As ILSW formation ceased and the subpolar gyre contracted through the 1990s (e.g. Häkkinen and Rhines, 2004), increased flow of warm, saline subtropical water into the eastern part of the North Atlantic ensued (Hátún et al., 2005). This in turn affected the hydrographic properties of the IC. In order to influence the interior Irminger Sea, the Atlantic-origin water must be fluxed out of the boundary current. Lateral exchange between the boundary current and the interior, typically in the form of mesoscale eddies, has been extensively investigated in the eastern Labrador Sea (e.g. Lilly et al., 2003; Straneo, 2006). A similar process likely takes place in the eastern Irminger Sea as well. A second mechanism leading to restratification is transport by baroclinic Rossby waves. In the subpolar North Atlantic the internal deformation radius is on the order of $10 \mathrm{~km}$ (Chelton et al., 1998). Accordingly, baroclinic Rossby waves would be able to cover the distance between the IC and the IG in less than 10 years. Though we did not see clear evidence of such a westward-propagating signal in the hydrographic data, it could be masked by synoptic variability or the competing effect of a cold, fresh influx along the spreading pathway of LSW from the Labrador Sea. If westward propagation was the primary mechanism of the IG intensification, the assumption of mass balance between the northward and southward branches of the gyre may be called into question. In this case water masses to the southeast of the originally defined northward limb of the gyre may flow northward alongside the gyre 
but not recirculate within the gyre.

Even though intensification of the IG circulation through a period of diminishing wind stress curl appears paradoxical, there is not necessarily a contradiction between our findings and the model results of Spall and Pickart (2003). Their model gyre was exposed to wind forcing during winter only, yet the circulation was maintained with minimal seasonal variability. An important aspect in this was the slow propagation speed of the baroclinic Rossby waves, which results in a long response time of the Irminger Gyre. As such, one would expect the gyre to start spinning down as it slowly adjusts to the present reduced level of forcing. Clearly this needs further investigation.

The disappearance of the potential vorticity (PV) anomaly between the early 1990s and the early 2000s (Fig. 4-13) provides an opportunity to estimate the diffusion coefficient directly from observations using the diffusion equation

$$
\frac{D \tau}{D t}=K \nabla^{2} \tau
$$

where $\mathrm{K}$ is the diffusion coefficient and $\tau$ is the tracer quantity of interest, in this case PV. The change in PV at the LSW level within the IG over the 10-year period and the Laplacian of the PV field between the IG and the IC were approximated from Figure 413 , resulting in a diffusion coefficient of about $160 \mathrm{~m}^{2} / \mathrm{s}$. For comparison, the diffusion coefficient was also evaluated using the parametric representation of Visbeck et al. (1997). Guided by baroclinic instability theory, Visbeck et al. (1997) proposed a transfer coefficient (corresponding to the diffusion coefficient) of the form

$$
K=\alpha \frac{f}{\sqrt{R i}} l^{2}
$$

where $\alpha$ is a proportionality constant (empirically found to be 0.015 ), $f$ is the Coriolis parameter, $R i=N^{2} /(d v / d z)^{2}$ is the Richardson number of the large-scale flow, and $l$ is a length scale measuring the width of the baroclinic zone. The mixing length scale was estimated from the Rhines scale $(\sqrt{U / \beta}$, Rhines, 1975) using a characteristic current speed of $0.1 \mathrm{~m} / \mathrm{s}$, resulting in approximately $90 \mathrm{~km}$ in the subpolar North Atlantic. The quantity $f / \sqrt{R i}$ is the growth rate of an Eady instability (Eady, 1949), and the physical basis for 
the transfer coefficient is the product of an eddy velocity $f l / \sqrt{R i}$ and a length scale $l$. As such, the mean Visbeck et al. (1997) transfer coefficient in the IG was $180 \mathrm{~m}^{2} / \mathrm{s}$, and approximately one third of this value if the LSW layer is considered separately. This result is in surprisingly good agreement with the coefficient estimated from the diffusion equation (Eq. 4.1), but below the range of 300-2000 $\mathrm{m}^{2} / \mathrm{s}$ calculated by Visbeck et al. (1997). They found the minimum value in a convective chimney, under conditions very similar to the weakly stratified LSW layer considered here. The good agreement between the coefficients stemming from the diffusion equation and the parametric representation may suggest that the form proposed by Visbeck et al. (1997) is a reasonable representation of eddy transfer, assuming that eddy diffusion was the primary mechanism leading to the collapse of the LSW dome. It is, however, unlikely that advection did not play a role as well.

A structural change in the deep Irminger Current was observed between the early 1990s and the early 2000s (Fig. 4-13). In the first pentad there was primarily a single deep extension of the IC located near the crest of the Reykjanes Ridge, while in the latter pentad a second deep extension of the current emerged farther down the ridge near the $2500 \mathrm{~m}$ isobath. This latter feature carried the bulk of the deep IC transport in the early 2000s, and was chiefly responsible for the overall increase in top to bottom IC transport noted above. The hydrographic properties of the two extensions differ (this is evident in Figure 4-12). While still of Atlantic origin, the water transported by the western deep extension is colder and fresher than that in the eastern, which suggests that the two deep extensions have different origins.

Such a notion is consistent with synoptic hydrographic surveys of the eastern North Atlantic (e.g. Read, 2001; Pollard et al., 2004) and subsurface float data (Bower et al., 2002). These studies have revealed that there are two distinct pathways from the North Atlantic Current to the Irminger Current. The outer pathway follows the boundary of the subpolar gyre around the rim of the Iceland Basin, while the inner pathway bifurcates from the North Atlantic Current near $30^{\circ} \mathrm{W}$ and flows northward, bypassing the Iceland basin. Near the southeastern corner of the Irminger Basin the two pathways merge to form the Irminger Current and proceed jointly northwards along the western flank of the Reykjanes Ridge. Using hydrographic data, Pollard et al. (2004) demonstrated that these pathways 
shifted between 1991 and 1996, apparently due to the contraction of the subpolar gyre. It is not unreasonable to think that the relative strengths of these two pathways may change in time as well, and that the increasing flow observed in the western IC extension could be a reflection of the large-scale changes that took place throughout the subpolar gyre from the early 1990 s to the early 2000 s.

\subsection{Summary and conclusions}

Significant changes took place in the subpolar North Atlantic between the early 1990s and early 2000s. Associated with a significant weakening in the atmospheric forcing, the formation of lower LSW in the Labrador Sea all but ceased, and the subpolar gyre circulation slowed and contracted.

In this study we analyzed a collection of 32 hydrographic transects across the southern Irminger Sea from the period 1991 to 2007. The dramatic changes that took place in the broad subpolar region are reflected in the Irminger Sea hydrographic data. Most notable is the collapse of the lower LSW dome that reached peak volume in 1995. An EOF analysis identified these changes as the primary mode of variability, and demonstrated a high degree of coherence between the subpolar gyre index of Häkkinen and Rhines (2004) calculated from North Atlantic SSH levels and the evolution of the local Irminger Sea hydrography.

From absolute geostrophic velocity sections referenced using satellite altimetry, we quantified for the first time some of the characteristics of the Irminger Gyre, a closed, cyclonic recirculation in the western Irminger Sea. The mean transport of the gyre was 6.8 $\pm 1.8 \mathrm{~Sv}$, and over the 17-year study period the transport of the gyre increased at a rate of 4.3 Sv per decade. This increase was associated with a steeper sea level gradient, which is partially due to changes in steric height. In particular, buoyant water, presumably fluxed from the Irminger Current, enhanced the restratification process in the eastern Irminger Basin. This is consistent with the increased presence of subtropical-origin water in the Irminger Current during the second half of the study period, related to the contraction of the subpolar gyre.

Consistent with the notion of a declining subpolar gyre, the upper layer transport of 
the Irminger Current decreased over the study period. However, the full-depth transport of the current increased due to the emergence of a second deep extension of the IC. Relative changes between two separate pathways that contribute to the IC may have affected this development. The mean northward full-depth IC transport was estimated to $20 \pm 3 S v$. On the western side of the basin the mean net southward full-depth Western Boundary Current transport was $-32 \pm 4 S v$ (this is the equatorward throughput, as the southward limb of the IG has been subtracted out). For the DWBC (denser than $\sigma_{\theta}>27.8 \mathrm{~kg} / \mathrm{m}^{3}$ ) we determined a mean net transport of $-9.6 \pm 1.3 \mathrm{~Sv}$, in good agreement with previous estimates. Consistent with other studies in both the Irminger and Labrador seas we found that the DWBC flow increased through the study period.

Recognizing the importance of sub-basin scale variation in the atmosphere and ocean in regard to convection in the Irminger Sea, we examined the hydrographic data both inside and outside of the Irminger Gyre, respectively. We demonstrated that the intermediate salinity maximum purportedly placing a limit on the depth of convection in the Irminger Sea (Bersch et al., 2007) was not continuously present within the IG. Furthermore, through a volumetric analysis of the ILSW layer within the Irminger Gyre, we found a single maximum in layer thickness in 1995, too early to be a remote signal from the Labrador Sea. In contrast, outside of the gyre there were two lLSW layer thickness peaks. The first (in 1994) was likely caused by local convection, while the second (in 1997) is only reconcilable in timing and properties with a remote Labrador Sea source. We believe that our results thus

clarify the relative roles of local versus remote convection in contributing to the presence of LSW in the Irminger Sea.

\subsection{Acknowledgments}

We are grateful to Øyvind Knutsen, Artem Sarafanov, Herlé Mercier, Pascale Lherminier, Manfred Bersch, Hendrik van Aken, Jens Meincke, Detlef Quadfasel, Kevin Thompson, Tom Rossby, and Sirpa Häkkinen for sharing their data, and to Norbert Verch and Jan Even Øie Nilsen for assistance with the data assembly. This manuscript has benefited from discussions with Julie Deshayes, Artem Sarafanov, Mike Spall, Fiamma Straneo, Carl 
Wunsch, David Fratantoni, Rui Ponte, Guoqi Han, Tatiana Rykova, Wilken-Jon von Appen, Beatriz Peña-Molino, Sheldon Bacon, and Kevin Thompson. The altimeter products were produced by SSALTO/DUACS and distributed by AVISO, with support from CNES (http://www.aviso.oceanobs.com/duacs/). The GRACE Tellus dynamic ocean topography product was obtained from the Jet Propulsion Laboratory (http://grace.jpl.nasa.gov/data/dot/). 


\section{Chapter 5}

\section{Conclusions and Discussion}

In this thesis deep convection and Labrador Sea Water (LSW) formation in the subpolar North Atlantic have been investigated, with special emphasis on the Irminger Sea and the small-scale atmospheric and oceanic processes influencing local overturning. Some of the main results are: (i) small-scale atmospheric (the westerly Greenland tip jet) and oceanic (the Irminger Gyre) features are of fundamental importance to deep convection in the Irminger Sea, (ii) deep mixed layers in the Irminger Sea were for the first time documented in winter 2007-08, and the reasons why the overturning took place were elucidated, and (iii) the competing signals of local versus remote formation of LSW were clarified and distinguished, suggesting that LSW was formed in the Irminger Sea in the early 1990s. ${ }^{1}$

\subsection{Ramifications of LSW formation in the Irminger Sea}

If LSW is indeed formed outside of the Labrador Sea, this alters our current understanding of the convective process in the subpolar North Atlantic. Presently, there exists in the literature a wide range of LSW formation rates (e.g. Pickart and Spall, 2007; Haine et al., 2008), due in part to different methods of estimation and definitions of LSW, as well as the variability of convective activity. This has made assessment of LSW production problematic. An additional source of LSW further compounds this difficulty, making it harder to quantify other aspects of LSW formation such as spreading rates and ventilation times.

\footnotetext{
${ }^{1}$ Please refer to Chapters 2-4 for more detailed conclusions and discussions.
} 
The notion of LSW formation in the Irminger Sea entails a new perspective in which to interpret both observations and model results, including a reassessment of the influence of LSW on NADW formation and the Meridional Overturning Circulation (MOC).

Another potential ramification is that convection in the Irminger Sea could have a more direct impact on the weather and climate in northwestern Europe than convection in the Labrador Sea. Given its closer proximity to the North Atlantic storm track and the Icelandic Low, release of heat through convection in the southwestern Irminger Sea may to a greater extent energize the cyclones that subsequently track towards Europe. On the other hand, proper resolution of tip jets, which are responsible for the greatest heat fluxes from the Irminger Sea, does not seem to have a large impact on European weather in a numerical weather prediction model (Jung and Rhines, 2007).

\subsection{Comparison with hindcast simulations}

In this section, difficulties associated with modeling the subpolar North Atlantic are discussed. The results of recent hindcast simulations compared to observations follows, with a special emphasis on convection in the Irminger Sea. Finally some suggestions to improve the realism of the simulations are provided.

High-resolution general circulation model (GCM) hindcasts face difficult challenges in the subpolar North Atlantic. In particular, small hydrographic contrasts between water masses are dynamically important, but difficult to maintain (e.g. Treguier et al., 2005; Haine et al., 2008). Few models realistically reproduce the observed hydrographic properties (e.g. Treguier et al., 2005; de Jong et al., 2009), and it was recently found that the GCM used by Yaeger and Jochum (2009) was unable to accurately simulate characteristics of both water mass properties and gyre circulation simultaneously, which may have a bearing also on other simulations. Indeed, most of the recent high-resolution GCM runs investigated by Treguier et al. (2005) did produce a realistic circulation, but were not close to the observed temperature and salinity fields. In the subpolar North Atlantic, a realistic simulation of the hydrographic properties takes on greater importance through the formation of LSW and its impact on climate and the MOC. 
Excessive convection is a common problem to many models, and tends to result from a lack of restratification (Treguier et al., 2005; Haine et al., 2008; de Jong et al., 2009). Direct simulation of eddy fluxes through further increase in resolution is likely the only way to overcome this issue. The Nordic seas overflows, in particular their magnitude and the amount of entrainment and mixing associated with their descent from the GreenlandIceland-Scotland sills, are also currently difficult to realistically reproduce. Very high horizontal and vertical resolution is required, in particular in the region where the overflows descend and are modified by ambient waters. However, this is not yet possible with the currently available computational power (Haine et al., 2008). This undoubtedly has an effect on the realism of the hindcasts, and may alter the sensitivity of the MOC to the rate of LSW formation in the subpolar gyre common to most simulations.

A set of recent hindcast simulations (e.g. Hátún et al., 2005; Treguier et al., 2005; Böning et al., 2006; Deshayes and Frankignoul, 2008) have reproduced the overall decline of the subpolar gyre circulation documented by Häkkinen and Rhines (2004), as well as the reduced levels of convective activity since the mid-1990s. This is consistent with the results of Chapter 4 , as is the increase in temperature and salinity resulting from greater volumes of subtropical water in the eastern North Atlantic following the contraction of the subpolar gyre (Bersch et al., 2007; Sarafanov, 2009). However, while these large-scale features have been realistically simulated, the modeled hydrographic properties deviate significantly from measured values (Treguier et al., 2005; de Jong et al., 2009). Salinity drift is a particularly difficult problem to solve (e.g. Treguier et al., 2005).

As an explicit example, consider the location and depth of convection in the western subpolar gyre. Deep convection in the Irminger Sea was reported in several studies (e.g. Treguier et al., 2005; Deshayes et al., 2007). However, close inspection of the hindcast analyzed by Deshayes et al. (2007) reveals that the convection took place in the northeastern Irminger Sea, in the vicinity of the boundary current. According to the observed potential vorticity structure and levels of atmospheric forcing (Pickart et al., 2003b), this is not where deep convection takes place in the Irminger Sea. Indeed, the LSW formation in the early 1990s investigated in Chapter 4 took place inside the Irminger Gyre in the southwestern Irminger Sea. This difference in location may seem subtle, but turns out to have consid- 
erable consequences. Deshayes and Frankignoul (2008) found the MOC to be impacted more strongly by convection in the Irminger Sea than in the Labrador Sea. However, in their model, convection in the Irminger Sea took place adjacent to the boundary current, and hence immediately influenced the DWBC and thereby the MOC. In contrast, in the Labrador Sea convection took place within a recirculation gyre, where it was to a greater degree retained and prevented from affecting the MOC. These results highlight the importance of understanding precisely where and how deep convection occurs in the subpolar gyre - including the Irminger Sea.

In order to produce more realistic hindcasts from the Irminger Sea and more properly assess its importance, increased resolution in both models and the atmospheric products used to force the models is very likely of key importance. Not only will a fully eddyresolving model be capable of more accurately simulating the depth of convection through proper preconditioning and restratification via eddy fluxes, the small scale features important to convection in the Irminger Sea (the westerly Greenland tip jet and the Irminger Gyre) will also be properly included.

\subsection{Effects of an intensifying Irminger Gyre circulation}

The intensification of the Irminger Gyre (IG) through the 16-year period 1991-2007, documented in Chapter 4, is likely to have had an influence on the convective activity in the Irminger Sea. The obvious notion is that a stronger gyre would result in deeper convection. For instance, a stronger circulation would tend to increase the gyre's ability to retain water convected in previous winters, and thus enhance the preconditioning for the following winter. In concert with greater isopycnal doming, the stronger gyre circulation would hence be conducive for deep convection. However, this scheme does not agree with the observed trend of LSW formation, whereby deep convection took place in the early 1990s during the weaker gyre state, while there was no LSW formation during the subsequent intensifying phase of the IG. This discrepancy can to a great extent be explained by the much stronger buoyancy forcing during the first pentad of the 1990s (Fig. 4-14). Furthermore, during the deep convection in winter 2007-08, the deepest mixed layers were observed farther east in 
the Irminger Basin, outside of the IG (Chapter 3 and Femke de Jong, personal communication, 2008). Although the circulation was stronger that winter, the degree of isopycnal doming was much reduced compared to the early 1990s (Fig. 4-13). This suggests that the presence of a recirculation gyre may not have been overly important to convection in winter 2007-08, in part due to the lack of preconditioning. As cyclonic circulation is one of the criteria for open-ocean convection listed by Marshall and Schott (1999), its importance to deep convection in the Irminger Sea needs to be investigated further. The importance of small-scale features to deep convection in the Irminger Sea may imply that these criteria are less applicable in that region.

The intensity of the Irminger Gyre would also have an influence on the spreading of LSW from the Irminger Sea. A stronger gyre would to a greater extent trap the water parcels inside. As discussed above, this is conducive to deep convection, but at the same time would also limit the influence of the convected water outside of the gyre. Despite the inaccuracy of the location of deep convection in the GCM hindcast analyzed by Deshayes and Frankignoul (2008), it serves to illustrate the difference between convection inside and outside a recirculation gyre. In the Labrador Sea, deep convection mainly took place within the gyre, which tended to retain the convected product. In contrast, in the Irminger Sea convection took place outside the gyre in the vicinity of the boundary current, and as a result LSW from the Irminger Sea was directly exported via the DWBC, resulting in a strong influence on the MOC in their model. Clearly convected waters in or near the boundary currents are more easily exported from the convective region. ${ }^{2}$

The distribution of LSW in the subpolar North Atlantic has been mapped by several authors (e.g. Talley and McCartney, 1982; Straneo et al., 2003; Yashayaev et al., 2007a), and is a result of convective activity in both the Labrador and Irminger basins. In particular, the presence of the recirculation gyres leads to a two-way exchange of LSW between the Labrador and Irminger seas (Lavender et al., 2000; Spall and Pickart, 2003), which is in contrast to the Labrador Sea-centric view of LSW spreading solely from the Labrador Sea into the Irminger Sea. In fact, Kvaleberg et al. (2008) found that the observed distribution

\footnotetext{
${ }^{2}$ Convection within the western boundary current of the Labrador Sea has been observed (Pickart $e t$ al., 2002) and modeled (Deshayes and Frankignoul, 2008), but the properties of the resulting water mass are less extreme than for convection in the interior.
} 
of LSW is in better agreement with sources both in the Labrador and Irminger seas than with a single source in the Labrador Sea. The effects of LSW formation in the subpolar gyre are communicated to the outside via spreading in the DWBC and along interior pathways, and through its impact on the MOC and meridional heat transport. Hence the influence of LSW formation is not merely a regional phenomenon in the subpolar North Atlantic.

\subsection{Meridional heat transport and a changing climate}

Meridional heat transport by the Atlantic MOC is of significant importance for the climate of the northern hemisphere, in particular northwestern Europe (e.g. Vellinga and Wood, 2002). Numerous examples suggest that changes in the MOC will have climatic consequences. Past abrupt climate change documented in paleoclimatic records has been linked with changes in ocean circulation (e.g. Heinrich, 1988; Dansgaard et al., 1993; Rahmstorf, 2002; McManus et al., 2004). These events appear to have been centered in the subpolar North Atlantic, but their effects were felt globally. Such episodes are not limited to the past. Of more immediate concern are model studies suggesting that the convective activity in the subpolar region and the MOC are sensitive to anthropogenic climate change (e.g. Gregory et al., 2005; Stouffer et al., 2006).

In this section the meridional heat transport and overturning circulation in the current climatic state is first discussed. Various mechanisms likely to impact the MOC in a warming climate are then subsequently considered. The section concludes with a discussion of the time interval of observations likely required to detect a trend resulting from a changing climate, and an outlook on future work in this region.

The MOC in the presently evolving climatic state

Northward heat transport into the North Atlantic peaks at $1.3 \mathrm{PW}\left(1 \mathrm{PW}=10^{15} \mathrm{~W}\right.$, e.g. Hall and Bryden, 1982) in the subtropics. Decomposing the overturning circulation into three separate components; shallow, intermediate, and deep, where the latter two are associated with LSW and NADW formation, respectively, Talley (2003) found that as much as one third is accounted for by LSW formation. In contrast, Pickart and Spall (2007) 
estimated an intermediate northward heat flux an order of magnitude smaller than this from repeat hydrographic sections across the Labrador Sea. They found that the heat flux resulted predominantly from the horizontal rather than the overturning circulation. In Pickart and Spall (2007), only the northern half of the Labrador Sea was included. This is the region where greatest convective activity and largest heat loss is expected to occur, but a significant amount also takes place outside the Labrador Sea, in particular in the Irminger Sea, which was not accounted for in their study.

The generally shallower depths of convection in the subpolar gyre after the mid-1990s are indicative of a reduced heat loss to the atmosphere, and would tend to imply a decline in the poleward oceanic heat transport. The resulting contraction of the subpolar gyre, on the other hand, led to an increase in the temperature of the Atlantic inflow to the Nordic seas (Holliday et al., 2008), which would enhance the heat loss there. One may speculate that there is a compensation between reduced heat loss in the subpolar North Atlantic and increased heat loss in the Nordic seas and vice versa. The poleward heat transport through the Atlantic may therefore remain relatively steady, but the distribution of heat would change significantly, and likely have an impact on the climate of northwestern Europe. This line of reasoning assumes that there is not heat accumulation, which in all probability is not correct.

Intensification of the MOC occurred in many regional GCMs during the high-NAO period ending in the mid-1990s (e.g. Böning et al., 2006; Deshayes and Frankignoul, 2008). However, this is not the case in the ECCO state estimate at $24^{\circ} \mathrm{N}$ (Wunsch and Heimbach, 2006). There are a number of possible reasons for this discrepancy. On interannual time scales a lack of meridional coherence between the subpolar and subtropical Atlantic MOC was noted by Bingham et al. (2007), and convective activity in the subpolar North Atlantic is poorly represented in the ECCO model (Schott and Brandt, 2007; de Jong et al., 2009). Despite reduced rates of LSW formation since the early 1990s, the DWBC intensified (see Chapter 4 and Pickart et al., 1999; Dengler et al., 2006; Sarafanov et al., 2009b). This has not been noted in regional hindcast simulations, which tend to underestimate the overflow transport and entrainment, and may therefore attribute excessive influence on the MOC to LSW formation. Or it may simply be that the MOC is, in fact, not very sensitive to the rate 
of LSW formation in the subpolar gyre (Pickart and Spall, 2007).

\section{Mechanisms impacting convective activity and the MOC}

In the present warming climate the convective activity in the subpolar North Atlantic is expected to diminish, which would likely impact the MOC (e.g. Stouffer et al., 2006). Both surface warming and freshening, caused by Arctic and Greenland ice melt and an intensifying hydrological cycle, would contribute to stabilize the water column. The distribution of this freshwater matters greatly. In fact, in Chapter 3 it was shown that a certain amount of freshwater along the margins of the Labrador Sea was beneficial to deep convection in the interior in winter 2007-08. The increased stability of the water column led to enhanced local formation of ice, which shielded the boundary currents from air-sea interaction and consequently opened a pathway for unmodified cold, dry continental air to the interior convective region. During that winter the primary influx of fresh water was trough the Davis Strait, impacting mainly the northern and western margins of the Labrador Sea. This was not the case, however, during the Great Salinity Anomaly (GSA, Dickson et al., 1988), where a much larger influx of freshwater capped the interior Labrador Sea with a lowsalinity layer that prevented deep convection from taking place for several winters (Lazier, 1980). The GSA entered the Labrador Sea via the West Greenland Current, which is believed to be the dominant pathway of freshwater into the interior of the basin (Schmidt and Send, 2007).

Local factors are not the only agents influencing the convective activity in the subpolar North Atlantic. The origin of the GSA was the Arctic Ocean. A change in the atmospheric circulation was the most likely cause of the sudden release of fresh water that had been accumulating there. A similar release of fresh water presently accumulating in the Arctic Ocean may lead to another GSA (Peterson et al., 2006). Its export out of the Arctic via the East Greenland Current may have similar consequences for the convective activity when it reaches the subpolar gyre. In order to affect interior convection, a mechanism of exchange between the boundary current and the interior is required. Enhanced, topographically generated eddy activity in the West Greenland Current promotes exchange in the Labrador 
Basin (e.g. Bracco et al., 2008), but no corresponding mechanism has been identified for the Irminger Sea, which may thus be less affected by a new GSA. Remote influence also from the subtropics in the form of sea surface temperature and heat anomalies has been suggested (e.g. Sutton and Allen, 1997). A concern is that this source of variability is excluded from regional GCMs.

\section{Detection of trends signifying climate change}

The changes in the subpolar gyre's circulation, extent, and hydrographic properties reported in this thesis and elsewhere (e.g. Häkkinen and Rhines, 2004; Bersch et al., 2007; Sarafanov, 2009) that have taken place since the early 1990s are not sufficient to infer a long-term trend associated with a change in global climate. Rather, these changes are more likely associated with the atmosphere's NAO-modulated variability. ${ }^{3}$ The observed variability may be considered a superposition of the oceanic response to atmospheric variability and a long-term trend stemming from a slowly changing climate. In this case more than one cycle of prolonged NAO increase or decline (such as the one that took place between the mid-1960s and the present, Sarafanov, 2009) must be observed, implying a need for timeseries of at least multi-decadal if not centennial duration (see, for instance, Wunsch, 1999). Baehr et al. (2008) made an attempt to quantify the duration of observations required to reliably detect a change in the MOC at $26^{\circ} \mathrm{N}$ in the Atlantic. They found that continuous observations and repeated hydrographic transects every 5 years would both require a period of about 90 years to detect a weakening of the MOC with $95 \%$ reliability. This may be a relevant time scale to keep in mind for detection of a trend signifying a change in climate in the subpolar North Atlantic as well.

Even though the subpolar North Atlantic is among the most well-observed parts of the World Ocean, there is still much that remains uncertain about this region and its influence on global climate. Most model simulations display a delayed coherence between LSW formation and the vigor of the MOC, while observation-based analyses produce opposing results (e.g. Talley, 2003; Pickart and Spall, 2007). Focusing on LSW, estimates of forma-

\footnotetext{
${ }^{3} \mathrm{~A}$ divergence between the NAO index and an index describing the subpolar gyre circulation over the last decade was noted by Hátún et al. (2009). The large difference between the two high-NAO winters of 2006-07 and 2007-08 discussed in Chapter 3, in which deep convection took place only during the latter, is consistent with that.
} 
tion rates and spreading time scales have not converged, and the Irminger Sea source must be taken into account. In particular, the relative importance of the Labrador Sea versus the Irminger Sea as a source of LSW should be determined. Sustained observations, both from space and in situ, will be of crucial importance. Further increase in model resolution should improve the realism of regional hindcasts and state estimates, in which model physics and observations are combined. As a particularly climate-sensitive part of the World Ocean, the Irminger Sea and the subpolar North Atlantic continue to warrant close observation. 


\section{Bibliography}

Álvarez M, Pérez FF, Bryden H, Ríos AF. 2004. Physical and biogeochemical transports structure in the North Atlantic subpolar gyre. Journal of Geophysical Research 109: C03 027, doi:10.1029/2003JC002015.

Avsic T, Karstensen J, Send U, Fischer J. 2006. Interannual variability of newly formed Labrador Sea Water from 1994 to 2005. Geophysical Research Letters 33: L21S02, doi:10.1029/2006GL026913.

Bacon S. 1997. Circulation and fluxes in the North Atlantic between Greenland and Ireland. Journal of Physical Oceanography 27: 1420-1435.

Bacon S. 1998. Decadal variability in the outflow from the Nordic seas to the deep Atlantic Ocean. Nature 394: 871-873.

Bacon S, Gould WJ, Jia YL. 2003. Open-ocean convection in the Irminger Sea. Geophysical Research Letters 30: 1246, doi:10.1029/2002GL016 271.

Baehr J, Keller K, Marotzke J. 2008. Detecting potential changes in the meridional overturning circulation at $26^{\circ} \mathrm{N}$ in the Atlantic. Climatic Change 91: 11-27, doi:10.1007/s10 584-006-9153-z.

Bakalian F, Hameed S, Pickart RS. 2007. Influence of the Icelandic Low latitude on the frequency of Greenland tip jet events: Implications for Irminger Sea convection. Journal of Geophysical Research 112: C04 020, doi:10.1029/2006JC003 807.

Bendat JS, Piersol AG. 1986. Random data: Analysis and measurement procedures. Wiley: New York, NY, Second edn. 
Bengtsson L, Hodges KI, Hagemann S. 2004. Sensitivity of the ERA-40 reanalysis to the observing system: Determination of the global atmospheric circulation from reduced observations. Tellus 56A: 456-471.

Bersch M. 1995. On the circulation of the northeastern North Atlantic. Deep Sea Research 42: $1583-1607$.

Bersch M, Yashayaev I, Koltermann KP. 2007. Recent changes of the thermohaline circulation in the subpolar North Atlantic. Ocean Dynamics 57: 223-235, doi:10.1007/s10236007-0104-7.

Bingham RJ, Hughes CW, Roussenov V, Williams RG. 2007. Meridional coherence of the North Atlantic meridional overturning circulation. Geophysical Research Letters 34: L23 606, doi:10.1029/2007GL031 731.

Böning CW, Scheinert M, Dengg J, Biastoch A, Funk A. 2006. Decadal variability of subpolar gyre transport and its reverberation in the North Atlantic overturning. Geophysical Research Letters 33: doi:10.1029/2006GL026906.

Bower AS, Le Cann B, Rossby T, Zenk W, Gould J, Speer K, Richardson PL, Prater MD, Zhang HM. 2002. Directly measured mid-depth circulation in the northeastern North Atlantic Ocean. Nature 419: 603-607.

Bower AS, Lozier S, Gary SF, Böning CW. 2009. Interior pathways of the North Atlantic meridional overturning circulation. Nature 459: doi:10.1038/nature07979.

Bracco A, Pedlosky J, Pickart RS. 2008. Eddy formation near the west coast of Greenland. Journal of Physical Oceanography 38: 1992-2002, doi:10.1175/2008JPO3669.1.

Bryan FO, Böning CW, Holland WR. 1995. On the midlatitude circulation in a highresolution model of the North Atlantic. Journal of Physical Oceanography 25: 289-305.

Cassou C, Terray L, Hurrell JW, Deser C. 2004. North Atlantic winter climate regimes: Spatial asymmetry, stationarity with time, and oceanic forcing. Journal of Climate 17: $1055-1068$. 
Centurioni LR, Gould WJ. 2004. Winter conditions in the Irminger Sea observed with profiling floats. Journal of Marine Science 62: 313-336.

Chelton DB, deSzoeke RA, Schlax MG, El Naggar K, Siwertz N. 1998. Geographical variability of the first baroclinic Rossby radius of deformation. Journal of Physical Oceanography 28: 433-460.

Chelton DB, Schlax MG, Freilich MH, Milliff RF. 2004. Satellite measurements reveal persistent small-scale features in ocean winds. Science 303: 978-983.

Clarke RA. 1984. Transport through the Cape Farewell - Flemish Cap section. Rapp. P.-V. Réun.-Cons. Int. Explor. Mer. 185: 120-130.

Clarke RA, Gascard JC. 1983. The formation of Labrador Sea Water. Part 1: Large-scale processes. Journal of Physical Oceanography 13: 1764-1778.

Curry R, Dickson RR, Yashayaev I. 2003. A change in the freshwater balance of the Atlantic Ocean over the past four decades. Nature 426: 826-829.

Curry RG, McCartney MS. 2003. Ocean gyre circulation changes associated with the North Atlantic Oscillation. Journal of Physical Oceanography 31: 3374-3400.

Dansgaard W, Johnsen SJ, Clausen HB, Dahl-Jensen D, Gundestrup NS, Hammer CU, Hvidberg CS, Steffensen JP, Sveinbjörnsdottir AE, Jouzel J, Bond G. 1993. Evidence for general instability of past climate from a 250-kyr ice-core record. Nature 364: 218-220.

de Jong M, Drijfhout SS, Hazeleger W, van Aken HM, Severijns CA. 2009. Simulations of hydrographic properties in the northwestern North Atlantic Ocean in coupled climate models. Journal of Climate 22: 1767-1786, doi:10.1175/2008JCLI2448.1.

Defant A. 1936. Bericht über die ozeanographischen Untersuchungen des Vermessungsschiffes "Meteor" in der Dänemarkstrasse und in der Irmingersee. Sitzungsberichte der Preussischen Akademie der Wissenschaften, Physikalisch-Mathematische Klasse XIX: $232-242$. 
Dengler M, Fischer J, Schott FA, Zantopp R. 2006. Deep Labrador Current and its variability in 1996-2005. Geophysical Research Letters 33: L21S06, doi:10.1029/2006GL026702.

Deshayes J, Frankignoul C. 2008. Simulated variability of the circulation in the North Atlantic from 1953-2003. Journal of Climate 21: 4919-4933, doi:10.1175/2008JCLI1882.1.

Deshayes J, Frankignoul C, Drange H. 2007. Formation and export of deep water in the Labrador and Irminger Seas in a GCM. Deep Sea Research I 54: 510-532.

Dickson RR, Brown J. 1994. The production of North Atlantic Deep Water: Sources, rates and pathways. Journal of Geophysical Research 99: 12319-12341.

Dickson RR, Lazier JRN, Meincke J, Rhines PB, Swift J. 1996. Long-term coordinated changes in the convective activity of the North Atlantic. Progress in Oceanography $\mathbf{3 8}$ : 241-295.

Dickson RR, Meincke J, Malmberg SA, Lee AJ. 1988. The "Great Salinity Anomaly" in the northern North Atlantic 1968-1982. Progress in Oceanography 20: 103-151.

Dickson RR, Rudels B, Dye S, Karcher M, Meincke J, Yashayaev I. 2007. Current estimates of freshwater flux through Arctic and subarctic seas. Journal of Physical Oceanography 73: 210-230.

Dickson RR, Yashayaev I, Meincke J, Turrell B, Dye S, Holfort J. 2002. Rapid freshening of the deep North Atlantic Ocean over the past four decades. Nature 416: 832-837.

Doyle JD, Shapiro MA. 1999. Flow response to large-scale topography: The Greenland tip jet. Tellus 51: 728-748.

Ducet N, Traon PL, Reverdin G. 2000. Global high-resolution mapping of ocean circulation from TOPEX/Poseidon and ERS-1 and -2. Journal of Geophysical Research 105: 19477-19498.

Eady E. 1949. Long waves and cyclone waves. Tellus 1: 33-52. 
Eden C, Willebrand J. 2001. Mechanism of interannual to decadal variability of the North Atlantic circulation. Journal of Climate 14: 2266-2280.

Fairall CW, Bradley EF, Hare JE, , Grachev AA, Edson JB. 2003. Bulk parameterization of air-sea fluxes: Updates and verification for the COARE algorithm. Journal of Climate 16: $571-591$.

Falina A, Sarafanov A, Sokov A. 2007. Variability and renewal of Labrador Sea Water in the Irminger Basin in 1991-2004. Journal of Geophysical Research 112: C01 006, doi:10.1029/2005JC003 348 .

Faure V, Speer K. 2005. Labrador Sea Water circulation in the northern North Atlantic. Deep Sea Research II 52: 565-581.

Flatau MK, Talley L, Niiler PP. 2003. The North Atlantic Oscillation, surface current velocities, and SST changes in the subpolar North Atlantic. Journal of Climate 16: 23552369.

Fogelqvist E, Blindheim J, Tanhua T, Østerhus S, Buch E, Rey F. 2003. Greenland-Scotland overflow studied by hydro-chemical multivariate analysis. Deep Sea Research I 50: 73102.

Fratantoni PS, Pickart RS. 2007. The western North Atlantic shelfbreak current system in summer. Journal of Physical Oceanography 37: 2509-2533, doi:10.1175/JPO3123.1.

Ganachaud A, Wunsch C. 2000. Improved estimates of global ocean circulation, heat transport and mixing from hydrographic data. Nature 408: 453-457.

Gregory JM, Dixon KW, Stouffer RJ, Weaver AJ, Driesschaert E, Eby M, Fichefet T, Hasumi H, Hu A, Jungclaus JH, Kamenkovich IV, Levermann A, Montoya M, Murakami S, Nawrath S, Oka A, Sokolov AP, Thorpe RB. 2005. A model intercomparison of changes in the Atlantic thermohaline circulation in response to increasing atmospheric $\mathrm{CO}_{2}$ concentration. Geophysical Research Letters 32: L12 703, doi:10.1029/2005GL023 209. 
Haine T, Böning C, Brandt P, Fischer J, Funk A, Kieke D, Kvaleberg E, Rhein M, Visbeck M. 2008. North Atlantic Deep Water formation in the Labrador Sea, recirculation through the subpolar gyre, and discharge to the subtropics. In: Arctic-Subarctic Ocean Fluxes: Defining the role of the northern seas in climate, Dickson RR, Meincke J, Rhines P (eds). Springer: Dordrecht, The Netherlands, pp. 653-701.

Häkkinen S, Rhines PB. 2004. Decline of subpolar North Atlantic circulation during the 1990s. Science 304: 555-559.

Häkkinen S, Rhines PB. 2009. Shifting surface currents in the northern North Atlantic Ocean. Journal of Geophysical Research 114: C04 005, doi:10.1029/2008JC004 883.

Hall MM, Bryden HL. 1982. Direct estimates and mechanisms of ocean heat transport. Deep Sea Research 29: 339-359.

Hameed S, Shi W, Boyle J, Santer B. 1995. Investigation of the centers of action in the North Atlantic and North Pacific in the ECHAM AMIP simulation. In: Proceedings of the First International AMIP Scientific Conference, Monterey, California WCRP-92, WMP/TD-732. World Climate Research Programme, Geneva, pp. pp. 221-226.

Han G, Tang CL. 2001. Interannual variations of volume transport in the western Labrador Sea based on TOPEX/Poseidon and WOCE data. Journal of Physical Oceanography 31: 199-211.

Hansen J, Ruedy R, Glascoe J, Sato M. 1999. GISS analysis of surface temperature change. Journal of Geophysical Research 104: 30 997-31 022.

Hátún H, Payne MR, Beaugrand G, Reid P, Sandø AB, Drange H, Hansen B, Jacobsen JA, Bloch D. 2009. Large bio-geographical shifts in the north-eastern Atlantic Ocean: From the subpolar gyre, via plankton, to blue whiting and pilot whales. Progress in Oceanography 80: 149-162, doi:10.1016/J.POCEAN.2009.03.001.

Hátún H, Sandø AB, Drange H, Hansen B, Valdimarsson H. 2005. Influence of the Atlantic subpolar gyre on the thermohaline circulation. Science 309: 1841-1844. 
Heinrich H. 1988. Origin and consequences of cyclic ice rafting in the northeast Atlantic Ocean during the past 130,000 years. Quaternary Research 29: 142-152.

Holliday NP, Bacon S, Allen J, McDonagh EL. 2009. Circulation and transport in the Western Boundary Currents at Cape Farewell, Greenland. Journal of Physical Oceanography 39: 1854-1870, doi:10.1175/2009JPO4160.1.

Holliday NP, Hughes SL, Bacon S, Beszczynska-Möller A, Hansen B, Lavin A, Loeng H, Mork KA, Østerhus S, Sherwin T, Walczowski W. 2008. Reversal of the 1960s to 1990s freshening trend in the northeast North Atlantic and Nordic Seas. Geophysical Research Letters 35: L03 614, doi:10.1029/2007GL032 675.

Holliday NP, Meyer A, Bacon S, Alderson SG, de Cuevas B. 2007. Retroflection of part of the east Greenland current at Cape Farewell. Geophysical Research Letters 34: L07 609, doi:10.1029/2006GL029085.

Hoskins BJ, Hodges KI. 2002. New perspectives on the Northern Hemisphere winter storm tracks. Journal of the Atmospheric Sciences 59: 1041-1061.

Hurrell JW. 1995. Decadal trends in the North Atlantic Oscillation: Regional temperatures and precipitation. Science 269: 676-679.

Hurrell JW, Visbeck M, Busalacchi A, Clarke RA, Delworth TL, Dickson RR, Co-authors. 2006. Atlantic climate variability and predictability: A CLIVAR perspective. Journal of Climate 19: 5100-5121.

Johnson GC. 2008. Quantifying Antarctic Bottom Water and North Atlantic Deep Water volumes. Journal of Geophysical Research 113: C05 027, doi:10.1029/2007JC004 477.

Jung T, Rhines PB. 2007. Greenland's pressure drag and the Atlantic storm track. Journal of the Atmospheric Sciences 64: 4004-4030, doi:10.1175/2007JAS2216.1.

Jungclaus JH, Haak H, Latif M, Mikolajewicz U. 2005. Arctic-North Atlantic interactions and multidecadal variability of the Meridional Overturning Circulation. Journal of Climate 18: 4013-4031. 
Kalnay E, Kanamitsu M, Kistler R, Collins W, Deaven D, Coauthors. 1996. The NCEP/NCAR 40-year reanalysis project. Bulletin of the American Meteorological Society 77: $437-471$.

Käse RH, Biastoch A, Stammer DB. 2001. On the mid-depth circulation in the Labrador and Irminger Seas. Geophysical Research Letters 28: 3433-3436.

Kieke D, Rhein M, Stramma L, Smethie WM, Bullister JL, LeBel DA. 2007. Changes in the pool of Labrador Sea Water in the subpolar North Atlantic. Geophysical Research Letters 34: L06 605, doi:10.1029/2006GL028 959.

Knudsen M. 1899. Hydrography. Danish Ingolf expedition. Bd. 1, No. 2. Copenhagen.

Knutsen Ø, Svendsen H, Østerhus S, Rossby T, Hansen B. 2005. Direct measurements of the mean flow and eddy kinetic energy structure of the upper ocean circulation in the NE Atlantic. Geophysical Research Letters 32: L14 604, doi:10.1029/2005GL023615.

Koch P, Wernli H, Davies HC. 2006. An event-based jet-stream climatology and typology. International Journal of Climatology 26: 283-301.

Kristjánsson JE, McInnes H. 1999. The impact of Greenland on cyclone evolution in the North Atlantic. Quarterly Journal of the Royal Meteorological Society 125: 2819-2834.

Kristjánsson JE, Thorsteinsson S. 2009. Phase-locking of a rapidly developing extratropical cyclone by Greenland's orography. Quarterly Journal of the Royal Meteorological Society In revision.

Kvaleberg E, Haine TWN, Waugh DW. 2008. Middepth spreading in the subpolar North Atlantic Ocean: Reconciling CFC-11 and float observations. Journal of Geophysical Research 113: C08 019, doi:10.1029/2007JC004 104.

Kwok R. 2007. Baffin Bay ice drift and export: 2002-2007. Geophysical Research Letters 34: L19 501, doi:10.1029/2007GL031204.

Lavender KL, Davis RE, Owens WB. 2000. Mid-depth recirculation observed in the interior Labrador and Irminger Seas by direct velocity measurements. Nature 407: 66-69. 
Lavender KL, Davis RE, Owens WB. 2002. Observations of open-ocean deep convection in the Labrador Sea from subsurface floats. Journal of Physical Oceanography 32: 511526.

Lavender KL, Owens WB, Davis RE. 2005. The mid-depth circulation of the subpolar North Atlantic Ocean as measured by subsurface floats. Deep Sea Research I 52: 767785.

Lazier JRN. 1980. Oceanographic conditions at Ocean Weather Ship BRAVO, 1964-1974. Atmosphere-Ocean 18: 227-238.

Lazier JRN, Hendry R, Clarke RA, Yashayaev I, Rhines PB. 2002. Convection and restratification in the Labrador Sea, 1990-2000. Deep Sea Research I 49: 1819-1835.

Le Traon PY, Faugére Y, Hernandez F, Dorandeu J, Mertz F, Ablain M. 2003. Can we merge GEOSAT Follow-On with TOPEX/Poseidon and ERS-2 for an improved description of the ocean circulation? Journal of Atmospheric and Oceanic Technology 20: 889-895.

Lherminier P, Mercier H, Gourcuff C, Alvarez M, Kermabon C. 2007. Transports across the 2002 Greenland-Portugal Ovide section and comparison with 1997. Journal of Geophysical Research 112: C07 003, doi:10.1029/2006JC003 716.

Lherminier P, Mercier H, Huck T, Gourcuff C, Perez FF, Morin P, Kermabon C. 2009. The Meridional Overturning Circulation and the subpolar gyre observed at the A25OVIDE section in June 2002 and 2004. Journal of Geophysical Research Submitted for publication.

Lilly JM, Rhines PB, Schott F, Lavender K, Lazier JRN, Send U, D’Asaro EA. 2003. Observations of the Labrador Sea eddy field. Progress in Oceanography 59: 75-176.

Lohmann K, Drange H, Bentsen M. 2009. A possible mechanism for the strong weakening of the North Atlantic subpolar gyre in the mid-1990s. Geophysical Research Letters 36: L15 602, doi:10.1029/2009GL039166. 
Louarn E, Mercier H, Morin P, de Boisseson E, Bacon S. 2009. Upper Labrador Sea Water in the Irminger Sea during a weak convection period (2002-2006). Ocean Science Discussions 6: 20852113.

Marshall J, Schott F. 1999. Open-ocean convection: Observations, theory, and models. Reviews of Geophysics 37: 1-64.

McCartney MS, Talley LD. 1982. The subpolar mode water of the North Atlantic Ocean. Journal of Physical Oceanography 12: 1169-1188.

McCauley MP, Sturman AP. 1999. A study of orographic blocking and barrier wind development upstream of the Southern Alps, New Zealand. Meteorology and Atmospheric Physics 70: 121-131.

McInnes H, Kristjánsson JE, Schyberg H, Røsting B. 2009. An assessment of a Greenland lee cyclone during the Greenland Flow Distortion experiment - an observational approach. Quarterly Journal of the Royal Meteorological Society In revision.

McManus JF, Francois R, Gherardi JM, Keigwin LD, Brown-Leger S. 2004. Collapse and rapid resumption of Atlantic meridional circulation linked to deglacial climate changes. Nature 428: 834-837.

Mesinger F, DiMego G, Kalnay E, Mitchell K, Shafran PC, Coauthors. 2006. North American regional reanalysis. Bulletin of the American Meteorological Society 87: 343-360.

Milliff RF, Morzel J. 2001. The global distribution of the time-average wind stress curl from NSCAT. Journal of the Atmospheric Sciences 58: 109-131.

Moore GWK. 2003. Gale force winds over the Irminger Sea to the east of Cape Farewell, Greenland. Geophysical Research Letters 30: 1894, doi:10.1029/2003GLO18012.

Moore GWK, Pickart RS, Renfrew IA. 2008. Buoy observations from the windiest location in the world ocean, Cape Farewell, Greenland. Geophysical Research Letters 35: L18 802, doi:10.1029/2008GL034 845. 
Moore GWK, Renfrew IA. 2005. Tip jets and barrier winds: A QuikSCAT climatology of high wind speed events around Greenland. Journal of Climate 18: 3713-3725.

Nansen F. 1912. Das Bodenwasser und die Abkühlung des Meeres. Internationale Revue der gesamten Hydrobiologie and Hydrographie Band V: 1-42.

Nikolopoulos A, Pickart RS, Fratantoni PS, Shimada K, Torres DJ, Jones EP. 2009. The western Arctic boundary current at $152^{\circ} \mathrm{W}$ : Structure, variability, and transport. Deep Sea Research II 56: 1164-1181, doi:10.1016/j.dsr2.2008.10.014.

Ólafsson H, Bougeault P. 1996. Nonlinear flow past an elliptic mountain ridge. Journal of the Atmospheric Sciences 53: 2465-2489.

Ólafsson J. 2003. Winter mixed layer nutrients in the Irminger and Iceland seas, 1990-2000. ICES Marine Science Symposia 219: 329-332.

Parish TR. 1982. Barrier winds along the Sierra Nevada mountains. Journal of Applied Meteorology 21: 925-930.

Petersen GN, Kristjánsson JE, Ólafsson H. 2004. Numerical simulations of Greenland's impact on the Northern Hemisphere winter circulation. Tellus 56A: 102-111.

Petersen GN, Ólafsson H, Kristjánsson JE. 2003. Flow in the lee of idealized mountains and Greenland. Journal of the Atmospheric Sciences 60: 2183-2195.

Petersen GN, Renfrew IA, Moore GWK. 2009. An overview of barrier winds off southeastern Greenland during GFDex. Quarterly Journal of the Royal Meteorological Society In press.

Peterson BJ, McClelland J, Curry R, Holmes RM, Walsh JE, Aagaard K. 2006. Trajectory shifts in the Arctic and Subarctic freshwater cycle. Science 313: 1061-1066.

Pickart RS. 2004. Shelfbreak circulation in the Alaskan Beaufort Sea: Mean structure and variability. Journal of Geophysical Research 109: C04 024, doi:10.1029/2003JC001 912. 
Pickart RS, McKee TK, Torres DJ, Harrington SA. 1999. Mean structure and interannual variability of the slopewater system south of Newfoundland. Journal of Physical Oceanography 29: 2541-2558.

Pickart RS, Smethie WM. 1998. Temporal evolution of the deep western boundary current where it enters the subtropical domain. Deep Sea Research I 45: 1053-1083.

Pickart RS, Spall MA. 2007. Impact of Labrador Sea convection on the North Atlantic Meridional Overturning Circulation. Journal of Physical Oceanography 37: 2207-2227, doi:10.1175/JPO3178.1.

Pickart RS, Spall MA, Ribergaard MH, Moore GWK, Milliff RF. 2003a. Deep convection in the Irminger Sea forced by the Greenland tip jet. Nature 424: 152-156.

Pickart RS, Straneo F, Moore GWK. 2003b. Is Labrador Sea Water formed in the Irminger Basin? Deep Sea Research I 50: 23-52.

Pickart RS, Torres DJ, Clarke RA. 2002. Hydrography of the Labrador Sea during active convection. Journal of Physical Oceanography 32: 428-457.

Pickart RS, Torres DJ, Fratantoni PS. 2005. The east Greenland spill jet. Journal of Physical Oceanography 35: 1037-1053.

Pickart RS, Våge K, Moore GWK, Renfrew IA, Ribergaard MH, Davies HC. 2008. Convection in the western North Atlantic sub-polar gyre: Do small-scale wind events matter? In: Arctic-Subarctic Ocean Fluxes: Defining the role of the northern seas in climate, Dickson RR, Meincke J, Rhines P (eds). Springer: Dordrecht, The Netherlands, pp. 629652.

Pierrehumbert RT, Wyman B. 1985. Upstream effects of mesoscale mountains. Journal of the Atmospheric Sciences 42: 977-1003.

Pollard RT, Read JF, Holliday NP, Leach H. 2004. Water masses and circulation pathways through the Iceland Basin during Vivaldi 1996. Journal of Geophysical Research 109: C04 004, doi:10.1029/2003JC002067. 
Price JF, Weller RA, Pinkel R. 1986. Diurnal cycling: Observations and models of the upper ocean response to diurnal heating, cooling, and wind mixing. Journal of Geophysical Research 91: 8411-8427.

Rahmstorf S. 12002. Ocean circulation and climate during the past 120,000 years. Nature 419: 207-214.

Read JF. 2001. CONVEX-91: Water masses and circulation of the Northeast Atlantic subpolar gyre. Progress in Oceanography 48: 461-510.

Renfrew IA, Moore GWK, Guest PS, Bumke K. 2002. A comparison of surface layer and surface turbulent flux observations over the Labrador Sea with ECMWF analyses and NCEP reanalyses. Journal of Physical Oceanography 32: 383-400.

Renfrew IA, Moore GWK, Kristjánsson JE, Ólafsson H, Gray SL, Petersen GN, Coauthors. 2008. The Greenland flow distortion experiment. Bulletin of the American Meteorological Society 89: 1307-1324, doi:10.1175/2008BAMS2508.1.

Renfrew IA, Petersen GN, Sproson DAJ, Moore GWK, Adiwidjaja H, Zhang S, North R. 2009. A comparison of aircraft-based surface-layer observations over Denmark Strait and the Irminger Sea with meteorological analyses and QuikSCAT winds. Quarterly Journal of the Royal Meteorological Society In press.

Reverdin G, Verbrugge N, Kushnir Y. 1999. Upper ocean variability between Iceland and Newfoundland, 1993-1998. Journal of Geophysical Research 104: 29 599-29611.

Reynolds RW, Smith TM, Liu C, Chelton DB, Casey KS, Schlax MG. 2007. Daily highresolution-blended analyses for sea surface temperature. Journal of Climate 20: 54735496.

Rhines PB. 1975. Waves and turbulence on the $\beta$-plane. Journal of Fluid Mechanics 69: $417-443$.

Rio MH, Hernandez F. 2004. A mean dynamic topography computed over the world ocean from altimetry, in situ measurements, and a geoid model. Journal of Geophysical Research 109: C12 032, doi:10.1029/2003JC002 226. 
Rogers JC. 1990. Patterns of low-frequency monthly sea level pressure variability (18991986) and associated wave cyclone frequencies. Journal of Climate 3: 1364-1379.

Sabine CL, Feely RA, Gruber N, Key RM, Lee K, Coauthors. 2004. The oceanic sink for anthropogenic $\mathrm{CO}_{2}$. Science 305: 367-371.

Sampe T, Xie SP. 2007. Mapping high sea winds from space. Bulletin of the American Meteorological Society 88: 1965-1978, doi: 10.1175/BAMS-88-12-1965.

Sarafanov A. 2009. On the effect of the North Atlantic Oscillation on temperature and salinity of the subpolar North Atlantic intermediate and deep waters. ICES Journal of Marine Science 66: 14481454.

Sarafanov A, Falina A, Mercier H, Lherminier P, Sokov A. 2009a. Recent changes in the Greenland-Scotland overflow-derived water transport inferred from hydrographic observations in the southern Irminger Sea. Geophysical Research Letters 36: L13 606, doi:10.1029/2009GL038385.

Sarafanov A, Falina A, Mercier H, Lherminier P, Sokov A, Gourcuff C. 2009b. Assessing decadal changes in the Deep Western Boundary Current transport southeast of Cape Farewell (Greenland) from altimetry and hydrography. Journal of Geophysical Research Submitted for publication.

Sarafanov A, Sokov A, Demidov A, Falina A. 2007. Warming and salinification of intermediate and deep waters in the Irminger Sea and the Iceland Basin in 1997-2006. Geophysical Research Letters 34: L23 609, doi:10.1029/2007GL031 074.

Schär C. 1993. A generalization of Bernoulli's theorem. Journal of the Atmospheric Sciences 50: 1437-1443.

Schmidt S, Send U. 2007. Origin and composition of seasonal Labrador Sea freshwater. Journal of Physical Oceanography 37: 1145-1454.

Schott F, Brandt P. 2007. Circulation and deep water export of the subpolar North Atlantic during the 1990's. In: Ocean Circulation: Mechanisms and Impacts, Geophysical Monograph Series 173. pp. 91-118. 
Schwerdtfeger W. 1975. The effect of the Antarctic Peninsula on the temperature regime of the Weddell Sea. Monthly Weather Review 103: 45-51.

Seefeldt MW, Cassano JJ. 2008. An analysis of low-level jets in the greater Ross Ice Shelf region based on numerical simulations. Monthly Weather Review 136: 4188-4205, doi:10.1175/2008MWR2455.1.

Serreze MC, Carse F, Barry RG, Rogers JC. 1997. Icelandic Low cyclone activity: Climatological features, linkages with the NAO, and relationships with recent changes in the Northern Hemisphere circulation. Journal of Climate 10: 453-464.

Skeie RB, Kristjánsson JE, Ólafsson H, Røsting B. 2006. Dynamical processes related to cyclone development near Greenland. Meteorologische Zeitschrift 15: 147-156, doi:10.1127/0941-2948/2006/0114.

Smedsrud LH, Sorteberg A, Kloster K. 2008. Recent and future changes of the Arctic seaice cover. Geophysical Research Letters 35: L20 503, doi:10.1029/2008GL034 813.

Smith RB. 1989. Hydrostatic flow over mountains. In: Advances in Geophysics, vol. 31. Academic Press, pp. 1-41.

Spall MA, Pickart RS. 2003. Wind-driven recirculations and exchange in the Labrador and Irminger Seas. Journal of Physical Oceanography 33: 1829-1845.

Sproson DAJ, Renfrew IA, Heywood KJ. 2008. Atmospheric conditions associated with oceanic convection in the south-east Labrador Sea. Geophysical Research Letters 35: L06 601, doi:10.1029/2007GL032971.

Stouffer RJ, Yin J, Gregory JM, Dixon KW, Spelman MJ, Coauthors. 2006. Investigating the causes of the response of the thermohaline circulation to past and future climate changes. Journal of Climate 19: 1365-1387.

Straneo F. 2006. Heat and freshwater transport through the central Labrador Sea. Journal of Physical Oceanography 36: 606-628. 
Straneo F, Hamilton GS, Sutherland DA, Stearns LA, Davidson F, Hammill MO, Stenson GB, Rosing-Asvid A. 2009. Rapid circulation of warm subtropical waters in a major, East Greenland glacial fjord. Nature Geoscience In revision.

Straneo F, Pickart RS, Lavender KL. 2003. Spreading of Labrador Sea Water: An advective-diffusive study based on Lagrangian data. Deep Sea Research I 50: 701-719.

Sutherland DA, Pickart RS. 2008. The East Greenland Coastal Current: Structure, variability and forcing. Progress in Oceanography 78: 58-77, doi:10.1016/j.pocean.2007.09.006.

Sutton RT, Allen MR. 1997. Decadal predictability of North Atlantic sea surface temperature and climate. Nature 388: 563-567.

Sverdrup HU, Johnson MW, Fleming RH. 1942. The oceans: Their physics, chemistry and general biology. Prentice-Hall: New York, NY.

Sy A, Rhein M, Lazier JRN, Koltermann KP, Meincke J, Putzka A, Bersch M. 1997. Surprisingly rapid spreading of newly formed intermediate water across the North Atlantic Ocean. Nature 386: 675-679.

Talley LD. 2003. Shallow, intermediate, and deep overturning components of the global heat budget. Journal of Physical Oceanography 33: 530-560.

Talley LD, McCartney MS. 1982. Distribution and circulation of Labrador Sea Water. Journal of Physical Oceanography 12: 1189-1205.

Tapley BD, Chambers DP, Bettadpur S, Ries JC. 2003. Large scale ocean circulation from the GRACE GGM01 geoid. Geophysical Research Letters 30: doi:10.1029/2003GL018622.

Thompson KR, Huang J, Véronneau M, Wright DG, Lu Y. 2009. Mean surface topography of the northwest Atlantic: Comparison of estimates based on satellite, terrestrial gravity, and oceanographic observations. Journal of Geophysical Research 114: C07 015, doi:10.1029/2008JC004 859. 
Treguier AM, Theetten S, Chassignet EP, Penduff T, Smith R, Talley L, Beismann JO, Böning C. 2005. The North Atlantic subpolar gyre in four high-resolution models. Journal of Physical Oceanography 35: 757-774.

Trenberth KE, Caron JM. 2001. Estimates of meridional atmosphere and ocean heat transports. Journal of Climate 14: 3433-3443.

Tsukernik M, Kindig D, Serreze MC. 2007. Characteristics of winter cyclone activity in the northern North Atlantic: Insights from observations and regional modeling. Journal of Geophysical Research 112: D03 101, doi:10.1029/2006JD007 184.

Uppala SM, Kållberg PW, Simmons AJ, Andrae U, Bechtold VDC, Coauthors. 2005. The ERA40 re-analysis. Quarterly Journal of the Royal Meteorological Society 131: 29613012.

Våge K, Pickart RS, Moore GWK, Ribergaard MH. 2008. Winter mixed-layer development in the central Irminger Sea: The effect of strong, intermittent wind events. Journal of Physical Oceanography 38: 541-565.

Våge K, Pickart RS, Thierry V, Reverdin G, Lee CM, Petrie B, Agnew TA, Wong A, Ribergaard MH. 2009a. Surprising return of deep convection to the subpolar North Atlantic Ocean in winter 2007-2008. Nature Geoscience 2: 67-72, doi:10.1038/NGEO382.

Våge K, Spengler T, Davies HC, Pickart RS. 2009b. Multi-event analysis of the westerly Greenland tip jet based upon 45 winters in ERA-40. Quarterly Journal of the Royal Meteorological Society : published online, doi: 10.1002/qj.488.

van Aken HM, de Boer CJ. 1995. On the synoptic hydrography of intermediate and deep water masses in the Iceland Basin. Deep Sea Research 42: 165-189.

Vellinga M, Wood RA. 2002. Global climatic impacts of a collapse of the Atlantic thermohaline circulation. Climatic Change 54: 251-267.

Visbeck M, Marshall J, Haine T, Spall M. 1997. Specification of eddy transfer coefficients in coarse-resolution ocean circulation models. Journal of Physical Oceanography 27: $381-402$. 
Wattenberg H. 1938. Die Verteilung des Sauerstoffs im Atlantischen Ozean. Verlag von Walter de Gruyter \& Co.: Berlin.

Wentz FJ, Smith DK, Mears CA, Gentemann CL. 2001. Advanced algorithms for QuikScat and SeaWinds/AMSR. In: IGARSS'01 Proceedings. pp. 1079-1081.

Wernli H, Davies HC. 1997. A Lagrangian-based analysis of extratropical cyclones. I: The method and some applications. Quarterly Journal of the Royal Meteorological Society 123: 467-489.

Wernli H, Schwierz C. 2006. Surface cyclones in the ERA-40 dataset (1958-2001), part I: Novel identification method and global climatology. Journal of the Atmospheric Sciences 63: $2486-2507$.

Willis JK, Lyman JM, Johnson GC, Gilson J. 2007. Correction to "Recent cooling of the upper ocean”. Geophysical Research Letters 34: L16 601, doi:10.1029/2007GL030 323.

Wong APS, Johnson GC, Owens WB. 2003. Delayed-mode calibration of autonomous CTD float profiling salinity data by $\theta-S$ climatology. Journal of Atmospheric and Oceanic Technology 20: 308-318.

Wunsch C. 1999. The interpretation of short climate records, with comments on the North Atlantic and Southern Oscillations. Bulletin of the American Meteorological Society 80: $245-255$.

Wunsch C, Heimbach P. 2006. Estimated decadal changes in the North Atlantic Meridional Overturning Circulation and heat flux 1993-2004. Journal of Physical Oceanography 36: 2012-2024.

Wunsch C, Heimbach P. 2007. Practical global state estimation. Physica D 230: 197-208, doi:10.1016/J.PHYSD.2006.09.040.

Wüst G. 1943. Der subarktische Bodenstrom in der westatlantischen Mulde. Annalen der Hydrographie und Maritimen Meteorologie Heft IV/VI: 249-256. 
Yaeger SG, Jochum M. 2009. The connection between Labrador Sea buoyancy loss, deep western boundary current strength, and Gulf Stream path in an ocean model. Ocean Modelling 30: 207-224, doi:10.1016/J.OCEAMOD.2009.06.014.

Yashayaev I. 2007. Hydrographic changes in the Labrador Sea, 1960-2005. Progress in Oceanography 73: 242-276.

Yashayaev I, Bersch M, van Aken HM. 2007a. Spreading of the Labrador Sea Water to the Irminger and Iceland basins. Geophysical Research Letters 34: L10 602, doi:10.1029/2006GL028999.

Yashayaev I, Dickson RR. 2008. Transformation and fate of overflows in the northern North Atlantic. In: Arctic-Subarctic Ocean Fluxes: Defining the role of the northern seas in climate, Dickson RR, Meincke J, Rhines P (eds). Springer: Dordrecht, The Netherlands, pp. 505-526.

Yashayaev I, Loder JW. 2009. Enhanced production of Labrador Sea Water in 2008. Geophysical Research Letters 36: L01 606, doi:10.1029/2008GL036 162.

Yashayaev I, van Aken HM, Holliday NP, Bersch M. 2007b. Transformation of the Labrador Sea Water in the subpolar North Atlantic. Geophysical Research Letters 34: L22 605, doi:10.1029/2007GL031812.

Yu L, Weller RA. 2007. Objectively analyzed air-sea heat fluxes for the global ice-free oceans (1981-2005). Bulletin of the American Meteorological Society 88: 527539.

Zhang HM, Bates JJ, Reynolds RW. 2006. Assessment of composite global sampling: Sea surface wind speed. Geophysical Research Letters 33: L17714, doi:10.1029/2006GL027086.

Zhang J, Lindsay R, Steele M, Schweiger A. 2008. What drove the dramatic retreat of Arctic sea ice during summer 2007? Geophysical Research Letters 35: L11 505, doi:10.1029/2008GL034005. 